\title{
FEASIBLITY STUDY: APPLICATION OF RCM TECHNIQUES \\ FOR SUBSTATION MAINTENANCE AT THE BONNEVILLE POWER ADMINISTRATION
}

by

\author{
Steven L. Purucker \\ Bruce E. Tonn \\ Richard T. Goeltz \\ Randy D. James \\ Stephen Kercel \\ D. Tom Rizy \\ Marc L. Simpson \\ James W. Van Dyke \\ Energy Division
}

May 28, 1992

Prepared by the Oak Ridge National Laboratory

Oak Ridge, Tennessee 37831 managed by

Martin Marietta Energy Systems, Inc. for the

U.S. DEPARTMENT OF ENERGY

Bonneville Power Administration under Contract No. DE-AC05-840R21400 


\section{TABLE OF CONTENTS}

EXECUTTVE SUMMARY $\ldots \ldots \ldots \ldots \ldots \ldots \ldots \ldots \ldots \ldots \ldots \ldots \ldots$ xi

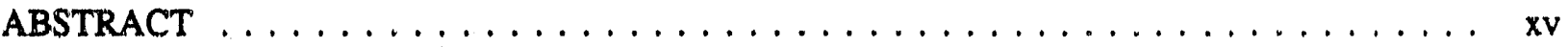

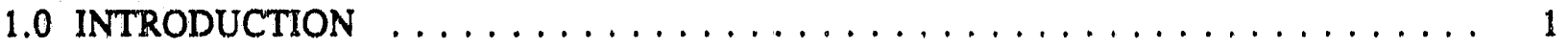

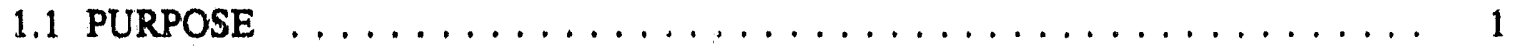

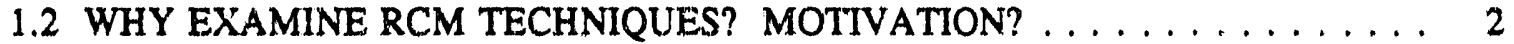

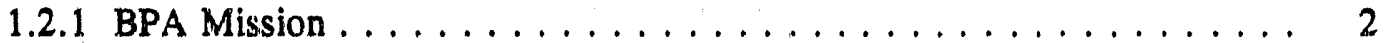

1.2.2 Utility Stewardship $\ldots \ldots \ldots \ldots \ldots \ldots \ldots \ldots \ldots \ldots \ldots \ldots$

1.2 .3 Utility Service $\ldots \ldots \ldots \ldots \ldots \ldots \ldots \ldots \ldots \ldots \ldots$

1.2 .4 Stable Rates $\ldots \ldots \ldots \ldots \ldots \ldots \ldots \ldots \ldots \ldots \ldots \ldots \ldots, 4$

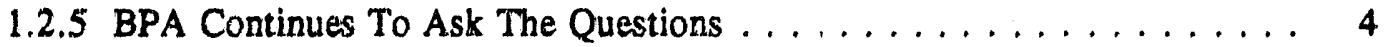

1.3 WHAT IS RCM? ..................... 4

1.3.1 RCM Objectives ..................... 7

1.3.1.1 Reduce Maintenance Costs . . . . . . . . . . . . . . 7

1.3.1.2 Optimize Maintenance Resources . . . . . . . . . . . . 7

1.3.1.3 Optimize Maintenance Tasks . . . . . . . . . . . . . . 7

1.3.1.4 Optimize RCM Instrumentation $\ldots \ldots \ldots \ldots \ldots \ldots \ldots \ldots 7$

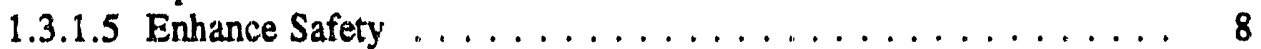

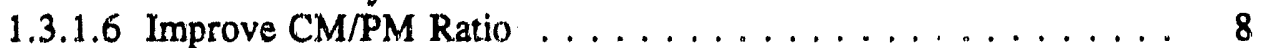

1.3.1.7 Provide Life Extension $\ldots \ldots \ldots \ldots \ldots \ldots \ldots \ldots$

1.3.2 The RCM Process . . . . . . . . . . . . . . . . 8

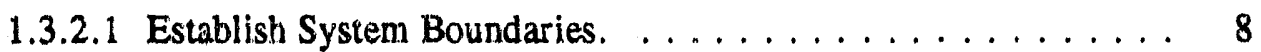

1.3.2.2 Define System Functions $\ldots \ldots \ldots \ldots \ldots \ldots \ldots \ldots$

1.3.2.3 Identify Failure Modes $\ldots \ldots \ldots \ldots \ldots \ldots \ldots$. . . . . .

1.3.2.4 Apply RCM Decision Logic . . . . . . . . . . . . . . . 9

1.3.2.5 Design Instrumentation System $\ldots \ldots \ldots \ldots \ldots \ldots . .9$

1.3.2.6 Redefine Preventative Mainteriance (PM) Tasks . . . . . . 9

1.3.2.7 Evaluate RCM Performance ................ 10

1.3.2.8 Track Critical Maintenance Parameters . . . . . . . . . 10

2.0 BACKGROUND $\ldots \ldots \ldots \ldots \ldots \ldots \ldots \ldots \ldots \ldots \ldots \ldots \ldots \ldots \ldots$

2.1 POWER SYSTEM RELIABILITY AND RCM $\ldots \ldots \ldots \ldots \ldots \ldots \ldots \ldots, 11$

2.2 TRADITIONAL POWER SYSTEM RELLIABILITY $\ldots \ldots \ldots \ldots \ldots \ldots 12$

2.3 RELIABILITY TECHNIQUES APPLICABLE TO RCM $\ldots \ldots \ldots \ldots \ldots, 14$

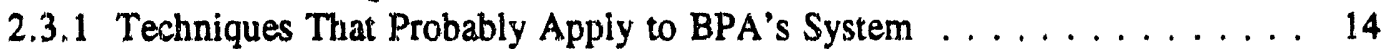

2.3.1.1 Failure Mode and Effect Analysis (FMEA) . . . . . . . 15

2.3.1.2 Regression Analysis $\ldots \ldots \ldots \ldots \ldots \ldots \ldots \ldots \ldots$

2.3.1.3 Expert Systems ...................... 16

2.3.1.4 Bayesian Approach For The Study of Reliability/Availability Problems ........................ 16

2.3.2 Techniques That Probably Do Not Apply to BPA's System . . . . . . 17

2.3.2.1 Fault Tree Analysis (FTA) $\ldots \ldots \ldots \ldots \ldots \ldots \ldots \ldots 17$

2.3.2.2 Machine Learning $\ldots \ldots \ldots \ldots \ldots \ldots \ldots \ldots \ldots$

2.3.2.3 Statistical Modeling $\ldots \ldots \ldots \ldots \ldots \ldots \ldots \ldots \ldots 18$ 
TABLE OF CONTENTS (Continued)

2.3.2.4 Reliability Block Diagram _... . . . . . . . . . . . 19

2.3.2.5 Time Series Analysis (TSA) . . . . . . . . . . . . . . 19

2.3.2.6 Markov Model ...................... 20

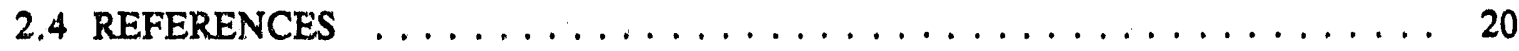

3.0 BPA EQUTPMENT . . . . . . . . . . . . . . . . . . . . 27

3.1 EXISTING TRANSFORMER AND BREAKER MAINTENANCE $\ldots \ldots \ldots \ldots \ldots 27$

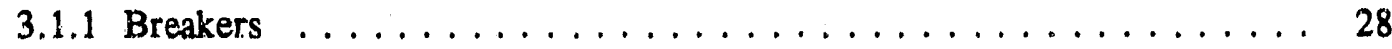

3.1.1.1 Breaker Maintenance Activities . . . . . . . . . . . 28

3.1.1.2 Breaker Maintenance Activity Description . . . . . . . . . 33

3.1 .2 Transformers ........................... 37

3.1.2.1 Transformer Maintenance Activities . . . . . . . . . . . . 37

3.1.2.2 Transformer Maintenance Activity Description . . . . . . . . 40

3.2 ANALYSIS OF DATA FROM BONNEVILLE'S SUBSTATION MAINTENANCE

INFORMATION SYSTEM $\ldots \ldots \ldots \ldots \ldots \ldots \ldots \ldots \ldots \ldots \ldots \ldots$

3.2.1 Maintenance Data and Development of RCM Methodologies . . . . . . . , 41

3.2 .2 Data Preparation . . . . . . . . . . . . . . . . . . 42

3.2.3 Analysis of Unplanned Maintenance . . . . . . . . . . . . . . . 43

3.3 EQUIPMENT TO BE INCLUDED IN THE RCM PROTO'TYPE . . . . . . . . . . 50

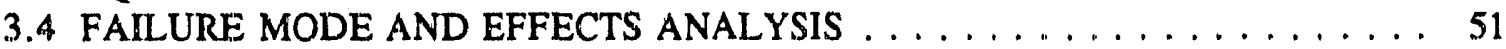

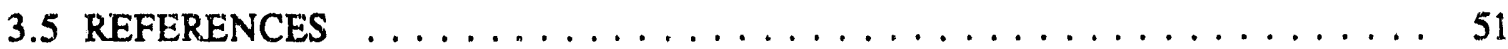

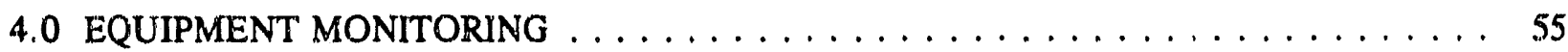

4.1 EQUIPMENT CONDITIONS THAT CAN BE MONITORED . . . . . . . . . . 55

4.2 DIAGNOSTIC TECHNIQUES AVAILABLE NOW $\ldots \ldots \ldots \ldots \ldots \ldots \ldots$

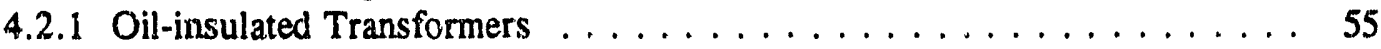

4.2.1.1 Dissolved gas analysis ................... 55

4.2.1.2 Bubble formation in oil .................. 59

4.2.1.3 Partial Discharges (Acoustic emission method . . . . . . . 60

4.2.1.4 Temperature $(\mathrm{T}) \ldots \ldots \ldots \ldots \ldots$

4.2.1.5 Moisture ........................ 61

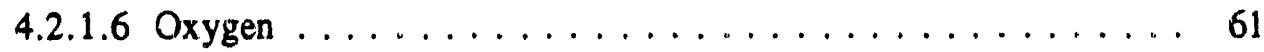

4.2 .1 .7 Vibration . . . . . . . . . . . . . . . . . 61

4.2.1.8 Dielectric Strength of the Oil $\ldots \ldots \ldots \ldots 6 \ldots \ldots \ldots$

4.2.1.9 Other oil related tests . . . . . . . . . . . . . . . 62

4.2.1.10 Commercial transformer monitoring system . . . . . . . . . 62

4.2.2 Gas-insulated Equipment . . . . . . . . . . . . . . . . . . 62

4.2.2.1 Gaseous Decomposition products of $\mathrm{SF}_{6}$ - Chemical Methods . . 62

4.2.2.2 Partial Discharge by acoustical methods . . . . . . . . . . . 63

4.2.2.3 Partial Discharge in solid spacers - Voids . . . . . . . . . . 63

4.2.2.4 PD detection by the UHF method . . . . . . . . . . . 63

4.3 RESEARCH AND DEVELOPMENT OPPORTUNITIES . . . . . . . . . . . . 64

4.3.1 Diagnostic Techniques Requiring Development . . . . . . . . . . . . . . 64

4.3.2 Diagnostic Techniques Requiring Research . . . . . . . . . . . . 66

4.3.2.1 Oil-insulated Transformers ................. 66

4.3.2.2 Gas-insulated Equipment . . . . . . . . . . . . . . . 67 
TABLE OF CONTENTS (Continued)

4.4 REFERENCES $\ldots \ldots \ldots \ldots \ldots \ldots \ldots \ldots \ldots \ldots \ldots \ldots \ldots$

5.0 BENEFITS OF RELIABILITY CENTERED MAINTENANCE $\ldots \ldots \ldots \ldots \ldots \ldots 71$

5.1 THE ECONOMIC OBJECTIVE OF RCM $\ldots \ldots \ldots \ldots \ldots \ldots \ldots \ldots, 73$

5.2 DATA . . . . . . . . . . . . . . . . . . . 74

5.3 BENEFITS FROM REDUCING PREVENTIVE MAINTENANCE . . . . . . . 74

5.4 BENEFITS FROM REDUCING CORRECTIVE MAINTENANCE . . . . . . . . 80

5.5 BENEFITS FROM EXTENDING EQUIPMENT LIFE BY REDUCING CATASTROPHIC FAILURES AND DELAYING SCHEDULED RETIREMENT . . 80

5.6 IMPROVING RCM COST EFFECTIVENESS THROUGH TARGETING $\ldots \ldots 81$

5.7 ADDITIONAL BENEFITS $\ldots \ldots \ldots \ldots \ldots \ldots \ldots \ldots \ldots \ldots \ldots . \ldots 2$

5.8 MEASURE RCM EFFECTIVENESS $\ldots \ldots \ldots \ldots \ldots \ldots \ldots \ldots \ldots, 83$

5.9 CONCLUSIONS $\ldots \ldots \ldots \ldots \ldots \ldots \ldots \ldots \ldots \ldots \ldots \ldots \ldots$

5.10 REFERENCES ............................ 85

6.0 FUNCTIONAL REQUIREMENTS $\ldots \ldots \ldots \ldots \ldots \ldots \ldots \ldots \ldots \ldots \ldots \ldots$

6.1 INTRODUCTION $\ldots \ldots \ldots \ldots \ldots \ldots \ldots \ldots \ldots \ldots \ldots \ldots \ldots \ldots \ldots$

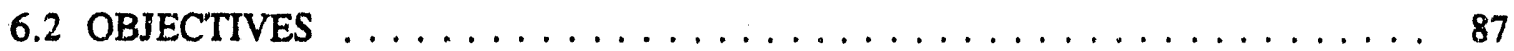

6.3 HARDWARE REQUIREMENTS $\ldots \ldots \ldots \ldots \ldots \ldots \ldots \ldots \ldots \ldots$

6.3.1 Hardware Architecture . . . . . . . . . . . . . . . . . . 89

6.3 .2 Instrumentation $\ldots \ldots \ldots \ldots \ldots \ldots \ldots \ldots \ldots \ldots \ldots$

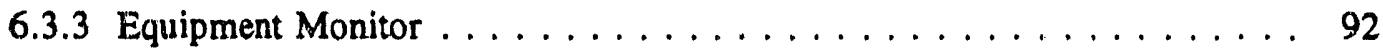

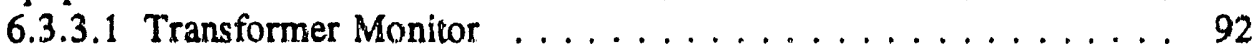

6.3.3.2 Circuit Breaker Monitor . . . . . . . . . . . . . 93

6.3.4 Substation Monitor . . . . . . . . . . . . . . . . . 94

6.3.5 Interface With Existing SCADA Environment $\ldots \ldots \ldots \ldots \ldots \ldots 95$

6.3.6 System Monitor . . . . . . . . . . . . . . . . . . . . . . 96

6.4 MAINTENANCE LECISION SUPPORT REQUIREMENTS . . . . . . . . . . 96

6.4.1 Corrective Maintenance Decision Support at Area Offices . . . . . . . . 98

6.4.2 Preventive Maintenance Decision Support at Area Offices . . . . . . . . 99 99

6.4.3 Preventive Maintenance Decision Support at Dittmer . . . . . . . . . 100

6.4.4 Corrective Maintenance Decision Support at Dittmer . . . . . . . . . . 100

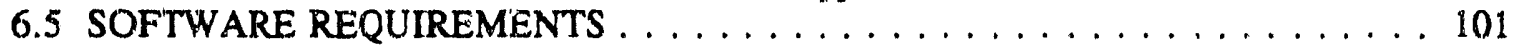

6.5.1 Software Tools . . . . . . . . . . . . . . . . . . . 103

6.5.2 Maintenance Decision Support Modeling . . . . . . . . . . . . . 103

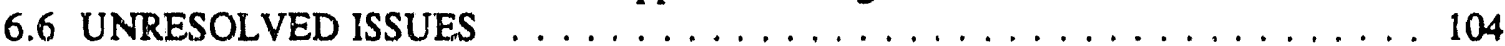

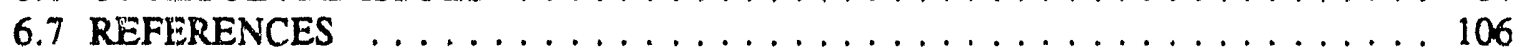

7.0 CONCLUSIONS AND RECOMMENDATIONS $\ldots \ldots \ldots \ldots \ldots \ldots \ldots$ 


\section{LIST OF TABLES}

Table 2.1. Techniques which probabiy apply to BPA's system . . . . . . . . . . . 15

Table 2.2. Techniques which probably do not apply to BPA's system $\ldots \ldots \ldots \ldots \ldots \ldots$

Table 3.1. FY89 Breaker maintenance practices . . . . . . . . . . . . . . . . . . 29

Table 3.2. Maintenance for $\mathrm{M} 400$ series breakers $\ldots \ldots \ldots \ldots \ldots \ldots \ldots$

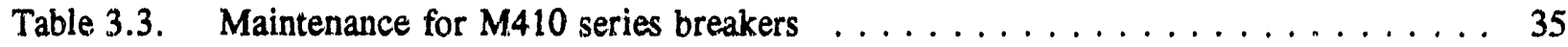

Table 3.4. Maintenance for M420 series breakers $\ldots \ldots \ldots \ldots \ldots \ldots \ldots \ldots$

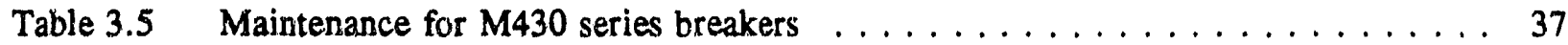

Table 3.6. FY89 Transformer maintenance practices . . . . . . . . . . . . . . . . . . . . 39

Table 3.6A. Maintenance for transformers . . . . . . . . . . . . . . . . . . . . . . 40

Table 3.7. SMIS data received and available for analysis $\ldots \ldots \ldots \ldots \ldots \ldots \ldots \ldots$

Table 3.8. Annual summary of breaker data . . . . . . . . . . . . . . . . . . . . . 44

Table 3.9. Annual summary of transformer data . . . . . . . . . . . . . . . . 45

Table 3.10. Breaker reliability for all breakers on-line from 1986 through 1989 , by interrupting media ... . . . . . . . . . . . . . . . . . . . . . . . . . 49

Table 3.11. Transformer reliability for all transformers on-line from 1986 through 1989 , by voltage group . . . . . . . . . . . . . . . . . . . . . . . . 49

Table 3.12. Alvey transformers and breakers included in the prototype . . . . . . . . . 50

Table 3.13. Transformer failure mode and effects analysis . . . . . . . . . . . . . 52

Table 3.14. Breaker failure mode and effects analysis . . . . . . . . . . . . . . 54

Table 4.1. Breaker conditions that can be monitored . . . . . . . . . . . . . . . 56

Table 4.2. Breaker conditions that can be monitored off-line . . . . . . . . . . . . . 57

Table 4.3. Power transformer conditions that can be monitored . . . . . . . . . . . 58

Table 5.1. Estimated economic benefits of RCM for BPA substation transformers and circuit breakers . . . . . . . . . . . . . . . . . . . . . 72

Table 5.2. RCM benefits by breaker and transformer types $\ldots \ldots \ldots \ldots \ldots \ldots \ldots$

Table 5.2. RCM benefits by breaker and transformer types (Cont.) $\ldots \ldots \ldots \ldots \ldots$

Table 5.2. RCM benefits by breaker and transformer types (Cont.) . . . . . . . . . . . 77

Table 5.2. RCM benefits by breaker and transformer types (Cont.) $\ldots \ldots \ldots \ldots \ldots$

Table 5.2. RCM benefits by breaker and transformer types (Cont.) . . . . . . . . . . . . 79

Table 5.3. Possible maintenance metrics . . . . . . . . . . . . . . . . . . . . 84 


\section{LIST OF FIGURES}

Fig. 3.1. Breaker ages $\ldots \ldots \ldots \ldots \ldots \ldots \ldots \ldots$

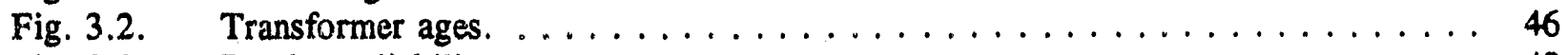

Fig. 3.3. Breaker reliability vs age $\ldots \ldots \ldots \ldots \ldots \ldots \ldots \ldots \ldots \ldots \ldots \ldots$

Fig. 6.1. Phase 1 - RCM hardware architecture . . . . . . . . . . . . . . . 90

Fig. 6.2. Ultimate $-\mathrm{RCM}$ hardware architecture $\ldots \ldots \ldots \ldots \ldots \ldots \ldots \ldots \ldots$

Fig. 6.3. $\quad R C M$ decision support components and criteria . . . . . . . . . . . . . 97

Fig. 6.4. $\quad$ RCM software development . . . . . . . . . . . . . . . . . . 102 


\section{EXECUTTVE SUMMARY}

Oak Ridge National Laboratory (ORNL) performed a feasibility study for the Bonneville Power Administration (BPA) to determine whether or not Reliability Centered Maintenance (RCM) is applicable to BPA's substation maintenance. This paper presents the findings of the study and proposes a prototype RCM system for BPA's substation maintenance. The prototype will be limited initially to transformers and breakers.

The feasibility study examined five areas of concern to BPA and the ways in which RCM could aid BPA in these areas. The areas are as follows:

- to support the BPA mission, which is to supply reliable power at the least cost and to provide research leadership to the utility industry;

- $\quad$ to manage BPA resources wisely;

- to provide a more reliable power supply, better customer service, and fewer emergencies and problems;

- to reduce costs; and

- to answer questions related to improving maintenance.

RCM can directly affect these areas. RCM was developed in the airline industry to improve services and reduce costs by developing maintenance plans that maximize reliability at the lowest possible cost. It does this by identifying real-time incipient equipment problems, thereby averting potentially catastrophic failures and by providing decision support through recommendations that will aid in identifying and scheduling preventative maintenance. To identify potential real-time problems, an RCM system uses equipment monitors on critical substation equipment and computer software that helps analyze equipment data. The RCM decision support recommendations are based on the following:

- maintenance criteria,

- maintenance history,

- experience with similar equipment,

- real-time field data, and

- resource constraints. 
The recommendations also identify the type of maintenance to be performed and help establish a maintenance schedule.

Because the implementation of RCM is dependent on measures of system reliability, the study also examined ways of measuring substation equipment reliability. Four techniques were evaluated that probably apply to BPA's system. They were evaluated through an examination of the literature, including case studies of existing RCM systems. They are the following:

- Failure Mode and Effect Analysis (FMEA),

- regression analysis,

- expert systems, and

- Bayesian techniques.

An evaluation of techniques that probably do not apply to BPA's system is also included.

Two types of maintenance are performed on transformers and breakers: corrective maintenance (CM) and preventative maintenance (PM). The current CM and PM practices were analyzed using BPA's Performance Level Guides (PLGs) and System Maintenance Information System (SMIS), and by performing an FMEA through discussions with BPA's transformer and breaker experts. This analysis is useful to the development of an RCM system because of the following:

- maintenance records can be used to predict future failure probabilities and reliability,

- a current profile of planned and unplanned maintenance practices can be generated by equipment type,

- equipment characteristics can be described and they can be correlated with maintenance needs,

- analysis results can support economic studies such as statistics on equipment age at replacement and replacement cost, and

- analysis of a maintenance database can aid in the design and development of an RCM system by making it easier to integrate current corporate resources and procedures.

To identify real-time problems, which is one of the primary objectives of an RCM system, 
equipment monitors and analytical software are needed. An analysis was performed that identified transformer and breaker conditions that can be monitored. This analysis was based primarily on information from BPA staff. An evaluation of currently available diagnostic methods for oil-insulated transformers and gas-insulated equipment was also performed, based on a review of current literature. While there are various diagnostic methods available for monitoring transformer and breaker conditions, there is also the need to research and develop additional transformer sensors. This research and development effort should include the following:

- the selection of a set of measurements keyed to transformer health rather than or in addition to incipient failure indicators,

- the exploitation of non-invasive diagnostic techniques, and

- the incorporation of state-of-the-art sensor technology where appropriate and practical.

The feasibility study also examined the financial benefits to BPA of an RCM system. The analysis used data from BPA's SMIS for the fourth quarter of fiscal year 1990 cumulative. The conclusion is that over $\$ 8$ million in annual benefits are available to BPA if RCM is applied to breakers and transformers at all BPA substations. The way an RCM system would reduce costs is by lowering the overall PM and CM costs and by reducing capital costs. RCM can provide the data necessary to precisely define PM requirements which reduces PM costs by eliminating unnecessary PM. It also reduces CM costs by identifying PM needs that are missed in a regular "rule of thumb" maintenance plan. Capital costs are reduced by appropriate PM which helps avoid catastrophic equipment failure, making it possible to delay replacement.

There are additional benefits from RCM that were not estimated. These include the benefits of higher reliability and safety to personnel. Another potential benefit is improving equipment selection by evaluating RCM data to identify characteristics of equipment that lead to lower PM and CM costs.

This paper also presents the functional requirements for the proposed RCM system. There are three areas of functional requirements that were evaluated through discussions with BPA personnel and by examining current literature.

The first area is the hardware. Ultimately, the RCM system must have the ability to operate within the existing Supervisory Control and Data Acquisition (SCADA) system, and it must be able to 
communicate maintenance schedules to the SMIS. The RCM research effort will also determine the optimum number of equipment sensors actually needed to maintain the quality of the inferences drawn by the RCM system. Equipment monitors will 1) detect equipment operation anomalies, 2) diagnose the conditions of the transformers and breakers, and 3) make PM and CM recommendations. A substation monitor will consolidate and integrate the equipment monitors at the substation level. Ultimately, a system monitor at Dittmer will integrate and evaluate the data from the substation monitors. Initially, this function will reside on the substation monitor.

The second area of functional requirements is decision support. There are four decision support components as follows:

- $\quad$ CM decision support at the substations, or area offices;

- PM decision support at the substations, or area offices;

- CM decision support at the system headquarters (Dittmer); and

- $\quad$ PM decision support at the system headquarters (Dittmer).

The third area of functional requirements is software. The software tools must be flexible and must be conducive to exploring ways to evaluate and analyze the data. All the software components must provide effective methods for integration. Software is needed to provide a decision support model and the ability to communicate with the SMIS.

In conclusion, RCM is a tool which can be applied by BPA to substation maintenance to improve reliability while reducing maintenance costs. The feasibility study ends with a set of recommendations about how to proceed with the prototype RCM at Alvey substation. 


\begin{abstract}
This feasibility study examines reliability centered maintenance (RCM) as it applies to Bonneville Power Administrations (BPA) substation maintenance program. Reliability techniques are examined and evaluated. Existing BPA equipment maintenance procedures are documented. Equipment failure history is considered. Economic impacts are estimated. Various equipment instrumentation methods are reviewed. Based on this analysis a prototype system is proposed.

The prototype will be implemented in two phases. Phase 1 is to be completed in 1992, it includes instrumenting one power transformer and one oil circuit breaker. Software development will focus on displaying data Phase 2 is to be completed the following year. The remaining transformers and breakers will be instrumented during the second phase. Software development will focus on predictive maintenance techniques and maintenance decision support.
\end{abstract}




\subsection{INTRODUCTION}

\subsection{PURPOSE}

The purposes of this study are 1) to examine the feasibility (pros and cons) of Reliability Centered Maintenance (RCM) as it applies to Bonneville Power Administration's (BPA) substation maintenance and 2) to propose a prototype RCM system. A feasibility study will help in the decision making process, but field experience will be required to quantify the true benefits of RCM. Maintenance is expensive. However, improper maintenance is even more expensive and "mistakes" may not show up for years. Thus, changing maintenance procedures warrants a "go slow" (prototype) approach.

This study is presented in seven sections: introduction, background, BPA equipment, equipment monitoring, benefits of RCM, functional requirements for an RCM system, and conclusions. The introduction section defines and examines the motivation for RCM. It also suggests objectives for BPA's substation RCM program and defines the process for implementing an RCM system.

The background section examines traditional power system reliability and puts substation reliability and RCM into perspective. Techniques used for reliability are also reviewed. This brief summary assesses which techniques are potentially applicable to BPA's RCM system. Similar RCM activities by other utilities, the Electric Power Research Institute (EPRI), equipment vendors, and others are documented. These other RCM experiences are viewed from the perspective of transferring this technology and experience to BPA's RCM prototype.

In the next section, BPA's equipment is examined. Existing transformer and breaker maintenance practices are summarized, and BPA's substation maintenance information system (SMIS) maintenance records are analyzed. The objective of this analysis is to quantify frequency and duration reliability rates for substation equipment. Also, transformer and breaker failure modes are documented.

Equipment monitoring is considered in the next section. Transformer and breaker conditions that can be monitored are identified and assessed. Equipment monitorirg options are presented and discussed 
and research needs are identified. Substation equipment is considered further and conclusions are presented on how BPA's equipment may be included in the RCM prototype.

The benefits of the proposed RCM system are examined in the next section. Among the benefits considered are mitigation of significant equipment failures while in-service, the cost of power interruptions, equiprnent life extens:on, changes in maintenance procedures, and targeting maintenance to equipment $\mathrm{k}$ here the risk and consequence of failure are high.

In the next section, a prototype RCM system is proposed. Functional requirements are identified. These requirements are general and form a basis for the future design. The general hardware system and software architecture are documented.

The final section contains conclusions and recommendations. It addresses the implementation of an RCM prototype.

\subsection{WHY EXAMINE RCM TECHNIQUES? MOTIVATION:}

\subsubsection{BPA Mission}

The BPA mission contains two major objectives. These are discussed in this section.

1) To supply reliable power at the least cost

Reliable power supply and minimum cost are usually economic opposites. Higher reliability generally involves increased investment and maintenance cosi. However, RCM may lead to reduced equipment failure rates without increasing maintenance costs. Thus, RCM has the potential of improving reliability while reducing costs. 
2) To maintain research leadership in the industry

Another aspect of BPA's mission is to contribute to advances in the utility industry through research and development, testing, and sharing of R\&D experiences. An industry problem is the increasing average age of utility equipment. This problem is complicated because reduced load growth has slowed construction activities. Also, financial pressures have caused utilities to defer expenditures. Equipment continues to age; however, plans to replace the entire stock over time are not being made. Some equipment is nearing the end of its useful life. Equipment left in service too long fails; old equipment becomes a safety liability. Furthermore, if equipment fails it may either destroy or accelerate the need to replace associated equipment. RCM may help determine when equipment nears the end of its useful lift.

\subsubsection{Utility Stewardship}

Utilities have a large investment in their substations. Each utility has a responsibility to manage resources, such as people and equipment, wisely. The problem is striking an appropriate balance. Too much maintenance is unnecessarily expensive. On the other hand inadequate maintenance is also expensive. Equipment failures are generally more costly, in human and financial terms, than maintenanco.

A goal of RCM is to establish an acceptable reliability level and perform maintenance to maintain that reliability level. Realizing this goal opens the possibility of examining increased or decreased reliability criteria in light of costs. Currently, maintenance procedures are the driving force determining maintenance expenditures and observable reliability levels. RCM may be used as a tool to turn the process around. The driving force may then become reliability level and expenditures resulting in maintenance procedures. RCM should provide a tool to effectively manage resources based on reliability and costs. Realistically, data on reliability/cost tradeoffs will take years to fine tune. But once collected, RCM will become a powerful tool for managing maintenance.

\subsubsection{Utility Service}

RCM should help provide a more reliable power supply, better customer service, and fewer emergencies and problems. Currently, maintenance procedures are based on fixed-time intervals and inspections. Continual monitoring of key failure precursors may help utility personnel discern when an 
expensive piece of equipment is about to fail. A goal of RCM is to perform maintenance at the latest reasonable time without severely impacting equipment serviceability.

Some failures are the result of electrical transients. Other failures only appear to be the result of transients. Some failures may be avoidable if proper instrumentation and controls are in place so warning signs (precursors) can be identified and monitored.

\subsubsection{Stable Rates}

Higher reliability and lower maintenance costs support stable electricity rates.

\subsubsection{BPA Continues To Ask The Questions}

BPA needs to be able to answer the following maintenance questions. How can maintenance be done better? Are there any desirable alternatives to the way maintenance is being done now?

\subsection{WHAT IS RCM?}

RCM is a technique that is used to develop maintenance plans and criteria so the operational capability of equipment is achieved, restored, or maintained. The objective of the RCM process is to focus attention on system equipment in a manner that leads to the formulation of an optimal maintenance plan. The RCM concept originated in the airline industry in the 1970s and has been used since 1985 to establish maintenance requirements for nuclear power plants. The RCM process is initially applied during the design and development phase of equipment or systems on the premise that reliability is a design characteristic. It is then reapplied, as necessary, during the operational phase to sustain a more optimal maintenance program based on actual field experiences. The purpose of the RCM process is to develop a maintenance program that provides desired or specified levels of operational safety and reliability at the lowest possible overall cost. The objectives are to predict or detect and correct incipient failures before they occur or before they develop into major defects, reduce the probability of failure, detect hidden problems, and improve the cost-effectiveness of the maintenance program. 
RCM accomplishes two basic purposes: (1) It identifies in real-time incipient equipment problems, averting potentially expensive catastrophic failures by communicating potential problems to appropriate system operators and maintenance personnel. (2) It provides decision support by recommending, identifying, and scheduling preventive maintenance. Recommendations are based on maintenance criteria, maintenance history, experience with similar equipment, real-time field data, and resource constraints. Recommendations identify the type of maintenance to be performed, such as inspection, testing, routine maintenance, or detailed maintenance. Recommendations also help establish a maintenance schedule. Scheduling should include the concepts of maintenance priority and local scheduling so field personnel can prioritize preventive maintenance.

Hardware and software are used to accomplish these two purposes. The RCM system includes instrumentation that monitors critical substation equipment as well as computer software that helps analyze equipment data.

A unique aspect of the BPA RCM system involves predicting the "health" of individual equipment. Equipment is manufactured by different vendors. Its design, materials, manufacturing, and vintage differ. Once placed in service, equipment ages and experiences unique operating conditions. Experiences vary according to voltage level and duty requirernents. Likewise, quality of maintenance and replacement parts vary. Predicting the health of equipment is similar to, but not as complex as, determining the health of individual people. To determine the health of individual equipment, incipient diagnostic knowledge, preventive maintenance expertise, and instrumentation are combined into a single RCM system. By considering the equipment's unique characteristics like age, design, duty, and operating/maintenance history, along with the equipment's common characteristics like experience with sister units, reliability, traditional maintenance practices, and failure modes as well as maintenance resources and management goals, work can begin on determining equipment health and hence maintenance needs. Hopefully unnecessary "exploratory surgery" can be reduced where equipment is opened up, inspected, then closed up without any maintenance taking place. It is unrealistic to assume that this project will result in being able to accurately determine equipment health in all situations. However, if the project's direction can be clearly established, progress can be made toward the goal of optimizing maintenance. 
RCM may be viewed simplistically as an input/output process. Maintenance decisions are based on input information such as the following:

- understanding the physical processes inside the equipment,

- maintenance expertise,

- scheduling expertise,

- observations coming from monitoring equipment,

- maintenance criteria,

- manufacturer's recommendations,

- time elapsed since last maintenance,

- operating conditions experienced since last maintenance,

- economics,

- reliability,

- age of the equipment,

- historical data,

- maintenance budget,

- prior maintenance,

- safety,

- construction budget, and

- operating philosophy.

The outputs of RCM are maintenance decisions. Maintenance includes a range of activities such as the following:

- internal and external equipment inspection,

- testing,

- time-based preventive maintenance (PM),

- condition-based PM,

- corrective maintenance ( $(M)$, and

- no maintenance action.

What might an RCM system be expected to accomplish for BPA? What steps must one go through to implement an RCM system? These two questions are addressed next under the headings of RCM objectives and the RCM process. 


\subsubsection{RCM Objectives}

The objectives of the installed RCM need to be considered before the system is designed. Consideration must be given to the desired impacts of the intended RCM system on BPA's power system. These objectives should address the mission of a fully implemented RCM system at BPA. The proposed RCM system for BPA are limited to substation maintenance only. The following sections enumerate RCM objectives.

\subsubsection{Reduce Maintenance Costs}

To quantify reductions in substation maintenance costs (consisting of corrective and preventive maintenance). Currently, BPA's maintenance requirements exceed maintenance resources. RCM may be viewed as a tool to help manage the maintenance workload.

\subsubsection{Optimize Maintenance Resources}

Maintenance resources can be realigned to effectively implement RCM, increase reliability, and improve safety. BPA management may see the need to make organizational changes due to modified maintenance procedures brought about because of RCM.

\subsubsection{Optimize Maintenance Trasks}

To consider the impact of maintenance criteria, which determine when maintenance is required, on maintenance effectiveness. To establish the appropriate balance between the different maintenance procedures such as inspections, surveillance testing, time-oriented maintenance, condition-oriented maintenance, and no action. To optimize the time between maintenance intervals. Bonneville has a tremendous amount of experience in time-driven maintenance. However, BPA does not have the ability to monitor transformers and breakers extensively while on-line. Real-time data will help provide better information for optimizing maintenance practices.

\subsubsection{Optimize RCM Instrumentation}

To identify what values need to be monitored in real-time to provide the data required to make more informed maintenance decisions. If data requirements are not absolutely known, the prototype system may need to be over-instrumented in order to determine experimentally the most economic and effective instrumentation system. The prototype system can then be evaluated and a typical substation 
RCM instrumentation package can be identified, designed, and installed in additional substations as appropriate.

\subsubsection{Enhance Safety}

Safety is an important consideration for utilities. Establishing measures of safety and safety goals and tracking the impact of maintenance decisions on safety, lost time accidents, deaths, etc. are results of safety practices. RCM may be used to reduce catastrophic failures, thus improving safety.

\subsubsection{Improve CM/PM Ratio}

The goal is to establish a more favorable corrective maintenance (CM) to preventive maintenance (PM) ratio. If this ratio is too high, there is not enough PM being done. On the other hand, if the ratio is too low, it may be an indication that too much PM is being done. What is the best CM/PM ratio for BPA? Historical maintenance expenditures will help provide insight into this complex decision.

\subsubsection{Provide Life Extension}

How will RCM impact equipment retirement decisions? Retirement criteria may need to be reconsidered in light of additional information available from RCM. RCM may lead to equipment life extension. Perhaps retirement criteria for equipment can be established, based on RCM, which results in extending equipment life. The economic impact of equipment life extension is discussed in Chapter 5.0 .

\subsubsection{The RCM Process}

The anticipated steps required for implementation of the RCM system are listed in this section. These steps are sequential: work should be completed or nearly completed in one area before the next step is started.

\subsubsection{Establish System Boundaries}

Define system boundaries. Alvey substation was selected for the RCM prototype system. Substation equipment are the RCM components for the final systern; transformers and breakers are the RCM components for the prototype. 


\subsubsection{Define System Functions}

Identify substation functions and define functional failures that must be addressed. Equipment failures that disrupt power supply reliability must receive additional attention by RCM. The RCM system will be designed to optimize preventive maintenance and mitigate catastrophic equipment failures since these failures are particularly expensive.

A desired reliability level for substation circuits needs to be identified. What is the target reliability level for BPA's substations? What is the relationship between BPA's contingency level criteria and substation reliability? Substation reliability is separate and distinct from generation systern reliability, transmission system reliability, equipment reliability, or customer reliability.

\subsubsection{Identify Failure Modes}

Identify the dominant failure modes associated with equipment failures. Several approaches may be considered as follows:

- summarize BPA's maintenance history and experience, including interviews with maintenance personnel;

- review industry experience based on other utility and vendor experiences; and

- apply analytical techniques such as failure mode and effects analysis (FMEA), fault tree analysis, sequence of events, and/or system modeling.

\subsubsection{Apply RCM Decision Logic}

Apply RCM decision logic to determine preventative maintenance tasks. This process should help identify those values that need to be monitored by the RCM system.

\subsubsection{Design Instrumentation System}

Design an instrumentation monitoring system that will meet $\mathrm{RCM}$ requirements.

\subsubsection{Redefine Preventative Maintenance (PM) Tasks}

The RCM will propose PM tasks, prioritized according to the following activities:

$$
\text { equipment inspections, }
$$

surveillance tests,

time-based PM, 
condition-based PM, and

no-action options or suggest equipment design changes.

\subsubsection{Evaluate RCM Performance}

The RCM system must be based on sound maintenance principles and experience. Perhaps a RCM review board is needed to insure quality decisions. Evaluation and control mechanisms need to be put into place to provide a tangible basis for evaluation as follows:

- define and revise baseline criteria and equipment monitoring thresholds for condition-based and time-based PM;

- explore extensions to maintenance periods proposed by RCM analysis;

- examine organizational interfaces required to implement RCM;

- quantify cost, safety, and reliability implications associated with RCM; and

- determine the overall effectiveness of RCM.

\subsubsection{Track Critical Maintenance Parameters}

Identifying key measurable parameters will give insight into the effectiveness of RCM. These key values must be tracked and examined for trends. Items which may apply include the following:

- CM (number and severity),

- types of failure modes,

- maintenance costs, and

- safety impacts. 


\subsection{BACKGROUND}

\subsection{POWER SYSTEM RELIABILITY AND RCM}

The "reliability" of an electric power system refers to the ability of the electric system to provide consumers with continuous electrical service of satisfactory power quality. The electric utility industry maintains a high level of system reliability because when the electric supply to consumers is disrupted, even for a short period of time, the results can range from minor inconvenience to major economic loss to endangerment of human life. Reliability provided to each consumer varies from location to location on the system. Different reliability levels are experienced by the generation, transmission, and distribution systems. The IEEE Power Engineering Task Force on Bulk Power System Reliability describes a proper level of electric utility system reliability as that which meets customer load demands and energy at the lowest possible cost while maintaining acceptable levels of service quality. Provisions for higher degrees of service reliability involve higher expenditures for both additional facilities and increased maintenance.

Today there is a tendency among electric utilities to defer expenditures for expansion and improvement as long as possible. This tendency results in equipment experiencing more severe operating conditions. Norrnally, when equipment experiences more severe operating conditions and becomes older, closer attention is given to maintenance. This attention may be in the form of either working harder (where additional site visits are made) or working smarter (where additional reliability techniques are applied). This section identifies and evaluates additional reliability techniques applicable to RCM (see Sect. 2.3).

Maintenance activities may be classified as either corrective or preventive maintenance. Generally, corrective maintenance is concerned with observed problems while preventive maintenance anticipates problems and initiates action before problems are observed. Reliability techniques may be applied to either corrective or preventive maintenance. 


\subsection{TRADITIONAL POWER SYSTEM RELIABILITY}

Service reliability is measured in terms of the number of consumers affected, the number of interruptions, and the duration of interruptions. Reliability indices include the following:

- number of interruptions per consumer served,

- number of consumers affected per consumer served,

- number of consumer hours of interruption per consumer served,

- average number of consumers affected per consumer served, and

- $\quad$ average outage duration (hours) per consumer served.

The reliability of the electric power system is a concern for both system operators and planners. Operators are concerned with the reliability of the system when it is in one of its likely operating states. They are interested in short-term risk assessments because they need fast results that can be used to implement new operating decisions before problems arise. System planners are concerned with the reliability of the system as designed for all possible operating states and are thus interested in long-term risk assessments of the system.

The complexity and size of most electric power systems do not allow for an analysis of the ent: ie system in a completely realistic and exhaustive manner on a digital computer. For this reason, and because it may be more meaningful to select separate failure criteria, reliability indices, and modeling assumptions for each subsystem, the reliability of an electric system is studied by dividing the system up into subsystems. The main subsystems are generating systems, interconnections, the composites of generation and transmission known as the bulk power system, area supply systems, and distribution networks. Because of the extreme complexity of the power system, especially a large system, simplifying assumptions are generally used to build models of the system. Short-term reliability predictions, which are still under development, assist in day-to-day operating decisions. Long-term reliability analysis techniques are mature. They are performed to assist in long-range system planning.

Two different approaches have been used for reliability assessments of power systems: deterministic and probabilistic. In the deterministic approach, reliability criteria are established by selecting a set of contingencies which the system must withstand without service interruptions. Then a 
series of computer runs are made to evaluate the impact of single contingencies or combinations of contingencies. The probabilistic approach to reliability evaluation involves defining appropriate reliability indices to measure the reliability of the system. These reliability indices are used to assess the risk of a system failure. The power system is designed to keep these reliability indices below a predefined level. The primary indices indicate the probability of failure, the frequency of failure, and the average duration of failure. These indices are determined for each kind of corrective action (i.e., shedding of interruptable load, voltage reduction, and load reduction in part of the system) which may be taken after a systern contingency or disturbance. Comparison of alternative system plans are the most frequent application of probabilistic approaches.

The two concepts described above have quite a bit in common. Both address risk reduction and cost minimization. The system reliability concept is concerned with the overall reliability of the system and does not necessarily consider the reliability of all system components, including substation components. In addition, system reliability evaluation is based on either a deterministic approach which considers a preselected set of system contingencies or is based on a probabilistic approach which considers component reliabilities. RCM is much like system reliability at the component level. It considers reliability starting at the design phase and proceeds through to the operational phase. A unique characteristic of RCM is the decision logic that goes into identifying critical components, applying the decision logic to the critical failure modes, and collecting and building of adequate data on component reliability.

RCM may be used to target individual equipment or the system. Either the reliability of individual equipment or the reliability of the system is maximized. Traditionally, RCM has been applied to the system level, to maintain the function of the system (e.g., transmission system, nuclear power plant, or aircraft). However, the design of substations are very reliable: critical components like expensive transformer banks can usually be lost without loss of electrical service. Therefore, substation RCM should target individual equipment (e.g., transformers and breakers) in order to minimize maintenance resources (e.g., time and costs). 


\subsection{RELIABILITY TECHNTQUES APPLICABLE TO RCM}

A successful RCM program requires the availability of appropriate data such as usage, maintenance, and reliability histories of equipment and systems. The basis for RCM is generally derived from careful consideration of the following questions.

- What is the function of the system and its components?

- What types of failures occur? What is the frequency?

- What are the consequences of failures?

- What can be done to prevent failures?

Consequently, an "RCM Information/Decision Support System" that includes the aforementioned data would be valuable and beneficial to the maintenance analyst. To convert the raw data into meaningful information, software tools and techniques are needed in an RCM program. For instance, mathematical or statistical procedures help in deciding where maintenance resources should be allocated in order to better utilize maintenance resources while trying to improve component reliability.

This section addresses tools and techniques applicable to reliability analysis. These tools are evaluated from the viewpoint of applying them to BPA's RCM system. The techniques are assigned to one of two categories: those that probably apply to BPA's RCM system and those that probably do not apply. Four techniques appear to have the greatest application potential to BPA's RCM system. These techniques are failure mode and effects analysis, regression/correlation analysis, expert systems, and Bayesian techniques. The remaining techniques may be revived as the design progresses, but at this point these techniques are less likely to be applied to BPA's RCM prototype.

\subsubsection{Techniques That Probably Apply to BPA's System}

The techniques that apply to BPA's RCM system are analytical, judgement oriented, or simulation based. Failure mode and effect analysis and regression analysis are analytical techniques. Techniques may also be judgement or experience based because good maintenance practices depend on sound judgement and experience. Expert systems allow experience and judgement to be included. Bayesian techniques represents a combination of judgement oriented and statistical approaches. Dynamic system 
modeling techniques may be applied to power system transformers or breakers, and simulation techniques that extrapolate dynamic system conditions estimate when maintenance is required. Expert: systems in conjunction with transformer or breaker models may be used to project when maintenance is required. The four techniques that probably apply to BPA's system are discussed in the following subsections and are summarized below in Table 2.1 .

\begin{tabular}{|l|l|l|}
\hline \multicolumn{2}{|c|}{ Table 2.1. Techniques which probably apply to BPA's system } \\
\hline \multicolumn{1}{|c|}{ Technique } & \multicolumn{1}{|c|}{ Rationale } & \multicolumn{1}{c|}{ Application } \\
\hline $\begin{array}{l}\text { Failure Mode and } \\
\text { (FMEA) }\end{array}$ & $\begin{array}{l}\text { Examines failure mechanisms and the consequence } \\
\text { of each type of failure. Analysis is limited to } \\
\text { transformers and breakers. }\end{array}$ & $\begin{array}{l}\text { Helps determine what } \\
\text { values should be } \\
\text { monitored. }\end{array}$ \\
\hline $\begin{array}{l}\text { Regression } \\
\text { Analysis }\end{array}$ & $\begin{array}{l}\text { Examines data statistically to establish relationships } \\
\text { between data (i.e., failure rate vs age, or failure } \\
\text { rate vs voltage, or failure rate vs equipment type). }\end{array}$ & $\begin{array}{l}\text { Helps target } \\
\text { maintenance based on } \\
\text { equipment age and } \\
\text { voltage. }\end{array}$ \\
\hline Expert Systems & $\begin{array}{l}\text { Compare monitored and historical data from } \\
\text { transformer or breaker to maintenance criteria. The } \\
\text { expert system could suggest what type of } \\
\text { maintenance needs to be performed and when it } \\
\text { needs to be performed. }\end{array}$ & $\begin{array}{l}\text { Suggests maintenance } \\
\text { activities based on } \\
\text { maintenance criteria, } \\
\text { monitored data, and } \\
\text { historical data. } \\
\text { Failure analysis } \\
\text { potential. }\end{array}$ \\
\hline Bayesian & $\begin{array}{l}\text { Combines experience and data. Results of this } \\
\text { analysis may be used by the expert system. }\end{array}$ & $\begin{array}{l}\text { May be usad to } \\
\text { predict where a } \\
\text { failure may occur. }\end{array}$ \\
\hline
\end{tabular}

\subsubsection{Failure Mode and Effect Analysis (FMEA).}

FMEA is a structured analytical technique that documents failures and the impact of failures on equipment. It addresses functional failures, identifies the dominant failure modes, categorizes impacts (e. g., local, system, or organizational), and determines critical components within the equipment. In addition, it provides the input for determining which failure modes may be prevented by RCM, and which modes may be addressed by RCM. 


\subsubsection{Regression Analysis.}

Reliability is a "probability," and hence the mathematical structures of probability theory and statistics are important in reliability evaluation. Statistical methods can be used to measure, compare, and prodict characteristics of the distribution of time to some particular event or events of interest (e.g., system failures). Regression or correlation analysis helps to determine relationships between failure and failure-cause variables (e.g., failure rate vs. age). Parameters in the regression models are typically estimated by various statistical procedures. Binary response models are also frequently used when one considers only he failure or nonfailure of equipment over a specified time period. A regression model for RCM might relate observable values (e.g., the number of operations, the cumulative power loading, the rate of oil hydrogenization, and the time since last maintenance) to maintenance requirements.

\subsubsection{Expert Systems.}

Expert systems handle a wide range of problems. They may be developed to diagnose, interpret, predict, instruct, design, plan, monitor, advise, or control. An expert system can be integrated with other software including dynamic models, algorithms, data bases, or real-time systems. Expert systems can be designed to be flexible. Rules can be developed which reflect maintenance experience. Rules can be revised quickly without impacting other rules. In this manner an expert system can be incrementally improves. Expert system technology has been applied successfully to BPA's communication alarm processor project.

An RCM expert system will probably need access to monitored and historical data. Observed data can be compared to maintenance criteria and suggestions for maintenance may be initiated by the expert system. The recommendations by the expert system can be evaluated by those in charge of substation maintenance. Afterwards maintenance tasks can be scheduled by maintenance personnel.

\subsubsection{Bayesian Approach For The Study of Reliability/Availability Problems}

Bayesian methods provide one way of combining experience with observed data. The Bayesian approach uses conditional probabilities. The analysts use their experience to choose a probability and to apply it to the problem. It should be noted that Bayesian approaches are generally applicable to datasets where the data are limited but good experience is available. Other techniques should be used for data sets rich in information. For Bayesian methods in reliability refer to the book Bayesian Reliability Analysis, (New York: John Wiley, 1982) by Martz and Waller. 


\subsubsection{Techniques That Probably Do Not Apply to BPA's System}

There are other techniques for assessing reliability which probably do not apply to BPA's system. Techniques that probably do not apply may be classified as those which analyze static data or depend on accurate data, are difficult to automate, are non-dynamic approaches, or those that require actual failure experiences for input. The techniques that probably do not apply and the reasons they probably do not apply are discussed in the following subsections and summarized in Table 2.2.

Table 2.2. Techniques which probably do not apply to BPA's system

\begin{tabular}{|l|l|}
\hline \multicolumn{1}{|c|}{ Technique } & \multicolumn{1}{|c|}{ Rationale } \\
\hline Fault Tree Analysis (FTA) & $\begin{array}{l}\text { FTA may progress through several levels of cause and effect. } \\
\text { However, since the observable values are internalized within the } \\
\text { equipment, FMEA appears to be a better approach. }\end{array}$ \\
\hline Machine Learning & $\begin{array}{l}\text { Predicting transformer and breaker failures based on RCM } \\
\text { instrumentation in some instances is more art than science. } \\
\text { There are many unknowns about physical phenomena leading to } \\
\text { equipment failures which makes verification of machine learning } \\
\text { techniques difficult. Verification is important because failures } \\
\text { are expensive and occur infrequently. }\end{array}$ \\
\hline Statistical Modeling & $\begin{array}{l}\text { The type of data which will be used for RCM is not available } \\
\text { without RCM instrumentation. Statistical modeling requires an } \\
\text { analyst, so this approach may not work with real-time data. }\end{array}$ \\
\hline Reliability Block Diagrams & $\begin{array}{l}\text { Uses component reliability rates and repair times to examine the } \\
\text { impart of losing a component on the reliability of power supply. } \\
\text { Determines the impact of a failed component on substation } \\
\text { reliability. Since data is not readily available for alternative } \\
\text { maintenance scenarios this approach does not apply to RCM. }\end{array}$ \\
\hline Mime Series Analysis & $\begin{array}{l}\text { Time series analysis requires data from RCM instrumentation } \\
\text { along with equipment failure experiences. These data from } \\
\text { failures are not available. }\end{array}$ \\
\hline This method does not apply well to small system analysis and \\
does not lend itself to real-time data because it requires a skilled \\
analyst.
\end{tabular}

\subsubsection{Fault Tree Analysis (FTA)}

Fault tree analysis (FTA) was developed mainly by engineers who design and analyze complex systems. Basically, a fault tree is a model that graphically and logically represents various combinations of possible events, both fault and normal, occurring in a system that lead to the event of interest (e.g.,

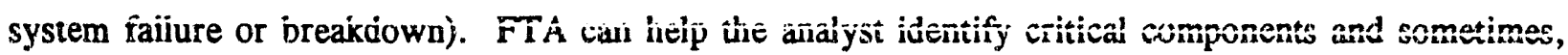


specific failure modes for a system. As a diagnostic tool, FTA can be used to predict the most likely causes of system failure in the event of a system breakdown. As a design tool, FTA aids in the identification of potential accidents due to system design and helps to eliminate costly design changes and retrofits.

FTA involves two steps: fault tree construction and fault tree analysis. Fault tree construction requires the input of an expert's knowledge on how the system is designed and operated. The second step involves the evaluation of the fault tree, either qualitatively or quantitatively. It is important to understand that a fault tree is not always a model of all possible system failure modes. The fault tree might only include faults related to certain selected system functions. Also, fault trees generally only include those faults that are determined by the analyst to be most credible. Reliability and Fault Tree Analysis, edited by Barlow, Fussell, and Singpurwalla (1975), provides many applications of FTA in reliability.

An attempt was made to apply FTA earlier in this study. However, after working with BPA staff, FTA did not capture the information necessary for RCM. FMEA appears to do a better job than FTA because detailed knowledge of fault sequences is not available from BPA and is required for FTA.

\subsubsection{Machine Learning}

Machine learning has three primary focuses: task-oriented analysis, computer simulation of human learning processes, and theoretical analysis of learning methods. Machine learning techniques include neural networks, classifier systems, and genetic algorithms. Most machine learning techniques require a learning process. Learning includes observing experiences where equipment fails or learning the signs and symptoms which are abnormal or appear prior to a failure. Machine learning techniques may eventually be applied to RCM; however, today there is not sufficient sensor data involving faults and maintenance to adequately teach the system.

\subsubsection{Statistical Modeling}

Statistical models require good data. Careful modeling of a system may help uncover components or modules that are particularly sensitive to damage or whose failure will lead to a system failure. Models that are most commonly applied in the study of reliability problems include poisson, extreme value, Weibull, exponential, gamma, lognormal, and inverse Gaussian distributions. These models map 
actual data to statistical models to see how closely the model fits. Goodness-of-fit procedures are available for testing modeling assumptions and evaluating the appropriateness of the selected models. The problem with statistical modeling is the uniqueness of individual pieces of equipment. Equipment variations and operating experiences are too complex to capture in a single nredictive statistical model. Also, statistical modeling requires an analyst so this approach may not work with real-time data.

\subsubsection{Reliability Block Diagram}

Classical probability theory is the basis for mathematical modeling in reliability analysis. Mathematical models state the probability of system success (defined as non-failure) in terms of individual component failure rates and reliabilities. Reliability block diagrams aid in the development of mathematical models which represent the physical system. They graphically display systems in terms of parallel and/or series components. This analysis may result in mean-time between failure (MTBF) predictions. The book Mathematical Theory of Reliability by Barlow and Proschan (1965) is an acknowledged authority on mathematical models and methods to the study of reliability problems.

Reliability block diagrams are used frequently for reliability analysis of design alternatives. The reliability of different failure modes under alternative maintenance scenarios is not well understood. In essence, the data are not available to apply reliability block diagrams to a dynamic system (e.g., transformer or breaker).

\subsubsection{Time Series Analysis (TSA)}

TSA is an "experienced-based" analysis. This analysis is related to Fourier analysis. By evaluating failure history and system failure frequency, TSA allows the analyst to identify possible failure cycles or trends as opposed to random failure levels. The theoretical basis of TSA is that unique cyclic failure patterns often exist in the operating experience of systems and equiptnent. Factors tist contribute to unique failure patterns include items such as design, maintenance, faults, operations, and equipment operating environment. These failure cycles often represent failure degradation mechanisms that could be associated with the root cause of equipment/system breakdowns. TSA is used to identify the failure modes and causes of critical components failure as well as the failure intervals. However, the complexity and diversity of the equipment, the infrequency of failures, and the diversity of the operating environment make it difficult to extract a pattern which is applicable to maintenance practices. 


\subsubsection{Markov Model}

The Markov process is a continuous time model. The Markov process requires that equipment states be defined, such as normal operation, emergency operation, or not operational. Also, the probabilities of transitioning from one state to another in a certain time period must be identified. These probabilities include failure rates and repair rates. The Markov model results in a set of first order differential equations that can be solved by classical methods, Laplace transforms, or computer simulation. The Markov method is difficult to use and requires a high skill level. Markov analysis applies better to large power network systems than to small substation sized systems.

\subsection{REFERENCES}

There are four main sources of information for substation RCM. These sources are nuclear power plant applications, airline/military applications, literature on reliability techniques or availability engineering, and articles on instrumenting power equipment.

The application of RCM to nuclear power plants was initiated by EPRI in the early 1980s. A 1984 EPRI study, "A Study to Identify the Potential Value of Commercial Aviation Experience to the Nuclear Industry," identified RCM as a candidate for technology transfer to the utility industry. The airline industry discovered that the application of $\mathrm{RCM}$ reduced maintenance costs while improving reliability. The airline industry observed consistent improvements in maintenance costs and reliability over the 16-year period that RCM had been used.

EPRI commissioned three RCM pilot projects to determine the usefulness of RCM for nuclear power plants. The first project was staged at Florida Power and Light's Turkey Point plant. The component cooling water system was selected due to high corrective and preventative maintenance costs. The second project was staged at Duke Power's McGuire station. The main feedwater system was selected because it had experienced operational problems and had recently been modified. 'These two projects demonstrated that $\mathrm{RCM}$ yields useful maintenance recommendations.

The third RCM pilot project was conducted at Southern California Edison's San Onofre. The auxiliary feedwater system was selected. It is a standby system which experiences infrequent operation 
while requiring frequent testing. Data collection activities were suggested to aid surveillance testing. Resulting data helps determine the need for condition-directed maintenance. This project included considering the impact of data from instrumentation in making maintenance decisions.

After these pilot studies were completed, two large-scale RCM demonstrations were begun. The purpose of these demonstrations were to show cost effectiveness, fine tune maintenance procedures, and justify plant life extension. These demonstrations were conducted at Rochester Gas and Electric's Ginna plant and Southern California Edison Electric's San Onofre nuclear plant.

Military RCM experience like BPA's RCM is equipment based. Like BPA, the Army overhauled equipment on a fixed time schedule. The military reduced maintenance cost and improved reliability after they adopted RCM.

Following are references on RCM related techniques.

B. Amstadter, Reliability Mathematics - Fundamentals; Practices; Procedures, McGraw-Hill Book Company, New York, New York, 1971.

M. Ash and H. Gorton, "A Practical End-of-Life Model for Semiconductor Devices," IEEE Transactions' on Reliability, Vol. 38, No. 4, pp. 485-493, October 1989.

R. Barlow, and F. Proschan, Mathematical Theory of Reliability, Wiley, New York, 1965.

R. Barlow, J. Fussell, and N. Singpurwalla, "Conference on Reliability and Fault Tree Analysis, "Society for Industrial and Applied mathematics, Philadelphia, Pennsylvania, 1975.

R. Billinton, T. Medicherla, and M. Sachdev, "Common-Cause Outages in Multiple Circuit Transmission Lines," IEEE Transactions on Reliability, Vol. R-27, No. 2, pp. 128-131, June 1978.

J. Bilikam, "Correspondence of Types I \& II Censored-Sample Estimators," IEEE Transactions on Reliability, Vol. R-32, No. 1, pp. 100-101, April 1983. 
D. Brauer and G. Brauer, "Reliability-Centered Maintenance," IEEE Transactions on Reliability, Vol. R36, No. 1, pp. 17-24, April 1987.

P. Chan and T. Downs, "Two Criteria for Preventive Maintenance," IEEE Transactions on Reliability, Vol. R-27, No. 4, pp. 272-273, October 1978.

A. Cockerill and M. Lavoie, "RAM Analysis Helps Cut Turbine-Generator Systems Costs," Power Engineeiting, pp. 27-29, July 1.990.

G. Contaxis, S. Kavatza, and C. Vournas, "An Interactive Package for Risk Evaluation and Maintenance Scheduling," IEEE. Transactions on Power Systems, Vol. 4, No. 2, pp. 389-395, May 1989.

G. Crellin, et al. "Use of RCM for McGuire Nuclear Station Feedwater System," EPRI Report NP4795, September 1986.

D. Cummings, S. Lapp, and G. Powers, "Fault Tree Synthesis From a Directed Graph Model for a Power Distribution Network, "IEEE Transactions on Reliability, Vol. R-32, No. 2, pp. 140-149, June 1983.

C. Dunglinson and H. Lambert, "Interval Reliability for Initiating and Enabling Events," IEEE Transactions on Reliability, Vol. R-32, No. 2, pp. 150-163, June 1983.

EPRI NP-6152, "Demonstration of Reliability-Centered Maintenance, Volume 1: Project Description," Janualy 1989.

EPRI NP-3364, "Commercial Aviation Experience of Value to the Nuclear Industry," January 1984.

EPRI NP-2166, "Basic Techniques in Availability Engineering," May 1982.

EPRI EL-4323, "Artificial Intelligence Technologies for Power System Operations," January 1986.

EPRI NP-6240, "The EPRI Knowledge Acquisition Workshop Handbook, " February 1989. 
EPRI NP-4141, "Functional Specifications for Al Software Tools for Electric Power Applications," August 1985.

EPRI NP-2507, "A Valve Assessment Aid to Complex Decision Making," July 1982.

C. Fong and J. Buzacott, "An Algorithm for Symbolic Reliability Computation with Path-Sets or CutSets," IEEE Transactions on Reliability, Vol. R-36, No. 1, pp. 34-37, April 1987.

C. Fong, R. Billinton, R. Gunderson, P. O'Neill, J. Raksany, A. Schneider, Jr., and B. Silverstein, "Bulk System Reliability - Measurement and Indices," IEEE Transactions on Power Systems, Vol. 4, No. 3, pp. 829-835, August 1989.

A. Gupta, "Reduced Tree Search for Optimal Preventive Maintenance of Generating Facilities," IEEE Transactions on Reliability, Vol. R-30, No. 5, pp. 476-477, December 1981.

M. Guth, "Practical Considerations in Developing an Instrument-Maintenance Plan," IEEE Transactions on Reliability, Vol. 38, No. 2, pp. 253-265, June 1989.

E. Hollnagel, G. Mancini, D. Woods, "Intelligent Decision Support in Process Environments," SpringerVerlag Berlin Heidelberg New York Tokyo, 1985.

T. Hook, et al. "Application of RCM to San Onofre Units 2 and 3 Auxiliary Feedwater System, "EPRI Report NP-5430, September 1987.

C. Hwang, F. Tillman, W. Wei, and C. Lie, "Optimal Scheduled-Maintenance Policy Based on MultipleCriteria Decision-Making, "IEEE Transactions on Reliability, Vol. R-28, No. 5, pp. 394-398, December 1979.

R. Michalski, et al., Machine Learning, Tioga Publishing Company, Palo Alto, California, 1983.

T. Nakagawa, "Sequential Imperfect Preventive Maintenance Policies," IEEE Transactions on Reliability, Vol. 37, No. 3, pp. 295-298, August 1988. 
F. Nowlan, et al. Reliability Centered Maintenance, prepared by United Airlines, Report No. A066-579, December 1978.

L. Page and J. Perry, "A Model for System Reliability with Common-Cause Failures," IEEE Transactions on Reliability, Vol. 38, No. 4, pp. 406-410, October 1989.

F. Patterson-Hine and B. Koen, "Direct Evaluation of Fault Trees Using Object-Oriented Programming Techniques," IEEE Transactions on Reliability, Vol. 38, No. 2, pp. 186-192, June 1989.

R. Patton, P. Frank, and R. Clark, "Fault Diagnosis in Dynamic Systems - Theory and Applications," Prentice Hall, Englewood Cliff, New Jersey, 1989.

W. Prince, E. Nielsen, and H. McNair, "A Survey of Current Operational Problems," IEEE Transactions on Power Systems, Vol. 4, No. 4, pp. 1492-1498, October 1989.

S. Sim and J. Endrenyi, "Optimal Preventive Maintenance with Repair," IEEE Transactions on Reliability, Vol. 37, No. 1, pp. 92-96, April 1988.

H. Tanaka, L. Fan, F. Lai, and K. Toguchi, "Fault-Tree Analysis by Fuzzy Probability," IEEE Transactions on Reliability, Vol. R-32, No. 5, pp. 453-457, December 1983.

Task Force on Bulk Power System Reliability of the IEEE-PES Application of Probability Methods Subcommittee, "Bulk Power System Reliability Concepts and Applications," IEEE Transactions on Power Systems, Vol. 3, No. 1, February 1988, pp. 109-117.

F. Tillman, W. Kuo, C. Hwang, and D. Grosh, "Bayesian Reliability \& Availability - A Review, IEEE Transactions on Reliability, Vol. R-31, No. 4, pp. 362-372, October 1982.

R. Vasudevan, et al. "Application of RCM to Component Cooling Water System at Turkey Point Units 3 and 4," EPRI Report NP-4271, October 1985. 
I. Walker and D. Cooper, "Measuring Maintenance Effectiveness," Power Engineering, pp 28-30, November 1990.

C. Wells, "Replacement vs Repair of Failed Components For a System With a Random Lifetime," IEEE Transactions on Reliability, Vol. 37, No 3, pp. 280-286, August 1988.

Z. Zhang, G. Hope, and O. Malik, "Expert Systems in Electric Power Systems - A Bibliographical Survey," IEEE Transactions on Power Systems, Vol. 4, No. 4, pp. 1355-1362, October 1989. 


\subsection{BPA EQUIPMENT}

\subsection{EXISTING TRANSFORMER AND BREAKER MAINTENANCE}

Current BPA maintenance practices for transformers and breakers are summarized in this section. BPA has a well developed system for maintenance. Their system is based on years of experience. This section describes existing maintenance gractices on two types of equipment: transformers and breakers. Instrumentation for BPA's RCM system will be limited initially to transformers and breakers.

Two basic types of maintenance are performed on equipment: preventive maintenance (PM) and corrective maintenance (CM). BPA's definitions for these are as follows.

Preventive maintenance is defined as, "Work performed to keep equipment in operating condition." Preventive maintenance consists of performing a standardized maintenance task leading to a Work Unit in a time interval prescribed by the Performance Level Guides (PLGs). All preventive work is scheduled via BPA's Substation Maintenance Information System (SMIS). Sometimes preventive maintenance develops into corrective maintenance: continue with preventive maintenance accounts until the activity changes, then use the corrective maintenance code $(C)$. The preventive indicator $(P)$ is used in conjunction with the maintenance activity to identify costs associated with the Work Unit when service is in accordance with the PLG.

Corrective maintenance is defined as, "Work performed to analyze and return equipment to sustained operating condition." A corrective task is required by equipment operating needs, rather than the PLGs. The corrective condition applies until repairs are completed and the equipment is returned to satisfactory operating condition. The corrective indicator $(C)$ is used in conjunction with corrective activity code "MA6C."

A determination as to whether work is preventive or corrective depends upon the reason for doing the work. If the work is scheduled via SMIS, preventive activities are used. If the work was not planned, but caused by equipment failure or malfunction, the corrective activity will be used. If a 
scheduled task which begins as a preventive maintenance task develops into a corrective one, the charges are apportioned.

\subsubsection{Breakers}

\subsubsection{Breaker Maintenance Activities}

This sect on identifies maintenance activity by breaker voltage, design type, and duty. These three characterisiics are uniquely identified by BPA's PL-6 equipment maintenance codes. Preventive and corrective maintenance are performed on each PL-6. Preventive maintenance is categorized into three activities and ic entified by an activity code. The three preventive maintenance activity codes are complete service (ME4), diagnostic service (ME5P), and mechanism service (ME8P). There is only one corrective maintenance activity, diagnose/repair (MA6C). Table 3.1 is based on 1989 maintenance data. The tables are organized according to PL-6 maintenance activity codes. The tables identify the number of breakers how many breakers were maintained in 1989 (maintenance frequency), the average manhours spen: on maintaining the breakers, the actual maintenance rate, and the PLG maintenance rate. Data in th ; first three columns are from SMIS. 
Table 3.1. FY89 Breaker maintenance practices

\begin{tabular}{|c|c|c|c|c|}
\hline & $\begin{array}{l}\text { Maintenance } \\
\text { Frequency }\end{array}$ & $\begin{array}{l}\text { Average } \\
\text { Man-Hrs }\end{array}$ & $\begin{array}{c}\text { Actual } \\
\text { Maint. } \\
\text { Rate }(\mathrm{Yrs})\end{array}$ & $\begin{array}{c}\text { PLG } \\
\text { Maint. } \\
\text { Rate (Yrs) }\end{array}$ \\
\hline \multicolumn{5}{|l|}{ EHV (345kV and above) } \\
\hline \multicolumn{2}{|l|}{ Air and Gas Blast (M411) } & \multicolumn{3}{|c|}{ Population: 150} \\
\hline \multicolumn{5}{|l|}{ Preventive Maintenance } \\
\hline Complete Service (ME4P) & 11 & 1034 & 14 & 6 \\
\hline Diagnostic Service (ME5P) & 22 & 22 & 7 & 3 \\
\hline Mechanism Service (ME8P) & 77 & 45 & 2 & 1 \\
\hline \multicolumn{5}{|l|}{ Corrective Maintenance } \\
\hline Diagnose/Repair (MA6C) & 5 & 413 & 30 & \\
\hline \multicolumn{2}{|l|}{ Gas Puffer (M413) } & \multicolumn{3}{|c|}{\begin{tabular}{|l|} 
Population: 35 \\
\end{tabular}} \\
\hline \multicolumn{5}{|l|}{ Preventive Maintenance } \\
\hline Complete Service (ME4P) & 0 & & & 12 \\
\hline Diagnostic Service (ME5P) & 0 & & & 6 \\
\hline Mechanism Service (ME8P) & 16 & $*$ & 2 & 1 \\
\hline \multicolumn{5}{|l|}{ Corrective Maintenance } \\
\hline Diagnose/Repair (MA6C) & 0 & & & \\
\hline \multicolumn{5}{|l|}{$230 \mathrm{kV}$} \\
\hline \multicolumn{2}{|c|}{ OCB - Line, Bus, and Transformer (M401) } & \multicolumn{3}{|c|}{ Population: 314} \\
\hline \multicolumn{5}{|l|}{ Preventive Maintenance } \\
\hline Complete Service (ME4P) & 56 & 102 & 6 & 4 \\
\hline Mechanism Service (ME\&P) & 0 & & & 1 \\
\hline Corrective Maintenance & 211 & 13 & & \\
\hline Diagnose/Repair (MA6C) & 6 & 19 & 52 & \\
\hline \multicolumn{2}{|l|}{ OCB - Capacitor (M402) } & \multicolumn{3}{|c|}{ Population: 5} \\
\hline \multicolumn{5}{|l|}{ Preventive Maintenance } \\
\hline Complete Service (ME4P) & 0 & & & 2 \\
\hline Mechanism Service (ME8P) & 4 & 9 & 1 & 1 \\
\hline \multicolumn{5}{|l|}{ Corrective Maintenance } \\
\hline Diagnose/Repair (MA6C) & 0 & & & \\
\hline
\end{tabular}


Table 3.1 FY89 breaker maintenance practices (continued)

\begin{tabular}{|c|c|c|c|c|}
\hline & $\begin{array}{l}\text { Maintenance } \\
\text { Frequency }\end{array}$ & $\begin{array}{l}\text { Average } \\
\text { Man-Hrs }\end{array}$ & $\begin{array}{c}\text { Actual } \\
\text { Maint. } \\
\text { Rate (Yrs) }\end{array}$ & $\begin{array}{c}\text { PLG } \\
\text { Maint. } \\
\text { Rate (Xrs) }\end{array}$ \\
\hline \multicolumn{5}{|l|}{$230 \mathrm{kV}$ (continued) } \\
\hline \multicolumn{2}{|c|}{ Gas \& Air Blast - Line, Bus, \& Transformer (M421) } & \multicolumn{3}{|c|}{ Population: 52} \\
\hline \multicolumn{5}{|l|}{ Preventive Maintenance } \\
\hline Complete Service (ME4P) & 6 & 109 & 9 & 6 \\
\hline Mechanism Service (ME8P) & 36 & 24 & 1 & 1 \\
\hline \multicolumn{5}{|l|}{ Corrective Maintenance } \\
\hline Diagnose/Repair (MA6C) & 1 & 170 & & \\
\hline \multicolumn{2}{|l|}{ Gas \& Air Blast - Capacitor (M422) } & \multicolumn{3}{|c|}{ Population: 14} \\
\hline \multicolumn{5}{|l|}{ Preventive Maintenance } \\
\hline Complete Service (ME4P) & 2 & 17 & 7 & 2 \\
\hline Mechanism Service (ME8P) & 11 & 27 & 1 & 1 \\
\hline \multicolumn{5}{|l|}{ Corrective Maintenance } \\
\hline Diagnose/Repair (MA6C) & 0 & & & \\
\hline \multicolumn{2}{|l|}{ Puffer (M431) } & \multicolumn{3}{|c|}{ Population: 60} \\
\hline \multicolumn{5}{|l|}{ Preventive Maintenance } \\
\hline Complete Service (ME4P) & 1 & * & 60 & 12 \\
\hline Diagnostic Service (ME5P) & 1 & $*$ & 60 & 6 \\
\hline Mechanism Service (ME8P) & 39 & $*$ & 2 & 1 \\
\hline \multicolumn{5}{|l|}{ Corrective Maintenance } \\
\hline Diagnose/Repair (MA6C) & 0 & & & \\
\hline \multicolumn{5}{|l|}{$115 \mathrm{kV}$} \\
\hline \multicolumn{2}{|c|}{ OCB - Line, Bus, \& Transformer (M403) } & \multicolumn{3}{|c|}{ Population: 421} \\
\hline \multicolumn{5}{|l|}{ Preventive Maintenance } \\
\hline Complete Service (ME4P) & 50 & 53 & 8 & 6 \\
\hline Mechanism Service (ME8P) & 305 & 11 & 1 & 1 \\
\hline \multicolumn{5}{|l|}{ Corrective Maintenance } \\
\hline Diagnose/Repair (MA6C) & 4 & 35 & 105 & \\
\hline
\end{tabular}


Table 3.1 FY89 breaker maintenance practices (continued)

\begin{tabular}{|c|c|c|c|c|}
\hline & $\begin{array}{l}\text { Maintenance } \\
\text { Froquency }\end{array}$ & $\begin{array}{l}\text { Average } \\
\text { Man-Hrs }\end{array}$ & $\begin{array}{c}\text { Actual } \\
\text { Maint. } \\
\text { Rate (Yrs) }\end{array}$ & $\begin{array}{c}\text { PLG } \\
\text { Maint. } \\
\text { Rate (Yrs) }\end{array}$ \\
\hline \multicolumn{5}{|l|}{$115 k \mathrm{~V}$ (continued) } \\
\hline \multicolumn{2}{|l|}{ OCB - Capacitor (M404) } & \multicolumn{3}{|c|}{ Population: 17} \\
\hline \multicolumn{5}{|l|}{ Preventive } \\
\hline Complete Service (ME4P) & 6 & * & 3 & 2 \\
\hline Mechanism Service (ME8P) & 6 & * & 3 & 1 \\
\hline \multicolumn{5}{|l|}{ Corrective Maintenance } \\
\hline Diagnose/Repair (MA6C) & 0 & & & \\
\hline \multicolumn{2}{|c|}{ Grs \& Air Blast - Line, Bus, \& Transformer (M423) } & \multicolumn{3}{|c|}{ Population: 3} \\
\hline \multicolumn{5}{|l|}{ Preventive Maintenance } \\
\hline Complete Service (ME4P) & 1 & $*$ & 3 & 6 \\
\hline Mechanism Service (ME8P) & 2 & * & 2 & 1 \\
\hline \multicolumn{5}{|l|}{ Corrective Maintenance } \\
\hline Diagnose/Repair (MA6C) & 0 & & & \\
\hline \multicolumn{2}{|l|}{ Gas \& Air Blast - Capacitor (M424) } & \multicolumn{3}{|c|}{ Population: 6} \\
\hline \multicolumn{5}{|l|}{ Preventive Maintenance } \\
\hline Complete Service (ME4P) & 1 & * & 6 & 2 \\
\hline Mechanism Service (ME8P) & 2 & * & 3 & 1 \\
\hline \multicolumn{5}{|l|}{ Corrective Maintenance } \\
\hline Diagnose/Repair (MA6C) & 0 & & & \\
\hline \multicolumn{2}{|l|}{ Puffer (M432) } & \multicolumn{3}{|c|}{ Population: 39} \\
\hline \multicolumn{5}{|l|}{ Preventive Maintenance } \\
\hline Complete Service (ME4P) & 0 & & & 12 \\
\hline Dingnostic Service (MESP) & 0 & & & 6 \\
\hline Mechanism Service (ME8P) & 13 & 12 & 3 & 1 \\
\hline \multicolumn{5}{|l|}{ Corrective Maintenance } \\
\hline Diagnose/Repair (MA6C) & 0 & & & \\
\hline
\end{tabular}


Table 3.1 FY89 breaker maintenance practices (continued)

\begin{tabular}{|c|c|c|c|c|}
\hline & $\begin{array}{l}\text { Maintenance } \\
\text { Frequency }\end{array}$ & $\begin{array}{l}\text { Average } \\
\text { Man-Hrs }\end{array}$ & $\begin{array}{c}\text { Actual } \\
\text { Maint. } \\
\text { Rate (Yrs) }\end{array}$ & $\begin{array}{c}\text { PLG } \\
\text { Maint. } \\
\text { Rate (Yrs) }\end{array}$ \\
\hline \multicolumn{5}{|l|}{$69 \mathrm{kV}$ and Below } \\
\hline \multicolumn{2}{|c|}{ OCB - Line, Bus, \& Transformer (M405) } & \multicolumn{3}{|c|}{ Population: 494} \\
\hline \multicolumn{5}{|l|}{ Preventive Maintenance } \\
\hline Complete Service (ME4P) & 64 & 20 & 8 & 6 \\
\hline Mechanism Service (ME8P) & 183 & 10 & 3 & 1 \\
\hline \multicolumn{5}{|l|}{ Corrective Maintenance } \\
\hline Diagnose/Repair (MA6C) & 7 & 16 & 70 & \\
\hline \multicolumn{2}{|l|}{ OCB - Capacitor (M406) } & \multicolumn{3}{|c|}{ Population: 34} \\
\hline \multicolumn{5}{|l|}{ Preventive Maintenance } \\
\hline Complete Service (ME4P) & 8 & 21 & 4 & 2 \\
\hline Mechanism Service (ME8P) & 15 & 11 & 2 & 1 \\
\hline \multicolumn{5}{|l|}{ Corrective Maintenance } \\
\hline Diagnose/Repair (MA6C) & 0 & & & \\
\hline \multicolumn{2}{|c|}{ Gas \& Air Blast - Line, Bus, \& Transformer (M425) } & \multicolumn{3}{|c|}{ Population: 22} \\
\hline \multicolumn{5}{|l|}{ Preventive Maintenance } \\
\hline Complete Service (ME4P) & 2 & 28 & 11 & 6 \\
\hline Mechanism Service (ME8P) & 8 & 11 & 3 & 2 \\
\hline \multicolumn{5}{|l|}{ Corrective Maintenance } \\
\hline Diagnose/Repair (MA6C) & 0 & & & \\
\hline \multicolumn{2}{|l|}{ Gas \& Air Blast - Capacitor (M420) } & \multicolumn{3}{|c|}{ Population: 14} \\
\hline \multicolumn{5}{|l|}{ Preventive Maintenance } \\
\hline Complete Service (ME4P) & 1 & * & 14 & 2 \\
\hline Mechanism Service (ME8P) & 6 & 10 & 2 & 1 \\
\hline \multicolumn{5}{|l|}{ Corrective Maintenance } \\
\hline Diaguose/Repair (MA6C) & 0 & & & \\
\hline
\end{tabular}


Table 3.1 FY89 breaker maintenance practices (continued)

\begin{tabular}{|c|c|c|c|c|}
\hline & $\begin{array}{c}\text { Maintenance } \\
\text { Frequency }\end{array}$ & $\begin{array}{c}\text { Average } \\
\text { Man-Hrs }\end{array}$ & $\begin{array}{c}\text { Actual } \\
\text { Maint. } \\
\text { Rate (Yrs) }\end{array}$ & $\begin{array}{c}\text { PLG } \\
\text { Maint. } \\
\text { Rate (Yrs) }\end{array}$ \\
\hline Puffer (M433) & & Population: 10 & \\
\hline Preventive Maintenance & & & & 12 \\
\hline Complete Service (ME4P) & 0 & & & 6 \\
\hline Diagnostic Service (ME5P) & 0 & & 2 & 1 \\
\hline Mechanism Service (ME8P) & 5 & 8 & & \\
\hline Corrective Maintenance & & & & \\
\hline Diagnose/Repair (MA6C) & 0 & & \\
\hline
\end{tabular}

*data not available

\subsubsection{Breaker Maintenance Activity Description}

Breaker maintenance activity codes (i.e., ME4P, ME5P, ME8P, and MA6C) describe the "type" of work being done (e.g., complete service, diagnostic service, mechanism service, or corrective diagnose/repair). However, the scope of work actually performed in the field for a specific activity code varies. For example ME4P (complete service) differs between a gas puffer EHV breaker and a $69 \mathrm{kV}$ oil circuit breaker due to differences in breaker design and service.

Maintenance descriptions for the "scope" of work performed in the field for each series of breaker follow. These descriptions are organized according to PL-6 codes. The PL 6 code, as described earlier, is a unique identifier which conveys breaker voltage, design type, and duty.

Oil Circuit Breakers - (M400 Series). The maintenance associated with this breaker series are ME4P Complete Service Activity, and ME8P Mechanism Services Activity. The PLGs identify the Preventive Maintenance activities for each PL-6. The corrective activity is MA6C Diagnose/Repair; it is used when maintenance is not scheduled by PLG requirements or SMIS. The following table describes the maintenance associated with the M400 series breakers. 
Table 3.2. Maintenance for M400 series breakers

PL-6 Breaker

Identifier Code

M401

$\mathrm{M} 402$

M403

M404

M405

M406

Maintenance

Activity Code

MA6C

ME4P

ME8P
Equipment Description

$230 \mathrm{kV}$ Oil Circuit Breakers, Line, Bus, and Transformers

$230 \mathrm{kV}$ Oil Circuit Breakers, Capacitors

115-kV Oil Circuit Breakers, Line, Bus, and Transformers

115-kV Oil Circuit Breakers, Capacitors

69-kV and Below Oil Circuit Breakers, Line, Bus, and Transformers

69-kV and Below Oil Circuit Breakers, Capacitor Switching

Maintenance Activity Definition

Diagnose/Repair. This code identifies time spent when maintenance work has not been planned or scheduled and is corrective.

Complete Service This code identifies time spent on major disassembly of the breaker and includes tasks described in ME8P Mechanisrn Service. Typical tasks consist of replacernent of oil; oil purification; maintenance of interrupters, contacts, linkages, cranks, bearings, mechanisms, hydraulic accumulators, and compressors; lubrication and oil tests; contact resistance and breaker speed measurements; bushing maintenance; cleanup; and other work normally performed on the entire breaker with the oil removed.

Mechanism Service This code identifies time spent on maintenance of the breaker's stored energy system. Typical tasks consists of maintaining, replacing, repairing, or adjusting of compressors, pumps, valves, operating mechanism, accumulators and strip heaters; lubrication; inspections; and tests such as megger and millivolt.

EHV Power Circuit Breaker (M410 Series) The preventive maintenance associated with this breaker series is ME4P Complete Service Activity, ME5P Diagnostic Service Activity, and ME8P Mechanism Service Activity. The preventive maintenance associated with each PL- 6 are identified in the PLG. The corrective activity, MA6C Diagnose/Repair, is used when maintenance is not scheduled by PLG requirements or SMIS. 
Table 3.3. Maintenance for M410 series breakers

PL-6 Breaker

Identifier Code

M411

M413

Maintenance

Activity Code

MA6C

ME4P

ME5P

ME8P
Equipment Description

EHV Air and Gas Blast Power Circuit Breakers

EHY Gas Puffer Power Circuit Breakers

Diagnose/Repair This code identifies time spent when maintenance work has not been planned or scheduled and is corrective.

Complete Service This code identifies time spent on major disassembly of the breaker and includes tasks described in ME5P Diagnostic Service and ME8P Mechanism Service. Typical tasks consist of replacement of gas; gas purification (if any); maintenance of interrupters, contacts, linkages, cranks, bearings, mechanism, air or hydraulic accumulators, and compressors; lubrication; gas tests; contact resistance and breaker speed measurements; bushing maintenance; cleanup; and other work normally performed on the entire breaker with the gas removed.

Diagnostic Service This code identifies time spent on typical tasks consisting of timing and electrical/mechanical testing of main and resistor contacts and related accessories. (Where Equipment Service Guides recommend timing as a part of the mechanism service, the diagnostic service can be deleted on an exception basis.)

Mechanism Service This code identifies time spent on maintenance of the breaker's stored energy system. 'Typical tasks consist of maintaining, replacing, repairing, or adjusting of compressors, pumps, valves, operating mechanism, accumulators, and strip heaters; lubrication; inspection; and tests such as megger, millivolt and timing (where recommended by the Equipment Service Guides).

Gas or Air Blast Circuit Breaker (M420 Series). These breakers store air or gas at high pressure so that the gas or air flows from high to low pressure during interruption to extinguish an arc. These breakers require a compressor to store the air or gas at high pressure,

The preventive maintenance associated with this series are ME4P Complete Service Activity and ME8P Mechanism Services Activity. 'The Corrective Activity, MA6C Diagnose/Repair, is used when maintenance is not scheduled by PLG requirements or SMIS. 
Table 3.4. Maintenance for 420 series breakers

PL-6 Breaker

Identifier Code

M421

M422

M423

M424

M425

M426

Maintenance

Activity Code

MA6C

ME4P

ME8P
Equipment Description

230-kV Gas and Air Blast Circuit Breakers, Line, Bus, and Transformers

230-kV Gas and Air Blast Circuit Breakers, Capacitor Switching

115-kV Gas and Air Blast Circuit Breakers, Line, Bus, and Transformers

115-kV Gas and Air Blast Circuit Breakers, Capacitor Switching

69-kV \& Below Gas and Air Blast Circuit Breakers, Line, Bus, and Transformer

69-kV \& Below Gas and Air Blast Circuit Breakers, Capacitor Switching

Maintenance Activity Definition

Diagnose/Repair This code identifies time spent when maintenance work has not been planned or scheduled and is corrective.

Complete Service This code identifies time spent on major disassembly of the breaker and includes tasks described in ME8P Mechanism Service. Typical tasks consist of replacement of gas; gas purification (if any); maintenance of interrupters, contacts, linkages, cranks, bearings, mechanism, air or hydraulic accumulators, and compressors; lubrication; gas tests; contact resistance and breaker speed measurements; bushing maintenance; cleanup; and other work normally performed on the entire breaker with the gas removed.

Mechanism Service This code identifies time spent on maintenance of the breaker's stored energy system. Typical tasks consist of maintaining, replacing, repairing, or adjusting of compressors, pumps, valves, operating mechanism, accumulators, and strip heaters; lubrication; inspections; and tests such as megger and millivolt.

Gas Puffer Circuit Breaker (M430 Series). These breaker interrupters use a puffer design which includes a puffer cylinder which compresses the gas during the open operation. The preventive maintenance associated with this breaker series are ME4P Complete Service Activity, ME5P Diagnostic Service Activity, and ME8P Mechanism Services Activity. The Corrective Activity, MA6C Diagnose/Repair, is uced when maintenance is not scheduled by PLG requirements or SMIS. 
Table 3.5. Maintenance for 430 series breakers

PL-6 Breaker

Identifier Code

M431

M432

M433

Maintenance

Activity Code

MA6C

ME4P

ME5P

ME8P

\section{Equipment Description}

230-kV Gas Puffer Circuit Breaker

115-kV Gas Puffer Circuit Breaker

69-kV and Below Gas Puffer Circuit Breaker

Diagnose/Repair This code identifies time spent when maintenance work has not been planned or scheduled and is corrective.

Complete Service This code identifies time spent on major disassembly of breaker and includes tasks described under ME5P Diagnostic Service and ME8P Mechanism Service. Typical tasks consist of replacement and/or filtering of the gas; maintenance of interrupters, contacts, linkages, cranks, bearing, mechanism, air or hydraulic accumulators and compressors; lubrication; contact resistance and breaker speed measurement; bushing maintenance; cleanup; and other work normally performed with the gas removed.

Diagnostic Service This code identifies time spent that does not involve major disassembly of the breaker. It also includes the tasks described under Mechanism Service. Typical tasks consist of timing and/or electrical/mechanical testing of main and resistor contacts and related accessories.

Mechanism Service This code identifies time spent on maintenance of the breaker's stored energy system. Typical tasks consist of maintaining, replacing, repairing, or adjusting of compressors, pumps, valves, operating mechanisms, accumulators, and strip heaters; lubrication; inspections; and tests such as megger and millivolt.

\subsubsection{Transformers}

\subsubsection{Transformer Maintenance Activities}

This section identifies maintenance activities for transformers 500kVA and above. There are two PL-6 codes associated with power transformers, M441 which is a power transformer with load tap changers (LTC), and M442 which is a power transformer without LTC. 
The six types of preventive maintenance for transformers are Complete Service (ME4P), Diagnostic Service (ME5P), Accessory Service (ME6P), LTC Service (ME7P), Mechanism Service (ME8P), and Special Test (MF1C/P). The corrective maintenance activity is Diagnose/Repair (MA6C). The tables which follow are based on 1989 maintenance data. The tables are organized according to PL-6 code. These tables identify the number of transformers, how many transformers were maintained in 1989 (maintenance frequency), the average man-hours spent maintaining the transformers, actual maintenance rate, and PLG maintenance rate. Data in the first three columns are from SMIS. 
Table 3.6. FY89 Transformer maintenance practices

\begin{tabular}{|c|c|c|c|c|c|}
\hline Description & $\begin{array}{l}\text { Activity } \\
\text { Code }\end{array}$ & $\begin{array}{l}\text { Maintenance } \\
\text { Frequency }\end{array}$ & $\begin{array}{l}\text { Average } \\
\text { Man-Hrs }\end{array}$ & $\begin{array}{c}\text { Actual } \\
\text { Maint. } \\
\text { Rate } \\
\text { (Yrs) }\end{array}$ & $\begin{array}{c}\text { PLG } \\
\text { Maint. } \\
\text { Rate } \\
\text { (Yrs) }\end{array}$ \\
\hline \multicolumn{4}{|c|}{ Power Transformers 500kVA and above with LTC (M441) } & \multicolumn{2}{|c|}{ Population: 467} \\
\hline \multicolumn{6}{|l|}{ Preventive Maintenance: } \\
\hline Complete Service & ME4P & 5 & 910 & 93 & 14 \\
\hline Diagnostic Service & ME5P & 21 & 15 & 22 & 7 \\
\hline Accessory Service & ME6P & 183 & 3 & 3 & 1 \\
\hline $\begin{array}{l}\text { Load Tap Changes } \\
\text { Services }\end{array}$ & ME7P & 31 & 18 & 15 & 4 \\
\hline Mechanism Service & ME8P & 60 & 3 & 8 & 1 \\
\hline Special Test & $\mathrm{MF} 1 \mathrm{C} / \mathrm{P}$ & 0 & 0 & & \\
\hline \multicolumn{6}{|l|}{ Corrective Maintenance: } \\
\hline Diagnose/Repair & MA6C & 3 & 19 & 156 & \\
\hline \multicolumn{4}{|c|}{ Power Transformers 500kVA and above without LTC (M442) } & \multicolumn{2}{|c|}{ Population: 63} \\
\hline \multicolumn{6}{|l|}{ Preventive Maintenance: } \\
\hline Complete Service & ME4P & 5 & * & 13 & 14 \\
\hline Diagnostic Service & ME5P & 32 & 9 & 2 & 7 \\
\hline Accessory Service & ME6P & 145 & 4 & 0.4 & 1 \\
\hline Special Test & $\mathrm{MF} 1 \mathrm{C} / \mathrm{P}$ & 0 & 0 & & \\
\hline \multicolumn{6}{|l|}{ Corrective Maintenance: } \\
\hline Diagnose/Repair & MA6C & 2 & $*$ & 32 & \\
\hline
\end{tabular}

*data not available 


\subsubsection{Transformer Maintenance Activity Description}

Transformer maintenance activity codes (i.e., ME4P, ME5P, ME6P, ME7P, ME8P, MFIC/P and M4IC) describe the type of work being done. Table 3.6A contains the codes and their definitions.

Table 3.6A. Maintenance for transformers

\section{Maintenance Activity Code}

ME4P

ME5P

ME6P

ME7P

ME8P

MFIC/P

MA6C

\section{Maintenance Activity Definition}

Complete Service This code identifies time spent on the major disassembly of the transformer and includes tasks described in ME5P Diagnostic Service and ME6P Accessory Service. Typical tasks are repairs on the core, coil, tap changers, oil tank, radiators, and other parts; removal of oil for internal inspection and/or regasketing of a transformer; bushing replacement; oil rehabilitation (e.g., degassing); and necessary processing or dryout of the transformer in order to return the unit to service.

Diagnostic Service This code identifies time spent performing electrical tests on transformers and includes tasks described in ME6P Accessory Service. Tests may include power factor, megger, turn ratio, impedance, resistance, and others.

Accessory Service This code identifies time spent on the maintenance of devices, usually mounted externally on the transformer tank, which are easily accessible from the transformer exterior without removal of oil or main covers. Typical items serviced are gas seal equipment, relief devices, alarms, recording devices, cooling fans, oil pumps, and other miscellaneous external accessories. Tasks such as combustible gas readings, oil tests, and others, are included in this activity.

(LTC) Load Tap Changer Service This code identifies time spent on the major disassembly of the tap changer and includes tasks described under ME8P Mechanism Service. Typical tasks are removing oil; opening of the compartment; and cleaning, replacing, repairing, or adjusting accessiblc components.

Mechanism Service This code identifies time spent on the servicing of tap changer's external accessories. Typical tasks consist of repairing, replacing, cleaning, or adjusting of motors, contactors, gears, and strip heater; 'ubrication; inspection; and tests.

Special Test This code identifies time spent on special tests not covered under other activity codes.

Diagnose/Repair This code identifies time spent when maintenance work was not planned or scheduled and is corrective. 


\subsection{ANALYSIS OF DATA FROM BONNEVILLE'S SUBSTATION MAINTENANCE INFORMATION SYSTEM}

\subsubsection{Maintenance Data and Development of RCM Methodologies}

Results of analysis of data on breakers and transformers from Bonneville's Substation Maintenance Information System (SMIS) are presented in this section. Analysis of equipment maintenance data contributes to the development of RCM methodologies in five ways. First of all, maintenance records can be used to formulate techniques to predict failure probabilities and reliability. Secondly, a profile of current maintenance practices, planned and unplanned, by equipment type can be generated. The third way is that equipment characteristics can be described and correlated with maintenance needs. The fourth way is that analysis results can support economic studies, for example, statistics on equipment age at replacement and replacement cost. Finally, experience in analysis of a maintenance database will be a tremendous aid in the design and development of an RCM system. A successfully implemented RCM program must be well integrated with existing corporate resources and procedures.

It is desirable that the equipment maintenance data be accurate, well maintained, and rich with information. Ideally, maintenance records should include the following details [Cockerill and Lavoie, 1990]:

- failure mode and diagnosis of the component or system,

- other components that failed as a result of the primary failure,

- the effect of the failure on system performance,

- repair and replacement time, including labor and materials,

- annual frequency of failure and cumulative figures over the life of the component, and

- cost of repair. 


\subsubsection{Data Preparation}

Bonneville maintains SMIS as an internal decision support system for the Division of Maintenance and the Area Offices [Bonneville, 1986]. SMIS includes information on the preventive maintenance schedule, on the maintenance work actually performed (work units), and on equipment characteristics (facilities). Facility data includes configuration specifications, equipment operating condition and characteristics, and maintenance-related data. Work unit data consists of work units performed, the Program Level Code (PL6), type of maintenance (activity code), and hours expended.

Data extracts from SMIS were performed in three phases. The first was a small extract used to test data handling prc cedures. In phase two, facility and work unit data for all breakers and transformers were sent to ORNL for analysis. As a result of experience with the test data, the phase two extract was error free and efficiently organized. Finally, the annual report for 1990 was used for economic analysis as reported in Section 5 of this document; it includes the number of facilities by PL6 and number of work units.

Considerable effort was required to become familiar with the characteristics of the SMIS data and to put quality assurance measures in place. Work began with the facility data. For facility data to be included, the energization date had to be known and the equipment had to be energized before the ending date for analysis, which was the end of 1989 , the last full year of data. Als $u$, numeric variables that were zero were set to "missing" (e.g., cost and $\mathrm{kV}$ ) so that analysis would only be done on non-zero values. Finally, facility records for certain types of equipment not included in this study (e.g., reactors) were dropped from the analysis.

To analyze work unit data, facility data had to be present. Also, the date of maintenance must have been between the energization date and the analysis ending date. Any zero value for the number of hours of maintenance was set to missing. Finally, the maintenance records were compressed into what we call maintenance events. Equipment often experienced several maintenance activities on consecutive days. If two maintenance records occurred within seven days, and were of the same type (i.e., planned or unplanned), then the records were combined into a single record to represent a maintenance event. 
A third data set was created which contained one record for each piece of equipment (facility) for each year of operation, (i.e., equipment-years of service). This data set serves as the basis for all analysis which is concerned with annual statistics and ensures that all such analysis is consistent. Table 3.3 summarizes the final data set available for analysis.

Table 3.7. SMIS data received and available for analysis

\begin{tabular}{||c|l|r|r||}
\hline \multirow{4}{*}{$\begin{array}{c}\text { Equipment } \\
\text { Type }\end{array}$} & \multicolumn{1}{|c|}{ Data Set } & \multicolumn{2}{|c|}{ Number of Records } \\
\cline { 2 - 4 } & Received & $\begin{array}{c}\text { Available for } \\
\text { Analysis }\end{array}$ \\
\hline \multirow{5}{*}{$\begin{array}{l}\text { Breakers } \\
\text { Transformers }\end{array}$} & Facility & 2,192 & 2,021 \\
\cline { 2 - 4 } & Work Unit & 15,423 & 11,975 \\
\cline { 2 - 4 } & Equipment-years & - & 41,328 \\
\cline { 2 - 4 } & Facility & 926 & 645 \\
\cline { 2 - 5 } & Work Unit & 9,023 & 4,904 \\
\cline { 2 - 5 } & Equipment-years & - & 12,567 \\
\hline
\end{tabular}

\subsubsection{Analysis of Unplanned Maintenance}

This section presents an analysis of unplanned maintenance data. Unplanned maintenance activities were analyzed because they pertain to equipment reliability rates. Annual "failure rates" $(\lambda)$, defined as the ratio of the number of unplanned maintenance activities to the population, are investigated. Also, relationships of $\lambda$ to equipment characteristics, such as age and voltage rating, are examined.

Table 3.8 presents an annual summary of a merge of the facility data and maintenance data for breakers. According to the data, installation of new breakers during the 1940's, 1950's, and 1960's averaged about 30 per year (number energized) while practically no breakers were de-energized. By 1970, 
there were 1,102 breakers on-line with an average age of 9 years, increasing to 1,590 on-line in 1980 with an average age of 15 years. Note that the database contains no maintenance records for the early years. During the mid-eighties a number of breakers were de-energized, a trend that continued through 1989. Also, during the mid-eighties the rate of planned maintenance stabilizes at about 0.67 . However, the rate of unplanned maintenance has an unusual spike in 1984, which may be attributed to record-keeping practices. Therefore, we report an average $\lambda$ from 1986 through 1989 of 0.03 , which is comparable to other figures reported in the industry [e.g., (Vorwerk, 1985), (Chu, 1986)]. The reciprocal of $\lambda$ yields a mean time between failure (MTBF) of 33 years. MTBF is an appropriate measure for components that experience renewal (i.e., maintenance) [Goldberg, 1981].

Table 3.8. Annual summary of breaker data

\begin{tabular}{|c|c|c|c|c|c|c|c|c|}
\hline \multirow[t]{2}{*}{ Year } & \multicolumn{3}{|c|}{ Number of Breakers } & \multirow{2}{*}{$\begin{array}{c}\text { Avg } \\
\text { Age } \\
\text { (Yrs) }\end{array}$} & \multicolumn{2}{|c|}{$\begin{array}{l}\text { Maintenance } \\
\text { Frequency }\end{array}$} & \multicolumn{2}{|c|}{$\begin{array}{l}\text { Maintenance } \\
\text { Rate }\end{array}$} \\
\hline & $\begin{array}{c}\text { Energize } \\
\mathrm{d}\end{array}$ & $\begin{array}{c}\text { De- } \\
\text { Energized }\end{array}$ & On-line & & Planned & Un-Planned & Planned & $\begin{array}{c}\text { Un- } \\
\text { Plannes: }\end{array}$ \\
\hline 1940 & & & 10 & 0 & & & & \\
\hline 1950 & & & 114 & 4 & & & & \\
\hline 1960 & & & 500 & 7 & & & & \\
\hline 1970 & & & 1102 & 9 & & & & \\
\hline 1980 & & & 1590 & 15 & & & & \\
\hline 1981 & & & 1641 & 15 & & & & \\
\hline 1982 & 72 & 0 & 1713 & 16 & 914 & 0 & 0.53 & 0.00 \\
\hline 1983 & 32 & 14 & 1745 & 16 & 1171 & 261 & 0.67 & 0.15 \\
\hline 1984 & 35 & 12 & 1766 & 17 & 1168 & 835 & 0.66 & 0.47 \\
\hline 1985 & 44 & 22 & 1789 & 18 & 1210 & 263 & 0.67 & 0.15 \\
\hline 1986 & 46 & 57 & 1822 & 18 & 1217 & 94 & 0.67 & 0.05 \\
\hline 1987 & 30 & 39 & 1795 & 19 & 1211 & 33 & 0.67 & 0.02 \\
\hline 1988 & 45 & 31 & 1801 & 19 & 1098 & 35 & 0.61 & 0.02 \\
\hline 1989 & 63 & 97 & 1833 & 19 & 1247 & 23 & 0.68 & 0.01 \\
\hline
\end{tabular}


Table 3.9 shows a similar history for Bonneville's transformers, including rate of construction, average age, and quality and availability of maintenance data. The $\lambda$ for transformers ar erages 0.03 for the final four years of data.

Table 3.9. Annual summary of transformer data

\begin{tabular}{|c|c|c|c|c|c|c|c|c|}
\hline \multirow[t]{2}{*}{ Year } & \multicolumn{3}{|c|}{ Number of Transformers } & \multirow{2}{*}{$\begin{array}{l}\text { Avg } \\
\text { Age } \\
\text { (Yrs) }\end{array}$} & \multicolumn{2}{|c|}{$\begin{array}{l}\text { Maintenance } \\
\text { Frequency }\end{array}$} & \multicolumn{2}{|c|}{ Maintenance Rate } \\
\hline & Energized & $\begin{array}{c}\text { De- } \\
\text { Energized }\end{array}$ & On-line & & Planned & $\begin{array}{c}\text { Un- } \\
\text { Planned }\end{array}$ & Planned & $\begin{array}{c}\text { Un- } \\
\text { Planned }\end{array}$ \\
\hline 1950 & & & 33 & 4 & & & & \\
\hline 1960 & & & 155 & 6 & & & & \\
\hline 1970 & & & 323 & 9 & & & & \\
\hline 1980 & & & 511 & 14 & & & & \\
\hline 1981 & & & 525 & 15 & & & & \\
\hline 1982 & 10 & 1 & 535 & 15 & 364 & 0 & 0.68 & 0.00 \\
\hline 1983 & 20 & 14 & 554 & 16 & 474 & 136 & 0.86 & 0.25 \\
\hline 1984 & 10 & 7 & 550 & 17 & 494 & 472 & 0.90 & 0.86 \\
\hline 1985 & 10 & 4 & 553 & 17 & 462 & 140 & 0.84 & 0.25 \\
\hline 1986 & 9 & 20 & 558 & 18 & 476 & 39 & 0.85 & 0.07 \\
\hline 1987 & 17 & 12 & 555 & 19 & 420 & 12 & 0.76 & 0.02 \\
\hline 1988 & 4 & 25 & 547 & 20 & 484 & 7 & 0.88 & 0.01 \\
\hline 1989 & 8 & 30 & 530 & 20 & 482 & 5 & 0.91 & 0.01 \\
\hline
\end{tabular}

In general, the de-energization of transformers has been increasing during the 1980's. From 1982 through 1989, 88 transformers were energized while 113 were de-energized. The average age of equipment de-energized between 1986 and 1989 was about 26 years. Assuming these trends continue during the early 1990's, the average age of equipment on-line will increase at a slower rate than before. Figures 3.1 and 3.2 show the distributions of age for breakers and transformers, respectively. 


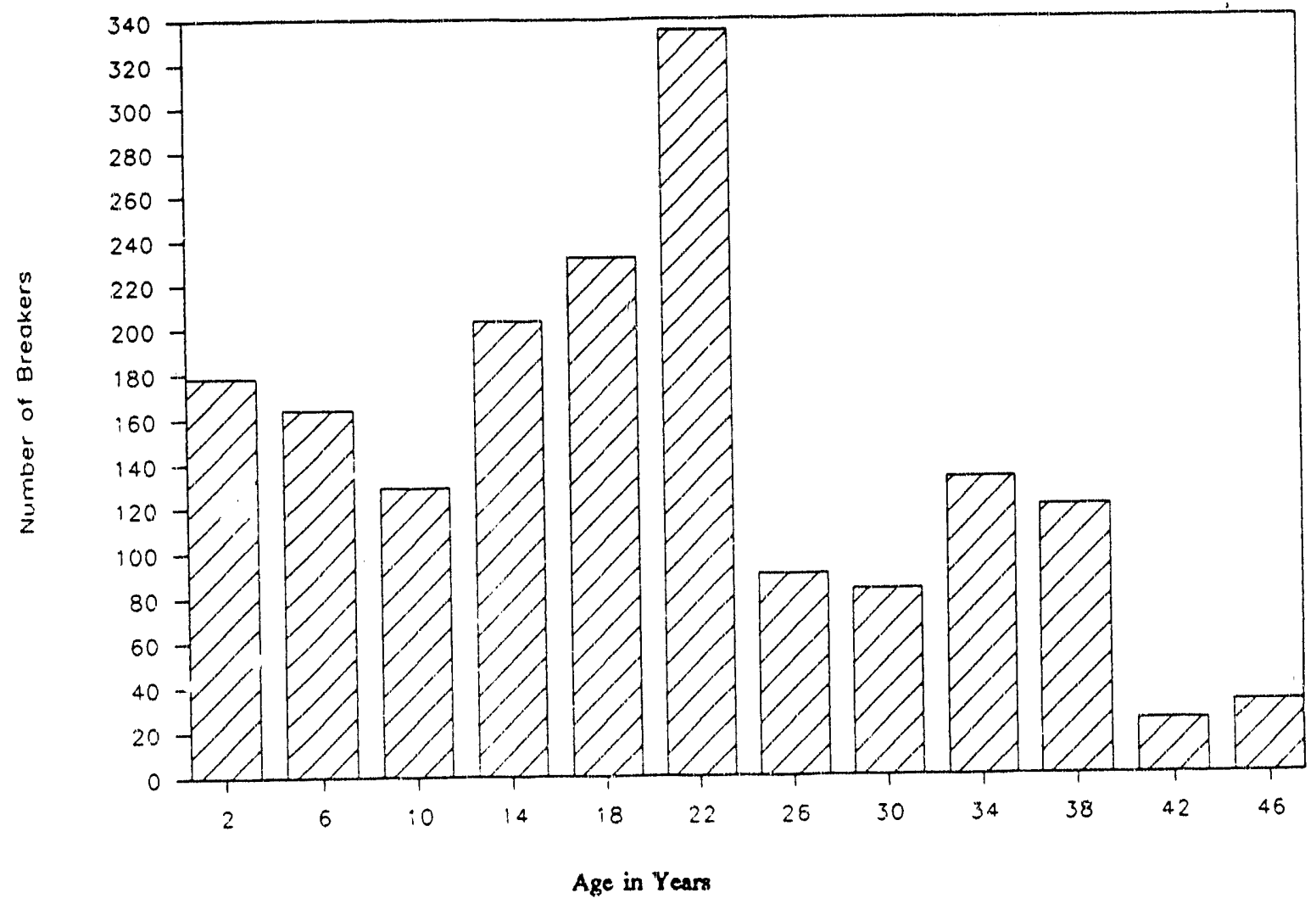

Fig. 3.1. Breaker ages.

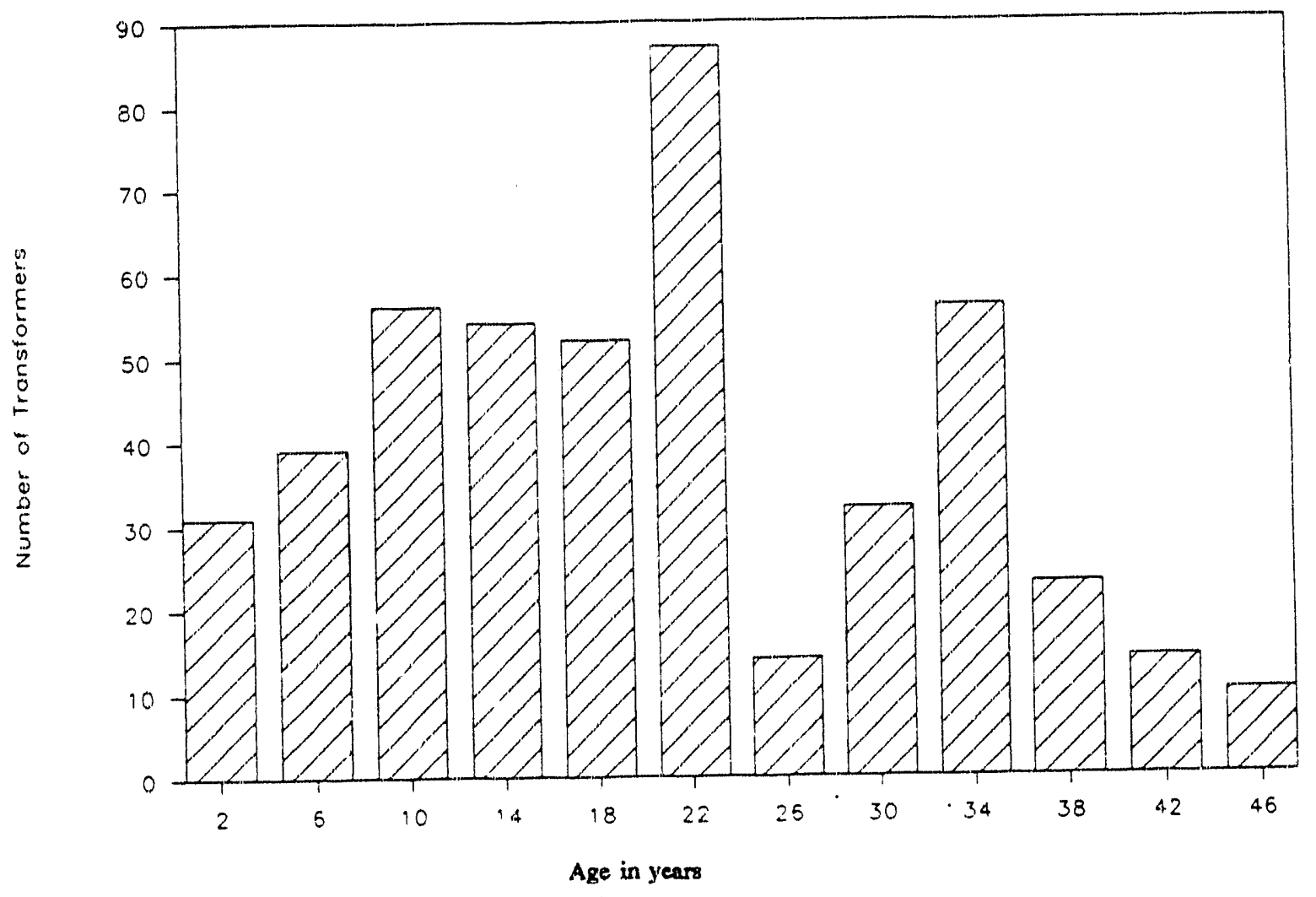

Fig. 3.2. Transformer ages. 
The average age of transformers and breakers in service during 1989 was about 20 years (see Fig.s 3.1 and 3.2). The distributions of age show a peak in construction about 22 years ago and growth during the last 20 years. Twenty-five percent of the breakers, about 430 breakers, are 26 years of age or older. Twenty-five percent of the transformers, aboit 155 breakers, are 31 years of age or older.

Fig. 3.3 is a plot displaying the relationship of $\lambda$ to breaker age considering breakers in service from 1986 through 1989. Each breaker that is on-line in each year contributes a count of one to the populations, and, of course, the age is increasing by one in each year. The numerator of $\lambda$ is the number of, for example, six-year-old breakers that experience unplanned maintenance. From the figure, it is clear that breakers often experience unplanned maintenance soon after energization. However, very old breakers, above 35 years of age, require little unplanned maintenance according to this SMIS data extract. This may be attributable to a vintage of breakers where the level of engineering, materials, and construction exceeds current practices. If smoothing were possible, the result may likely yield an upside down "bathtub curve." Analysis of transformer failure rates demonstrates similar behavior. 
Breakers:

Failure kate, by fịe -.. For 1986 through 1984

Flet of URATE*AGE. Legend: $\hat{m}=1$ tes, $B=2$ ous, etc.

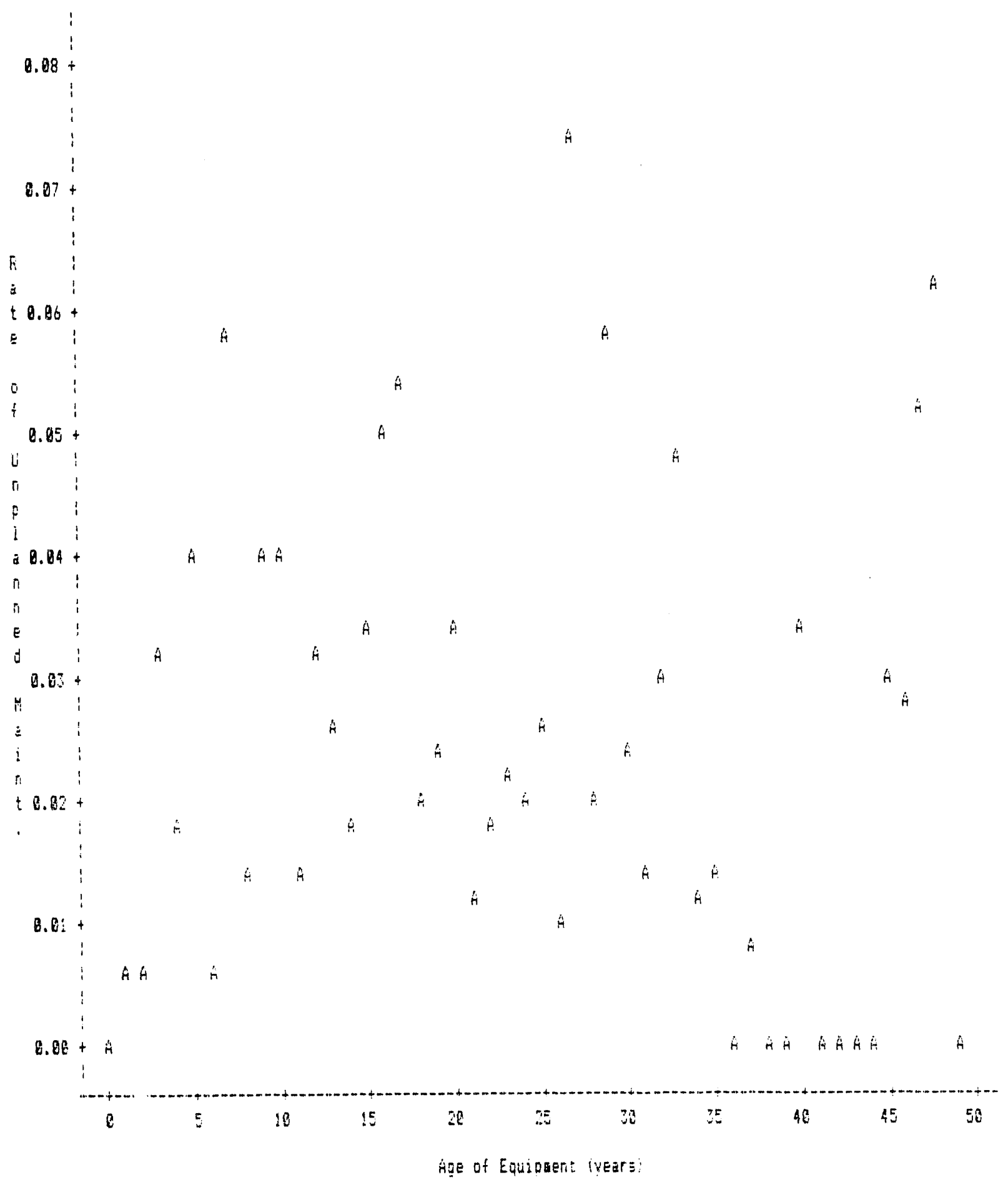

Fig. 3.3. Breaker reliability vs age. 
There are many ways to analyze $\lambda$ including age of the equipment, duty, manufacturer, work load, or a combination of these. For example, Table 3.10 shows $\lambda$ for all breakers on line from 1986 through 1989 by breaker type. The failure rate for air breakers is three times as high as the failure rate for $\mathrm{SF}_{6}$ breakers.

Table 3.10. Breaker reliability for all breakers on-line from 1986 through 1989 , by interrupting media

\begin{tabular}{|c|c|c|c|}
\hline \multicolumn{2}{|c|}{} & \multicolumn{2}{c|}{ Unplanned Maintenance } \\
\hline $\begin{array}{c}\text { Interrupting } \\
\text { Media }\end{array}$ & $\begin{array}{c}\text { Number } \\
\text { On-line }\end{array}$ & Frequency & Rate \\
\hline AIR & 864 & 42 & 0.047 \\
\hline GAS & 290 & 7 & 0.024 \\
\hline OIL & 5451 & 126 & 0.023 \\
\hline SF $_{6}$ & 376 & 6 & 0.016 \\
\hline
\end{tabular}

Table 3.11 shows how $\lambda$ may also vary by voltage rating for transformers. This analysis includes all transformers-years of service from 1986 through 1989. Analysis results show that high voltage ratings are positively correlated with high failure rates. Which means that more expensive higher voltage transformers are more likely to fail. If BPA were to target which transformers should receive additional monitoring for maintenance purposes, higher voltages transformers should be considered first.

Table 3.11. Transformer reliability for all transformers on-line from 1986 through 1989 , by voltage group

\begin{tabular}{|c|c|c|c|}
\hline & & \multicolumn{2}{|c|}{ Unplanned Maintenance } \\
\hline $\begin{array}{c}\text { Voltage } \\
\text { Group }(\mathrm{kV})\end{array}$ & $\begin{array}{c}\text { Number } \\
\text { On-line }\end{array}$ & Frequency & Rate \\
\hline $34-155$ & 676 & 2 & 0.003 \\
\hline 230 & 972 & 32 & 0.033 \\
\hline $345-500$ & 542 & 29 & 0.054 \\
\hline
\end{tabular}




\subsection{EQUIPMENT TO BE INCLUDED IN THE RCM PRO'TOTYPE}

Transformers and breakers represent major investments for BPA. These two pieces of equipment are the most expensive, most complex, and cause the most trouble if they fail while in service. The RCM prototype will monitor all the transformers and breakers at Alvey substation. Table 3.12 identifies the transformers and breakers that will be instrumented

Table 3.12. Alvey transformers and breakers included in the prototype

\begin{tabular}{|c|c|c|}
\hline Transformers & \multicolumn{2}{|c|}{} \\
\hline Voltage $(\mathrm{kV})$ & $1 \phi$ or $3 \phi$ banks & Quantity \\
\hline $1-500 / 230 / 34.5(\mathrm{LTC})^{2}$ & $1 \phi$ units & 1 \\
\hline $1-230 / 115(\mathrm{LTC})$ & $3 \phi$ bank & 3 \\
\hline $1-230 / 115(\mathrm{LTC})$ & $1 \phi$ units & 1 \\
\hline $1-115 / 34.5$ & $3 \phi$ bank & \\
\hline Breakers $(\mathrm{kV})$ & & Quantity \\
\hline Voltage & Type & 3 \\
\hline $500^{2}$ & GAS & 7 \\
\hline $230^{3}$ & OIL & 1 \\
\hline $230^{3}$ & GAS & 11 \\
\hline 115 & OIL & 1 \\
\hline 115 & GAS & 1 \\
\hline 34.5 & OIL & 1 \\
\hline 14 & OIL & \\
\hline & & \\
\hline
\end{tabular}

${ }^{1}$ Transformer instrumentation package ordered July 1991.

${ }^{2} 500 \mathrm{kV}$ breakers should be in service in late 1992.

33-230kV gas breakers will be installed by April 1992. 


\subsection{FAILURE MODE AND EFFECTS ANALYSIS}

A failure mode and effects analysis (FMEA) was compiled by talking with BPA's transformer and breaker experts. The transformer FMEA is contained in Table 3.13 while the breaker FMEA is in Table 3.14. These tables identify the failure mode, typical symptoms that accompany the failure, observables that may be monitored which precede the failure, time the symptoms persist before a failure occurs, the effect of the failure, an indication of whether the failure is catastrophic or not, and some indication of failure rates.

\subsection{REFERENCES}

Bonneville Power Administration, Division of System Maintenance, "Substation Maintenance," October 1989.

Bonneville Power Administration, 1986, "IBM SMIS User's Guide for Substation," Portland, Oregon.

F. Chu, Final Discussion: Failure Statistics, Repair Experience, GIS Reliability \& Availability, in Gas" Insulated Substations: Technology and Practice, edited by S.A. Boggs et. al., Pergamon Press, Elmsford, New York. pp. 559-560, 1986.

A. Cockerill, and M. Lavoie, "RAM Analysis Helps Cut Turbine-generator Systerns Costs," Power Engineering, July. pp 27-29, 1990.

C. Flurscheim, Power Circuit Breaker Theory and Design, IEE Power Engineering Series, 1982.

H. Goldberg, Extending the Limits of Reliability Theory, John Wiley \& Sons, New York, 1981.

H. Vorwerk, Operational Experience With GIS for 145 and $245 \mathrm{kV}$, in Gas-Insulated Substations, Technology and Practice, Pergamon Pres, Elmsford, New York. pp. 377-383, 1986. 
II

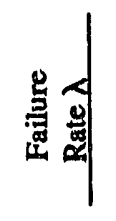

H.
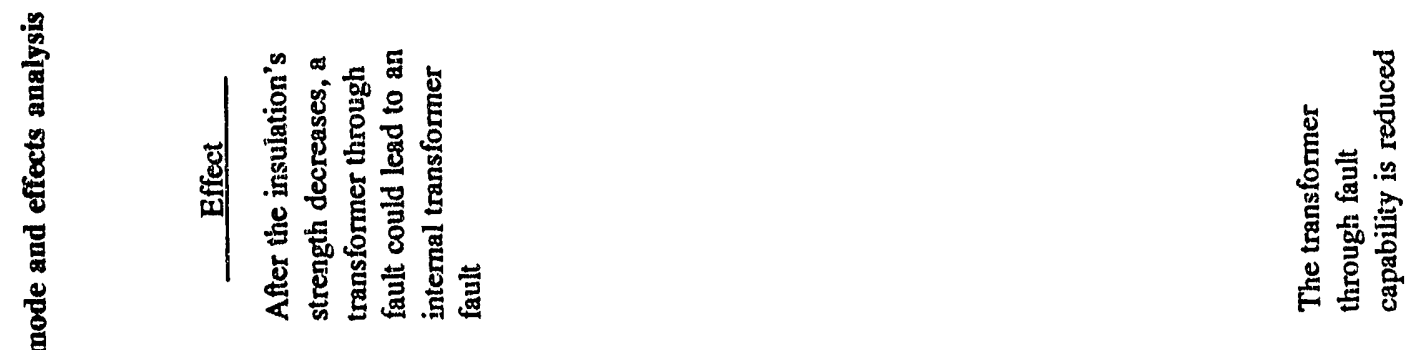

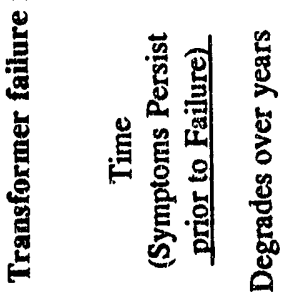

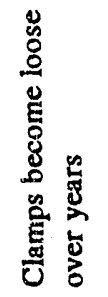

憵
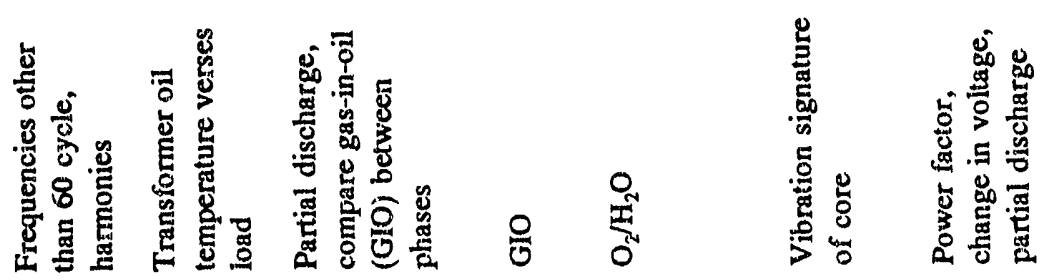

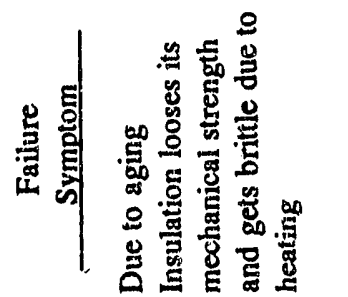
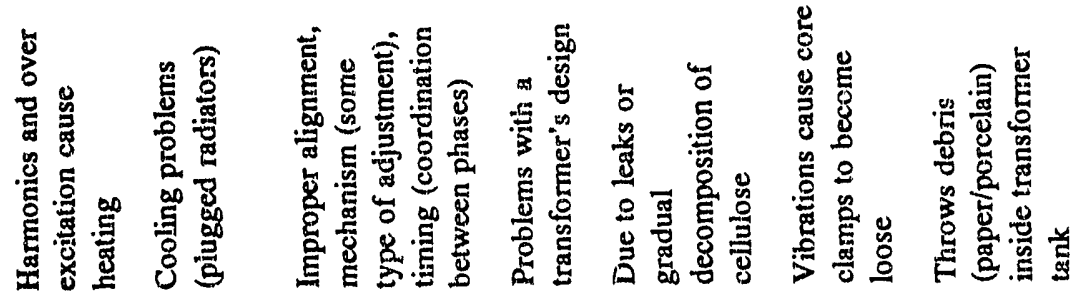

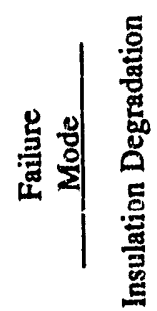

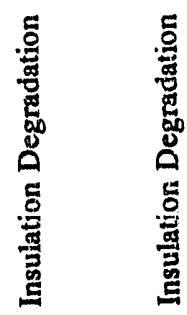

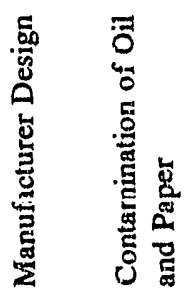

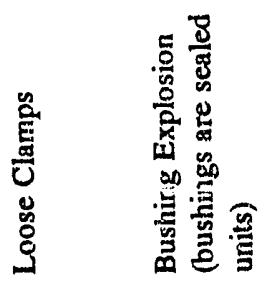


It.
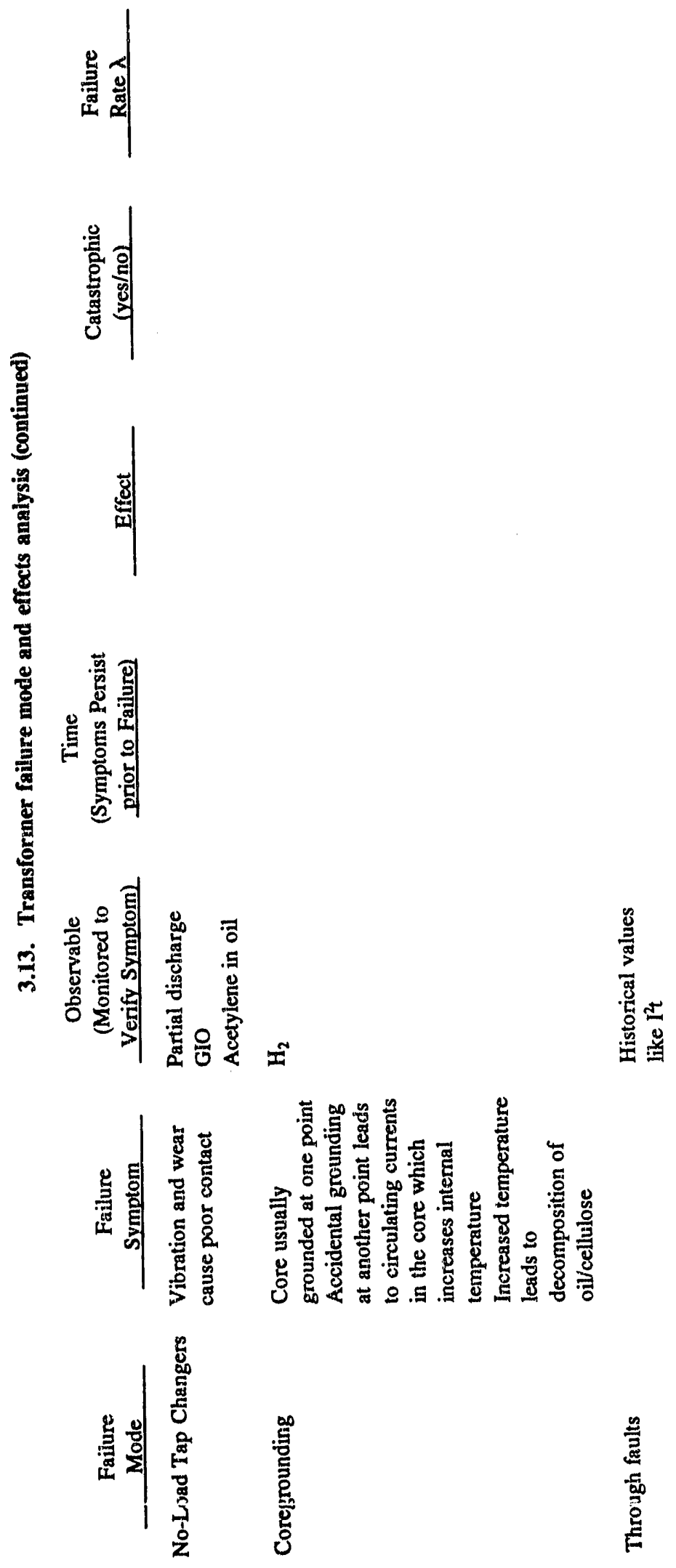
ํㅐ곡

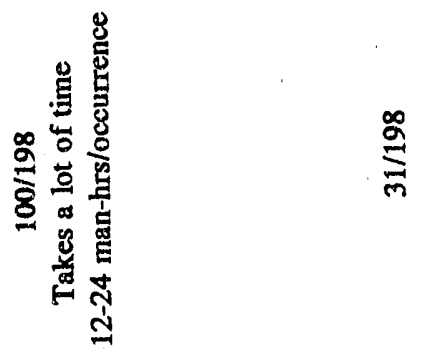

It

I

高

之

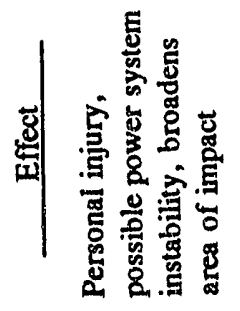

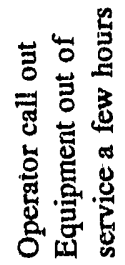

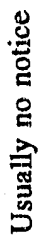

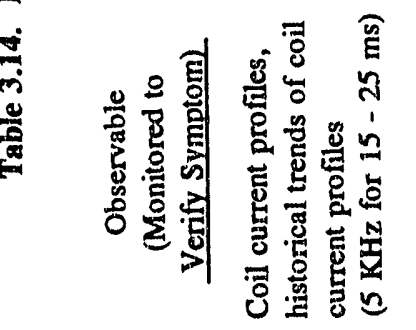

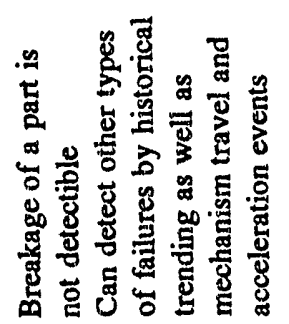

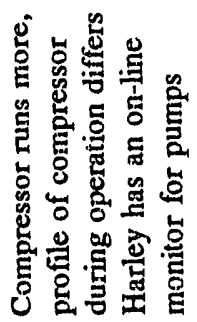

莺

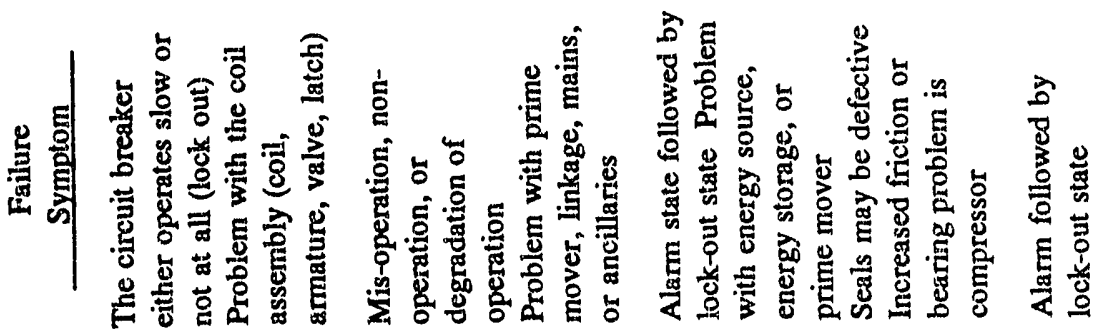

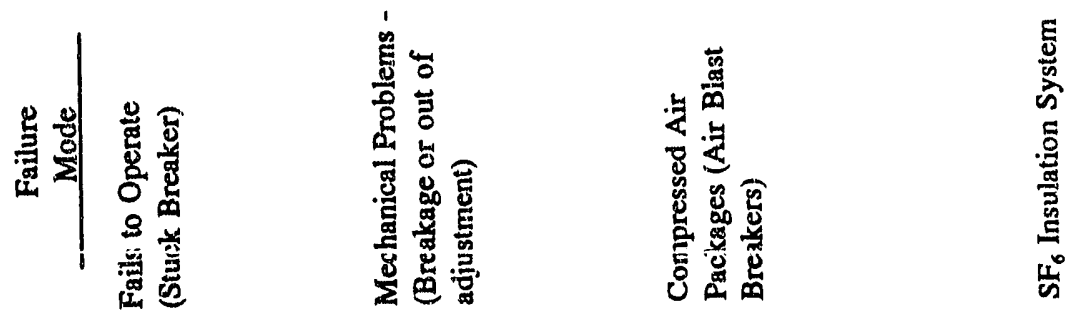




\subsection{EQUIPMENT MONITORING}

This chapter examines transformer and breaker monitoring. The first subsection assesses equipment conditions that can be monitored. The information in Section 4.1 came primarily from the BPA staff. The second section dicusses diagnostic techniques that are currently available. This chapter concludes by identifying research and development opportunities.

\subsection{EQUIPMENT CONDITIONS THAT CAN BE MONITORED}

Tables 4.1, 4.2, and 4.3 identify breaker and transformer conditions that can be monitored. Observable variables are identified and prioritized according to their importance for RCM. These tables also assess the availability of technology to monitor the variables identified. Reasoning is presented that identifies how this information might be used for RCM.

\subsection{DIAGNOSTIC TECHNIQUES AVAILABLE NOW}

Currently available diagnostic methods for oil-insulated transformers and gas-insulated equipment are presented in this section. Gas-insulated equipment may include gas-insulated substations (GIS), bus lines, sivitchgear (either oil or gas), and rotating machines (generators).

\subsubsection{Oil-insulated Transformers}

\subsubsection{Dissolved gas analysis}

Electrical discharges in the form of corona, arcs, $c_{\mathbb{A}}$ hot spots can deteriorate the oil and paper insulation in transformers resulting in the formation of gas. The gases then partially or totally dissolve in the oil and can be detected as an early indicator of problems. Dissolved gas analysis (DGA) has been used extensively for monitoring transformers during the past 20 years. Complete 

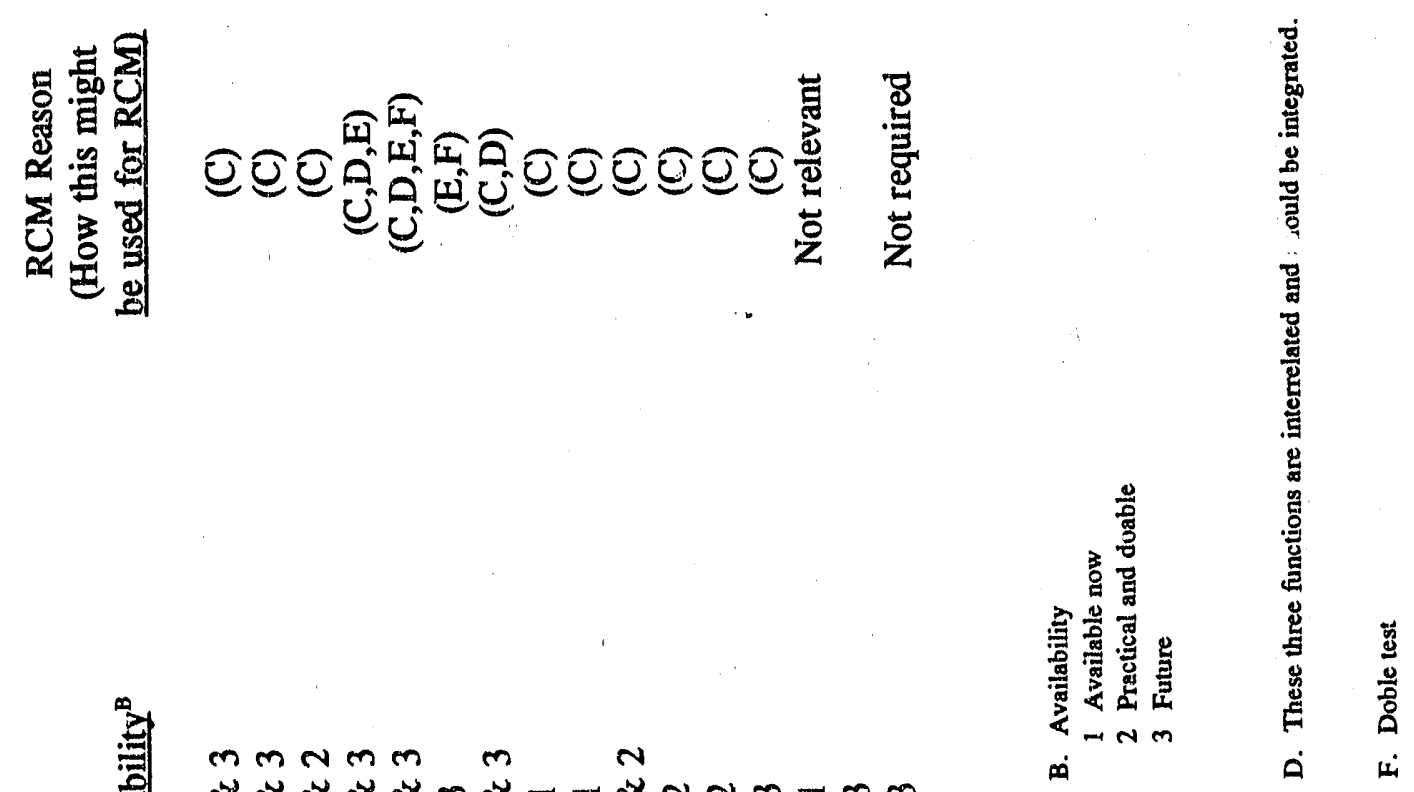



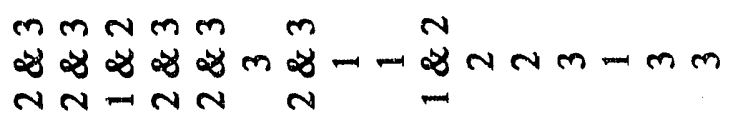

열

罣
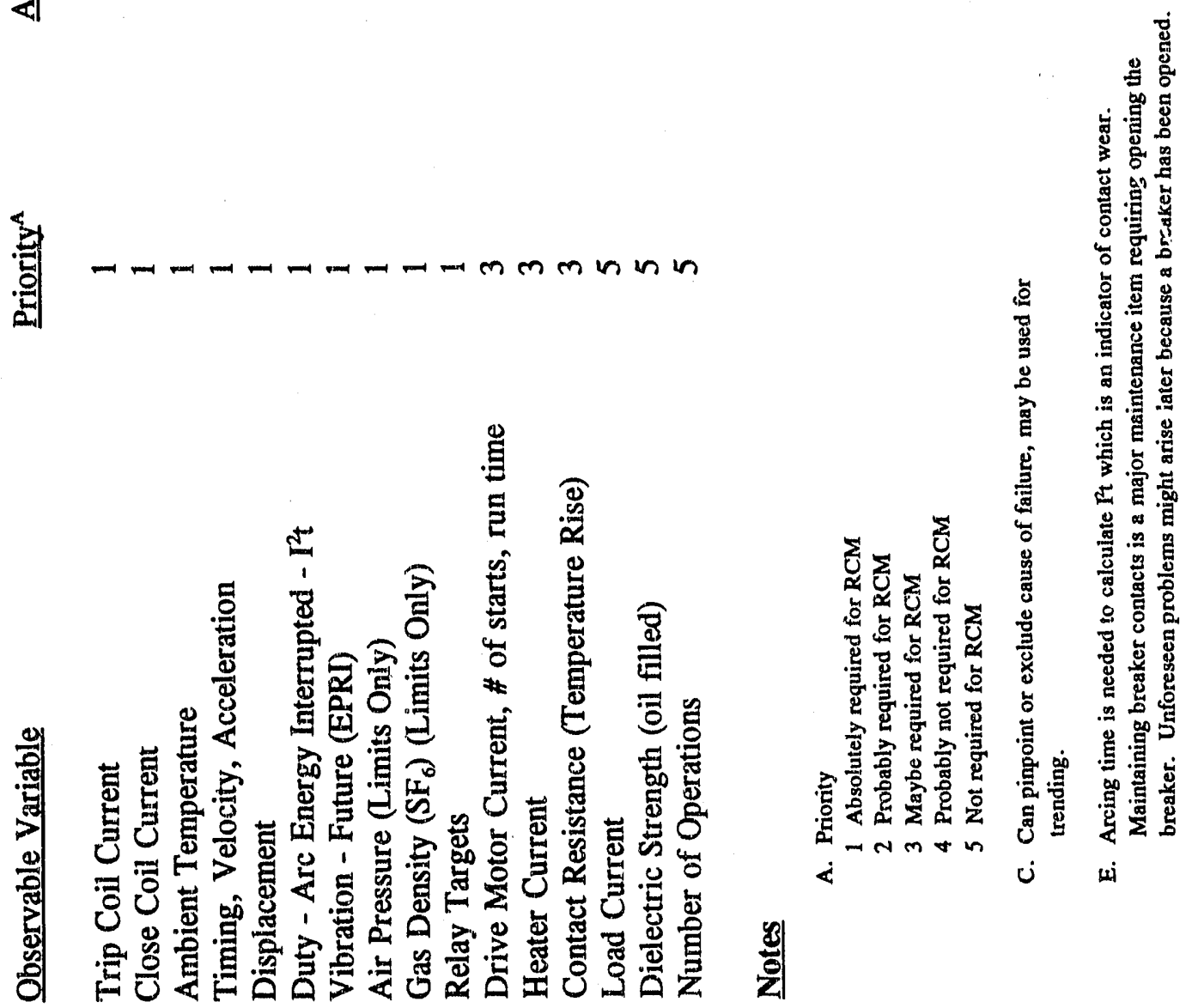

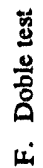

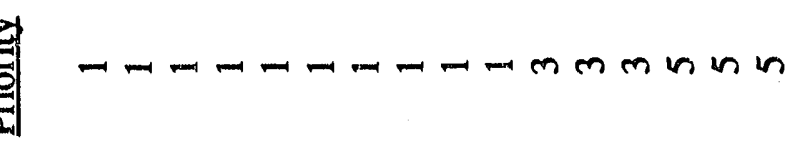

일 


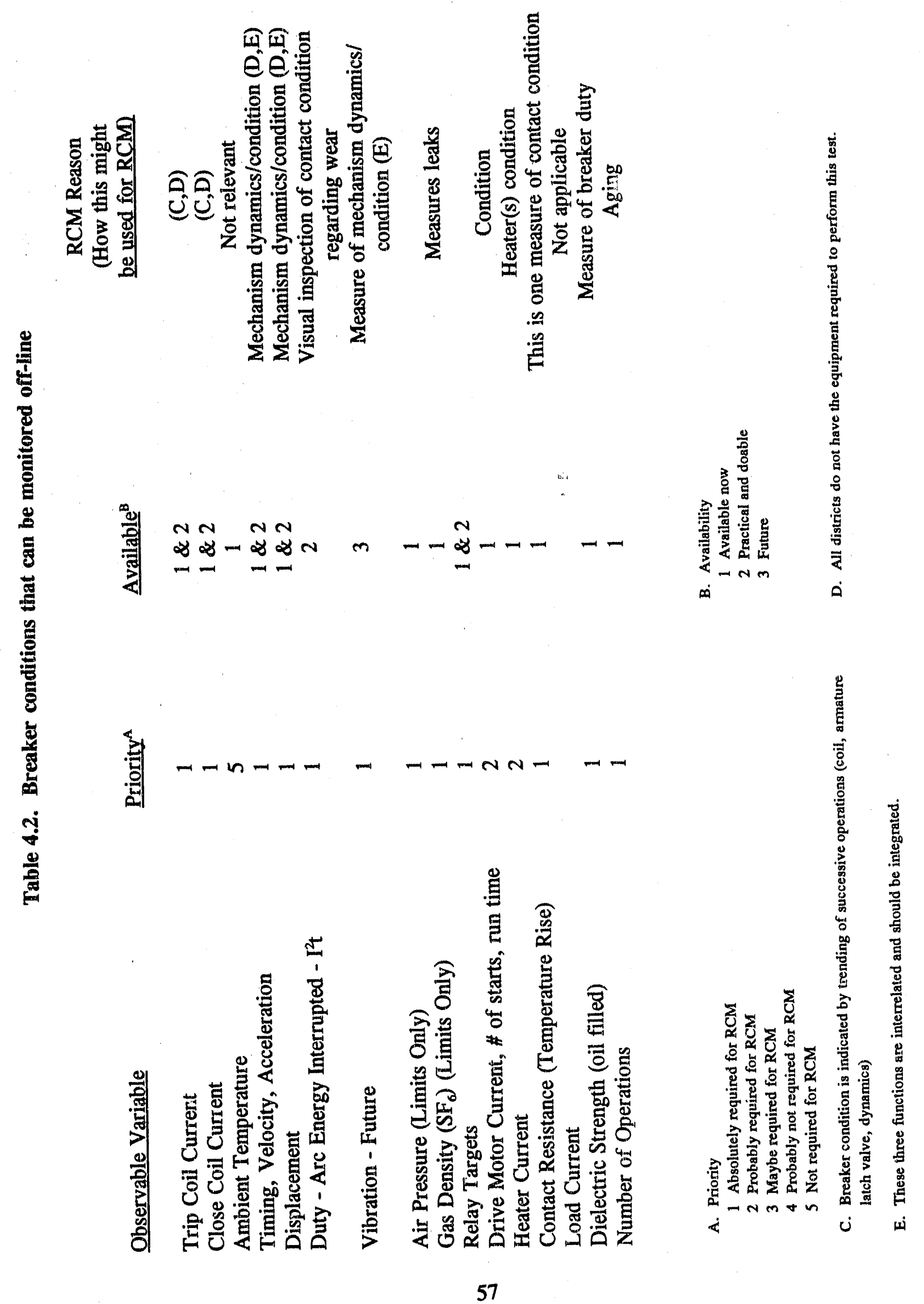




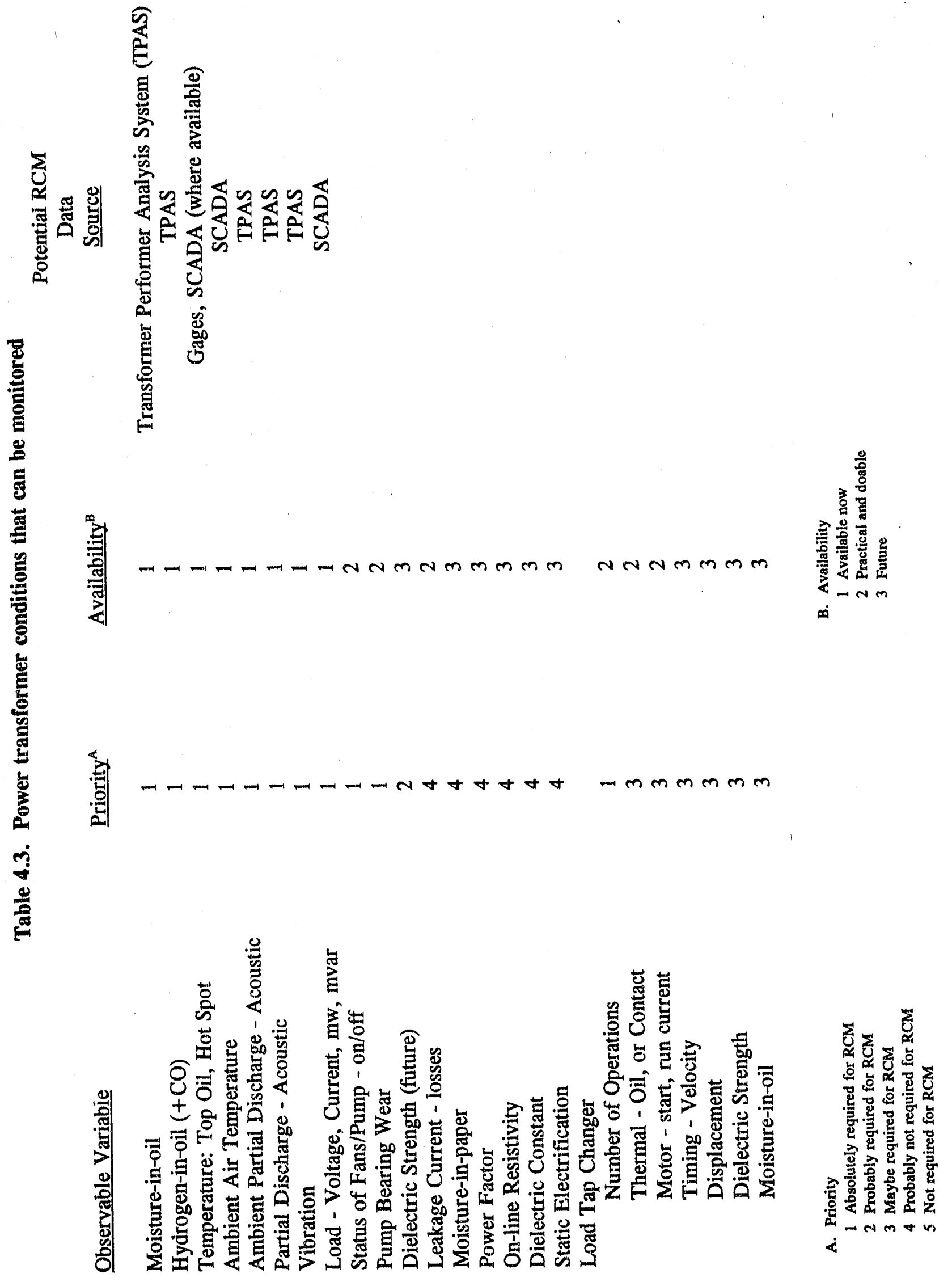


analysis requires laboratory testing by gas chromatograph (GC) and proper sampling procedures have been specified by IEC Publication 567, 1977. Such tests are usually performed at intervals from 3 months to 2 years depending on the utuity. The gases formed are the following:

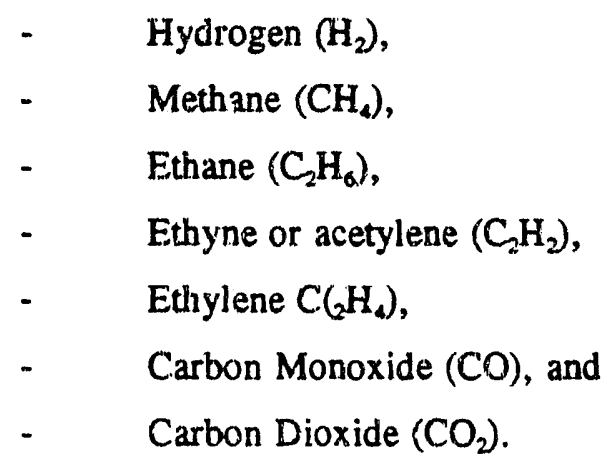

Information about the electrical discharge or hot spot temperature can be deduced from the ratios of gases formed. IEC/IEEE and others publish data and tables that indicate the type of transformer problem based on dissolved gases.

On-line monitoring is available only for determining the hydrogen level in oil. These detectors are not used extensively at present, but their use is expected to increase in the future. A few cornmercial systems are available now. Of the two methods currently used, one employs a portable GC which samples the oil every few hours, and the other uses a fuel cell type detector which samples the oil continuously.

Interpreting DGA is difficult due to the complexity of the transformer's insulation system. Determining unsafe levels is aided by data banks from previous DGAs such as those at Hydro-Quebec. The accuracy and precision of DGA is rather poor; large analysis discrepancies can occur between test labs. Some have called this technique an "art" rather than a science. Substantial interpretive analysis is still required to determine the nature of the change in gas concentrations. Analysis can be further complicated by sensor problems.

\subsubsection{Bubble formation in oil}

Changes in the equilibrium state of dissolved gas in oil can cause bubble formation to occur. Bubbles occur when there is a local increase in the concentration of gases, which is mostly desorbed water, $\mathrm{CO}$, and $\mathrm{CO}_{2}$, as a result of rapid temperature rise in the paper insulated conductor or thermal 
decomposition of the paper. The concern is that the presence of bubbles can reduce the $60 \mathrm{~Hz}$ and impulse strengths by $20-50 \%$. Presently, instrumentation for observing bubble formation does not exist. However, molsure sensors do give an indication that bubbles may be forming.

Hot spot temperature sensors have been developed based on the principle of fluoroptic thermometry. These are fiber optics probes which employ the fluorescence of rare earth phosphors. The intensity ratios of different lines are temperature dependent.

\subsubsection{Partial Discharges (Acoustic emission method)}

Partial discharge (PD), such as corona, is the result of electrical charges moving in a dielectric under the influence of a high electrical field. These electrical charges do not bridge the electrode gap and hence do not result in an immediate fault or short. However, degradation of the insulating medium dnes occur over time which can lead to catastrophic breakdown and permanent loss of insulating capability. The partial discharge is detected by monitoring either the electrical pulses or the mechanical shock waves (acoustic waves) generated by the PD. This section addresses the acoustic wave method.

Shock waves transmitted through the dielectric medium, in this case oil, are usually picked up by a resonant piezo-electric crystal mounted on the tank wall. The wave signature is characterized by packets of burst pulses of $120-160 \mathrm{kHz}$. A monitoring system consists of the sensor, proper acoustic coupling to the tank, and the necessary electronic equipment. Information on the number and amplitude of the PDs can be obtained. Since dielectrics attenuate the acoustic signal, detecting the location of the fault may require multiple sensors. The external acoustic method is not used for unattended monitoring due to possible noise problems caused by rain. However, J.W. Harley, Inc. has developed a internal piezolectirc acoustic sensor mounted on a fiberglass rod which is inserted into the oil. A ambient noise sensor is used to help discriminate hetween external noise caused by rain, sleet, etc. and internal noise thus making PD detertion possible. For acoustic emissions monitored in the laboratory, an acceptable level is usually about $2200 \mathrm{pC}$ (picocoulombs). $\mathrm{PD}$ and gas-in-oil methods make it possible to differentiate between thermal and electrical faults.

Stone describes an on-line monitoring technique which has been used at Ontario Hydro for instrument transformers. This method involves measuring current pulses which were resistant to false 
alarms. However, this device was not analyzed. Stone also describes an on-line power factor monitor for substation instrument transformers developed by TVA.

\subsubsection{Temperature (T)}

The chemical degradation of the oil and paper insulation accelerates as temperatures increase. Unexpected high temperatures are caused by a number of factors including core and load losses, hot spots due to insulation failure, and loss of cooling. The temperature at the top of the oil is usually monitored. Internal hot spot temperatures are estimated by adding $15^{\circ} \mathrm{C}$ to the top oil temperature. Sophisticated models that predict temperature at internal transformer points have been investigated by EPRI. Actual internal temperature measurements are not done since they would disturb the insulation system and could cause PD or reduce dielectric strength.

\subsubsection{Moisture}

Moisture is stored in the cellulose (paper) insulation. Deterioration of the paper and oil increase moisture levels, thus decreasing dielectric strength. Recommended levels are below $20 \mathrm{ppm}$, a level for which available test methods are unsatisfactory. J. W. Harley Inc. is using an on-line moisture monitor in their monitoring system which is being tested at several utilities including BPA.

\subsubsection{Oxygen}

Degradation of the oil by oxidation results in formation of a number of harrnful by-products, such as peroxides, which lead to production of sludge. Catalysts and accelerators, mainly moisture and copper, further increase oxidation. Oxidation inhibitor and peroxide tests are made to check the depletion of inhibitors and oxidizing impurities in the oil. These tests do not easily lend themselves to real-time systems.

\subsubsection{Vibration}

The periodic changes in magnetic flux in the transformer core lamination produce characteristic vibrations which can be monitored. Structural changes caused by aging result in different vibration patterns and give an indication of performance. In the MIT experiment an accelerometer mounted on the core and a time signal from a current transformer generated data which feed a software adaptive model. The sensitivity of this method is not known. Mounting vibration sensors inside the transformer, such as un ianininatiünis, mist to doñ so as act to disturb the trancformer. 


\subsubsection{Dielectric Strength of the Oil}

Many factors act to deteriorate the dielectric strength of the oil mostly through the production of contaminants in the form of solids, liquids, and gases. On-line testing brings complications because these tests produce contaminants which must not be put back into the main tank.

\subsubsection{Other oil related tests}

The neutralizution nurnber is a measure of the acidity of the oil and serves as an indicator of oil degradation. Also, interfacial tension measurements test oil/water interfaces. These tests indicate polar and oxidation by-product contaminants. Color indicators, specific gravity, visual inspection, power factor measurements, and sediment analysis each produce additional information on oil quality. Qualitative infrared absorption is useful for observing changes in oil composition; however, this analysis is too complex to be quantified. Refractive index and optical dispersion techniques give additional qualitative information on contaminants. Resistivity measurements also provide knowledge regarding conductive particles or impurities. These tests are too qualitative for use with expert systems.

\subsubsection{Commercial transformer monitoring system}

J. W. Harley, Inc. has developed a transformer performance analysis system (TPAS) which incorporates their internal acoustic detector, moisture sensor, hydron $H$, DGA, and several oil temperature sensors together with adaptive modeling software. This system is commercially available. Its development was funded in part by BPA.

\subsubsection{Gas-insulated Equipment}

\subsubsection{Gaseous Decomposition products of $\mathbf{S F}_{6}$ - Chemical Methods}

Corona or other partial discharges and arcs in gas-insulated equipment cause a fraction of the insulating gas to decompose and form both short-and long-lived by-products. The amount of by-products depend on the total energy of the fault. Impurities, such as water, are known to affect the ion and neutral chemistry of the discharge. The by-products can be either solid, such as the metal fluoride $\mathrm{AlF}_{3}$, or gaseous, such as $\mathrm{SOF}_{2}, \mathrm{SO}_{2} \mathrm{~F}_{2}$, or HF. Solid by-products are not suitable for monitoring since the chamber has to be opened to obtain samples. However, the presence of the gaseous compounds can be monitored. Indicator tubes are used to detect the major stable gaseous by-products by observing color change in a reagent. This technique is inexpensive and quite sensitive down to the ppm level for sulfur 
compounds and $30 \mathrm{ppb}$ for $\mathrm{HF}$. However, to obtain relative concentrations gas samples are taken periodically and sent to a laboratory for detailed analysis using gas chromatography/mass spectrometry analysis. Complications arise for switchgear because arcing occurs at the contacts under normal switching operation. On-line monitoring is not performed at present, but there is active research in a number of labs on the basic physics of $\mathrm{SF}_{6}$ decomposition, the fragments formed, and toxicities of the by-products. ORNL is a major participant in this area.

\subsubsection{Partial Discharge by acoustical methods}

The method of detecting PD for a gas insulated substation (GIS) is similar to that for oil. The PD source generates an acoustic signal in the $40-200 \mathrm{kHz}$ range (ultrasonic) which is picked up by a resonant piezoelectric sensor mounted on the exterior of the GIS compartment. This technique picks up the sound wave generated by free particles hitting the enclosure and by pressure pulses due to corona and capacitively coupled floating shields in $\mathrm{SF}_{6}$. The fault location is determined by signal attenuation. The acoustic emission sensors are relatively insensitive to PDs in voids of solid spacers due to absorption by the material. Ambient noise does not seem to present a monitoring problem. Field testing has been done since 1983 in which faults have been detected to within $25 \mathrm{~cm}$. Standardized criteria from test results are being developed for expert system application. However, no exact guidelines for risk are available yet.

\subsubsection{Partial Discharge in solid spacers - Voids}

Discharges occur in voids in solid spacers in GIS, giving rise to measurable electrical PD pulses. Ontario Hydro has developed a system using x-rays (XIPD) for detecting voids in solid epoxy spacers for GIS. X-rays provide the initiating electrons necessary to start the PD under normal operating conditions. An aging study is currently under way to test the effectiveness of this method.

\subsubsection{PD detection by the UHF method}

This method was developed by Hampton at the University of Strathclyde within the last several years. Capacitive couplers excited by PDs detect resonances in the bus chambers. Signals for PD pulses are in the $800.1200 \mathrm{MHz}$ range (with a fast rise time). These signals are fed to a wide band (1500 $\mathrm{MHz}$ ) spectrurn analyzer for comparison to a baseline frequency spectrum. Time of flight (signal propagation) measurements between couplers locate the PD source to the nearest coupler. Using conventional signal timing between couplers, one can locate the problem accurately (within $10 \mathrm{~cm}$ in one 
case). This method appears to be well suited for expert system development and is being investigated for the National Grid. Also, characterization of the different types of pulses is being investigated. There is considerable interest in this method for detecting PD since it successfully locates PDs in in-service equipment.

\subsection{RESEARCH AND DEVELOPMENT OPPORTUNITIES}

\subsubsection{Diagnostic Techniques Requiring Development}

The development and implementation of new or improved sensors for on-line diagnostic monitoring requires a multidisciplinary approach ranging from fundamental research to application. In some areas the technology exists already, so that design and engineering testing of devices can proceed immediately. Longer term research should first be conducted in laboratories, and then prototypes should be developed and tested using actual equipment. Characterization studies under real world conditions are necessary to aid development. Such tests are currently underway on oil transformers at AEP and BPA using equipment from J. W. Harley Inc. This section covers diagnostic techniques where the research is substantially complete and development is required. In other instances diagnostic techniques need to be transferred from another area, such as aerospace, and applied to power system equipment monitoring.

The major focus in selecting sensors for the commercial Westinghouse Transformer Monitoring System as well as the MIT Transformer System (now being commercialized by J. W. Harley Inc.) has been the detection of incipient failures. Measured parameters include the following:

\footnotetext{
- temperature,

- partial discharges,

- dissolved gas (Syprotec H-201),

- vibration, and

- $\quad$ operating parameters.
}

One problem in making these kinds of measurements in transformers has been obtaining access to regions of interest. Many practical limitations exist in modifying transformers in the field to include sensors. One offshoot of these limitations has been the development of complex models to predict 
measurement parameters of interest from more "convenient" measurements. For instance, the prediction of moisture content from the top oil temperature or predicting internal winding temperatures. The question of accuracy, however, always surfaces when critical measurement parameters are predicted rather than measured. J. W. Harley Inc. has made some inroads into making critical measurements, like moisture content, using a commercially available sensor that has been calibrated and modified for this application.

A second issue with the available/projected commercialized transformer monitors is that the stateof-the art in applicable sensor technology is not being tapped. For instance, Syprotec's dissolved gas monitor is used as an $\mathrm{H}_{2}$ sensor, even though it is also sensitive to $\mathrm{CO}_{2}$, ethylene, and acetylene. The dissolved gas monitor thus has no gas specificity. Dr. Guzman at Carnegie Research Institute (CRI) has developed a gas sensor system that measures levels of hydrogen, methane, ethylene, acetylene, and carbon dioxide, which could be applicable to RCM. ORNL has developed a programmable integrated circuit gas sensing device (IGAS), which identifies gas component molecules via pattern recognition techniques. Another example is the acoustic sensor used by J. W. Harley Inc. to monitor partial discharge. Installation of this sensor is non-trivial and the sensor is sensitive to external disturbances such as raindrops. Non-invasive demodulation techniques and vibration analysis may be useful in partial discharge characterization. Transformers will often produce vibration-induced sidebands due to structural resonances, subharmonics, and harmonic signals. Defects such as partial discharges will generate large amounts of high-frequency noise (usually white noise). Finally, leakage effects in transformers will exhibit wideband noise with a "flicker" (1/f) component. Several other technologies such as distributed fiber temperature sensors (e.g., Luxtron) may be applicable to hot spot measurements and internal winding temperature measurements. These and other fiber sensors (e.g., refractometry, optical specific dispersion, and $\mathrm{pH}$ ) however, are more practical when introduced in the manufacturing phase of the transformer rather than as a field retrofit.

The basic issue in sensor development for reliability centered maintenance is not simply the incorporation of the latest technology into existing measurements, but rather the selection of a set of measurements which best indicate the health of a transformer as opposed to the incipient failure of a transformer. This sensor concept may incorporate many of the measurements already chosen for incipient failure detection as well as newer sensor technology such as the CRI or ORNL gas sensor. Non-invasive characterization of electrical components via signal analysis techniques should be very helpful in 
establishing the health of transformers in the power industry. In conclusion, transformer sensor development for RCM should take several directions as follows:

- $\quad$ selection of a set of measurements keyed to transformer health rather than or in addition to incipient failure indicators,

- $\quad$ exploitation of non-invasive techniques for diagnostics, and

- incorporation of state-of-the-art sensor technology where appropriate and practical

\subsubsection{Diagnostic Techniques Requiring Research}

Fundamental research is needed in areas where the technology does not exist or the understanding of phenomena is lacking. It is unlikely that reliable sensors that work under a variety of conditions can be built without a thorough understanding of the mechanisms involved. New types of sensors and future generations of improved sensors must be based on fundamental knowledge. Future research programs should include basic foundational studies that will lead to applied research for diagnostic sensors.

In order to make predictions about equipment performance, reliability, maintenance, and end-oflife criteria, the aging characteristics of the different types of insulation systems under a variety of conditions must be known. The fundamental processes behind aging mechanisms must be identified and studied where this knowledge is insufficient.

\subsubsection{Oil-insulated Transformers}

There are four areas applicable to oil-insulated transformers that require research. Discussions of each area follow.

DGA methods Formation of various gases and their ratios resulting from different types of discharges is not understood very well. Basic studies on how gases are formed, the energetics within the discharge, and/or the temperature dependence of chemical recombination as a function of impurities and dielectrics are necessary to improve understanding. Also, gas by-products or early warning signs of oil deterioration should be better understood. 
Development of on-line sensors that determine gas species other than $\mathrm{H}_{2}$ are needed to extend diagnostic techniques to a higher level of precision. Carnegie Mellon is currently working on this. Ultimately, this work may allow determination of ratios of various gases, which in turn will help identify the type of PD or fault.

Bubble formation Previous studies conclude that a method for determining the moisture content of the insulation in the vicinity of the hot spot (related to bubble formation) is needed. The studies also recommend the development of a separate bubble detector.

Charge injection and prebreakdown processes The earliest oil prebreakdown event is charge injection into the dielectric which subsequently may lead to PD discharges, depending on local electric field strength. Knowledge of these processes and factors which enhance charge injection could lead to early indications of incipient problems. Work at the University of Tennessee, sponsored by DOE, has led to detection of the earliest prebreakdown pulses observed to date. The University of Tennessee is developing a model for low density, or bubble, detection. Such work is important in the development of sensors, diagnostics techniques, and in the understanding the aging mechanisms. Additional studies along these lines are necessary to better understand oil-insulated transformers.

Static electrification Electrokinetic effects in forced-oil-cooled power transformers have been responsible for a number of equipment failures in Japan and the U.S. This area has been the subject of several research projects and reports funded by EPRI. Charges generated by streaming electrification can buildup on insulators and distort the electric field causing dielectric degradation. Also, electric hydrodynamic effects in the fluid itself can generate instabilities in high electric field regions, which aiso deteriorates insulation capability. An absolute charge sensor has been developed by MIT that measures the charged fluid using a Faraday cage. This system is being applied to transformers to collect more information about failures of oil insulated transformers caused by oil-flow electrification. Further research is needed to develop at a diagnostic technique for early warning of charging problems.

\subsubsection{Gas-insulated Equipment}

There is only one area applicable to gas-insulated equipment that requires research. A discussion of this area follows. 
Partial Discharges - Chemical Gas Decomposition Techniques It may be possible to deduce information about the origin of partial discharges in GIS by examining the ratios of decomposition products. This analysis is analogous to gas-in-oil ratios for oil-insulated transformers. Researchers in Italy (i.e., CESI and ENEL) have done work on decomposition product ratios. Basic research on byproduct yields from various forms of PDs, such as corona, floating components, and possibly free particles and arcs, is needed for $\mathrm{SF}_{6}$ at different impurity levels. This type of research simulates realistic environments. ORNL has done considerable work to obtain decomposition yields for a number of PD processes in SF $_{6}$. Such basic data are needed for the development of expert system models to diagnose concentrations of decomposition species as a function of temperature, $\mathrm{H}_{2} \mathrm{O}$, pressure, other fragments, and other factors.

The decay or stability of such by-products in contact with surfaces and other impurities must be understood better. If decomposition species do not exist long enough to build up or be analyzed, they will not be useful as a diagnostic or can give false results. Further research is needed in the areas of PDs in spacer voids, charging of spacers, and degradation of floating components and contacts.

\subsection{REFERENCES}

A. Bargigia and A. Pigini, "Research on Diagnostic Methods for GIS," Working Proceedings of the IERE Workshop on Gas-Insulated Substations, Toronto, September 30 - October 4, 1990, 5-44 -5-46.

S. Boggs, "Partial Discharge Overview and Signal Generation," IEEE Electrical Insulation Magazine, Vol. 6, No. 4, pp. 33-39, July/August 1990, and subsequent articles in this series on PD.

J. Braun, "Long Term Dielectric Aging Mechanisms in GIS," Workshop Proceedings of the IERE Workshop on Gas-Insulated Substations, Toronto, September 30 - October 4, 1990, 4-1 - 4-7.

T. Crowley, "Automated Diagnosis of Large Power Transformers Using Adaptive Model-Based Monitoring," LEES Technical Report TR90-003, Thesis at MIT, June 1990.

M. Duval, "Dissolved Gas Analysis: It Can save Your Transformer," IEEE Electrical Insulation Magazine, Vol. 5, No. 6, Nov/Dec 1989, 22-27. 
EPRI Report EL/ER-6880, Project 8000-1, June 1990, Electrokinetic Effects in Power Transformers, Censselaer Polytechnic Institute. See also reports EL-6138 (General Electric) and EL-4501 (MTT). MIT has offered summer courses in static electrification.

EPRI Report EL-5999, "Transformer Overload Characteristics-Bubble Evolution," Westinghouse Electric Corporation, E. E. Woods, R. C. Wendel, and R. D. Dresser, Principal Investigators, August 1988 Interim Report.

EPRI Final Report EL-5384, "Bubble Formation in Transformers," Prepared by General Electric Company, W. A. Fessler, W. J. McNutt, and T. O. Rouse, Principal Investigators, August 1987.

EPRI Report EL-5807-SR, "Proceedings: Transformer Overload and Bubble Formation," G. Addis and S. Lindgren, Editors, Palo Alto, CA, December 8-9, 1987, Published June 1988, pp 7-1-8.

EPRI Report EL-2443, Volume 2, "Basic Transformer Life Characteristics volume 2: Evaluation of a Fluoroptic Thermometer as a Hot Spoi Sensor for Power Transformers," Luxtron Corporation, June 1982.

B. Hampton, "Update on UHF PD Diagnostic Methods," IERE Workshop, Toronto, September 30 October 4, 1990.

IEEE Dielectrics Tests Subcommittee, "Trial Use Guide for the Detection of Acoustic Emissions from Partial Discharges in Oi!-Immersed Power Transformers," PC57.127/D2, October, 1989.

IERE Workshop on Gas-Insulated Substations, September 30 - October 4, 1990, Toronto on diagnostics. T. Kitano, "Charasteristics of Portable Diagnostic Devices Practically Used in KEPCO," pp 5-32 - 5-34.

D. James, I. Sauers, G. Harman, G. Griffin, and M. Ryan, "Stability of Gaseous By-Products in Relation to Sampling of SF 6 Equipment," Working Proceedings of the IERE Workshop on Gas-Insulted Substations, Toronto, September 30 - October 4, 1990, 2-11 - 2-13.

D. Johnson, Bonneville Power Administration Memorandurn on Gas-In-Oil, unpublished. 
D. Johnson, R. Langan, J. Triner, and H. Moore, "The Development of an On-line Transformer Performance Analysis System," unpublished.

L. Lundgaard, "Condition control of GIS By Acoustical Methods," UHF Partial Discharge Detection in GIS, IERE Workshop, Toronto, September 30 - October 4, 1990, 5-1.

J. McBraun and F. Clur, "Novel Low-Cost SF 6 Arching By-Product Detectors for Field use in Gas. Insulated Switchgear," IEEE Trans on Power Systems, Vol. PWRD-1, No. 2, pp. 81-86, April 1986.

A. Morin II, M. Zahn, J. Melcher, and D. Otten, "An Absolute Charge Sensor for Fluid Electrification Measurements," IEEE Transactions on Electrical Insulation, Vol. 26, No. 2, pp. 181-199, April 1991.

"Oil Gas Monitors Advise of Impending Transformer Failure," Sensors, pp 6., December 1990.

B. Pryor, "UHF' partial Discharge Detection in GIS," IERE Workshop, Toronto, Sept. 30 -Oct. 4, 1990.

I. Sauers and G. Griffin (ORNL) e. g. Proceedings of the Sixth International Symposium on Gaseous Dielectrics, September, Knoxville, Tennessee 1990.

S. Smith, K. Castleberry, and C. Nowlin, "Machine Monitoring via Motor-Current Demodulation Techniques," Current Practices and Trends in Mechanical Failure Prevention, Proceedings of the 44th Meeting of the Mechanical Failures Prevention Group, pp. 87-96, April 1990.

G. Stone, "Partial Discharge - Part VII: Practical Techniques for Resuring PD in Operating Equipment," IEEE Electrical Insulation, Vol. 7, No. 4, pp.9-19, July/August 1991. 


\subsection{BENEFITS OF RELIABILITY CENTERED MAINTENANCE}

Several types of benefits are potentially available from RCM. Broadly, RCM results in economic benefits because it provides improved information about maintenance requirements of equipment. Maintenance activities can be more precisely coordinated with need, therefore reducing maintenance costs and capital costs, while providing more reliable service. In this chapter the types of benefits estimated for RCM are described and the assumptions used in making these estimates are itemized. This analysis focuses on benefits only. A cost-benefit analysis was not performed because RCM costs are too speculative. The estimates presented in Table 5.1 represent the potential benefits if RCM were applied to all substations in the BPA system. Of course, the actual effects of RCM are unknown. The assessment of benefits provides a frame of reference for evaluating the economic justification of applying RCM programs to the BPA system. This chapter ends with a discussion of potential benefits of RCM that have not been included in the scope of the quantitative assessment.

Table 5.1 presents an estimate of over $\$ 8$ million in annual benefits available if RCM were applied to circuit breakers and transformers at all BPA substations. The categories for which benefits have been estimated include lowering preventive maintenance costs by optimizing maintenance as realized through increasing maintenance intervals, reducing corrective maintenance costs to diagnose and repair equipment, reducing capital replacement costs through reducing catastrophic failures, and reducing capital costs by extending the life of older equipment. Transformer and breaker maintenance may be altered because RCM equipment monitoring will provide more information about the equipment than is currently available. Table 5.1 provides the estimated present value of potential RCM benefits over the equipment's life cycle and the equivalent benefits on a levelized annual basis. 
Table 5.1. Estimated economic benefits of RCM for BPA substation transformers and circuit breakers

\begin{tabular}{||l|r|r||}
\hline TRANSFORMERS & PRESENT VALUE & \multicolumn{1}{|c|}{ ANNUALIZED } \\
\hline Increased Maintenance Intervals & $\$ 1,255,000$ & $\$ 82,000$ \\
\hline Reduced Diagnosis/Repair & $\$ 11,519,000$ & $\$ 749,000$ \\
\hline Reduced Catastrophic Failures & $\$ 42,898,000$ & $\$ 2,500,000$ \\
\hline Delaying Scheduled Retirement & $\$ 38,777,000$ & $\$ 2,260,000$ \\
\hline CIRCUIT BREAKERS & & \\
\hline Increased Maintenance Intervals & $\$ 6,088,000$ & $\$ 397,000$ \\
\hline Reduced Diagnose/Repair & $\$ 22,051,000$ & $\$ 1,434,478$ \\
\hline Reduced Catastrophic Failures & $\$ 4,135,000$ & $\$ 269,000$ \\
\hline Delaying Scheduled Retirement & $\$ 9,778,000$ & $\$ 570,000$ \\
\hline \hline TOTAL RCM SAVINGS & $\$ 133,281,000$ & $\$ 8,050,000$ \\
\hline
\end{tabular}

Table 5.1 is based on the following assumptions:

- a 5\% discount rate and 30 year analysis period, except reduced catastrophic failures and delaying schedule retirement which are based on 40 years;

- average maintenance intervals increase by 1 year, except 1 year intervals which increase to 18 months;

- catastrophic failures are reduced by $50 \%$;

- diagnostic and repair costs are reduced by 50\% (costs were extracted from SMIS);

- direct maintenance costs for FY 1990, with overhead added, are based on the proportion of direct maintenance costs to the total of all substation costs reported in SMIS for FY-90 4th quarter cumulative;

- replacement costs for circuit breakers are from Sahag Chilingerion, (BPA Substation Maintenance-MMEB, 1991) and the number of units are from the BPA 10-Year Plan 1990-1999;

- replacement costs and number of units for transformers are from "BPA Operations, Maintenance, and Replacement 10-Year Plan 1990-1999;" and

- factor applied to total replacement costs (.042) is the summation of 2 year differences in Present Value factors at $5 \%$ discount rate for 40 years (i.e., transformer and breaker life is extended by 2 years). 


\subsection{THE ECONOMIC OBJECTIVE OF RCM}

The following analysis assesses potential benefits from reducing preventive maintenance (PM) costs, corrective maintenance (CM) costs, and capital (CAP) costs. The economic objective for maintaining equipment is to minimize the total costs ( $P M+C M+C A P)$ for a given level of system reliability through optimizing PM. The advantage of RCM is to provide information about maintenance requirements that allows the optimum PM to be more precisely identified.

In essence, $\mathrm{CM}$ and CAP costs are a function of PM. RCM provides additional information that more closely identifies the cost tradeoffs between CM, CAP, and PM. This information can be used to reduce the costs of $\mathrm{PM}, \mathrm{CM}$, and $\mathrm{CAP}$ by more precisely identifying the optimum PM requirements. Performing PM precisely when it is needed lowers CM while at the same time avoiding some unnecessary PM. The unnecessary PM is the result of regular maintenance cycles that are based on "experience" or "conservative rules of thumb" but do not have the detailed information that can be generated by RCM. Thus, the additional information generated through RCM monitoring helps to avoid some unnecessary PM (lowering PM costs) while at the same time addressing some of the needed PM (lowering CM costs) that would be missed in a regular cycle maintenance program. Appropriate preventive maintenance also helps reduce CAP by avoiding catastrophic equipment failure by giving better information about equipment condition and making it possible to delay replacement.

The benefits realized through RCM will tend to increase over time. There is an inherent time lag as information is generated through RCM and used to optimize a maintenance program. This information will not only provide a basis for optimizing maintenance but it may also provide a better basis for equipment purchase specifications and vendor selection based on systematic information about operation of existing equipment. Using RCM, the airline industry, xperienced no unit increases in maintenance costs over a 16.year period despite increasing size and complexity of aircraft. Over the same interval, the safety record also improved (EPRI 1989). 


\subsection{DATA}

The maintenance and repair cost data used to estimate RCM benefits are from BPA's System Maintenance Information System (SMIS) "Substation Maintenance Workload and Staff Utilization Report," Quarter 4 of FY 1990 cumulative. The non-direct costs include travel, tools and shops, general and administrative expenses, training programs, pollution abatement, and various other costs. As a result of reducing direct maintenance costs, overhead costs would also be reduced. To account for the reduction in overhead costs, the estimated reductions inis direct labor and material costs reported by type of equipment (see Table 5.2) were increased by the ratio of total non-direct to total direct costs reported in the SMIS cost data. This increased direct cost reductions attributed to RCM by $107 \%$ reflecting overhead for substation maintenance. For example, if preventive maintenance is estimated to be reduced by $\$ 400$ in direct material and $\$ 600$ in direct labor costs or $\$ 1,000$ in direct costs, another $107 \%$ or $\$ 1,070$ is added to account for overhead costs.

\subsection{BENEFITS FROM REDUCING PREVENTIVE MAINTENANCE}

RCM can reduce equipment maintenance costs by providing more precise mainienance scheduling. This can result in lower costs through increasing the average maintenance interval. With increased monitoring, average maintenance can be scheduled on an as-needed basis and/or scheduled maintenance intervals can be increased because RC $\mathrm{A}$ can better detect incipient problems. It is assumed that the average maintenance interval would be increased as preventive maintenance was scheduled on an as. needed basis as indicated by RCM monitoring. In order to estimate cost savings attributed to performing maintenance on an as-needed basis, it is assumed that the programmed maintenance intervals would increase by six months or one year depending on the existing programmed preventive maintenance interval reported in SMIS. All existing maintenance intervals of approximately one year were assumed to be increased by an additional six months and all intervals of two years and longer were assumed to be increased by an additional year. The present value of the reduced maintenance was calculated for a 30 -year period at a 5\% discount rate. This resulted in annual savings of $\$ 82,000$ for transformers and about $\$ 397,000$ for circuit breakers. Most of the reduced costs resulted from increasing the one-year maintenance interval to 18 months. Relatively little savings resulted from increasing maintenance intervals that were 3 years and longer. This reflects the fact that most of the maintenance intervals are two years or less. 


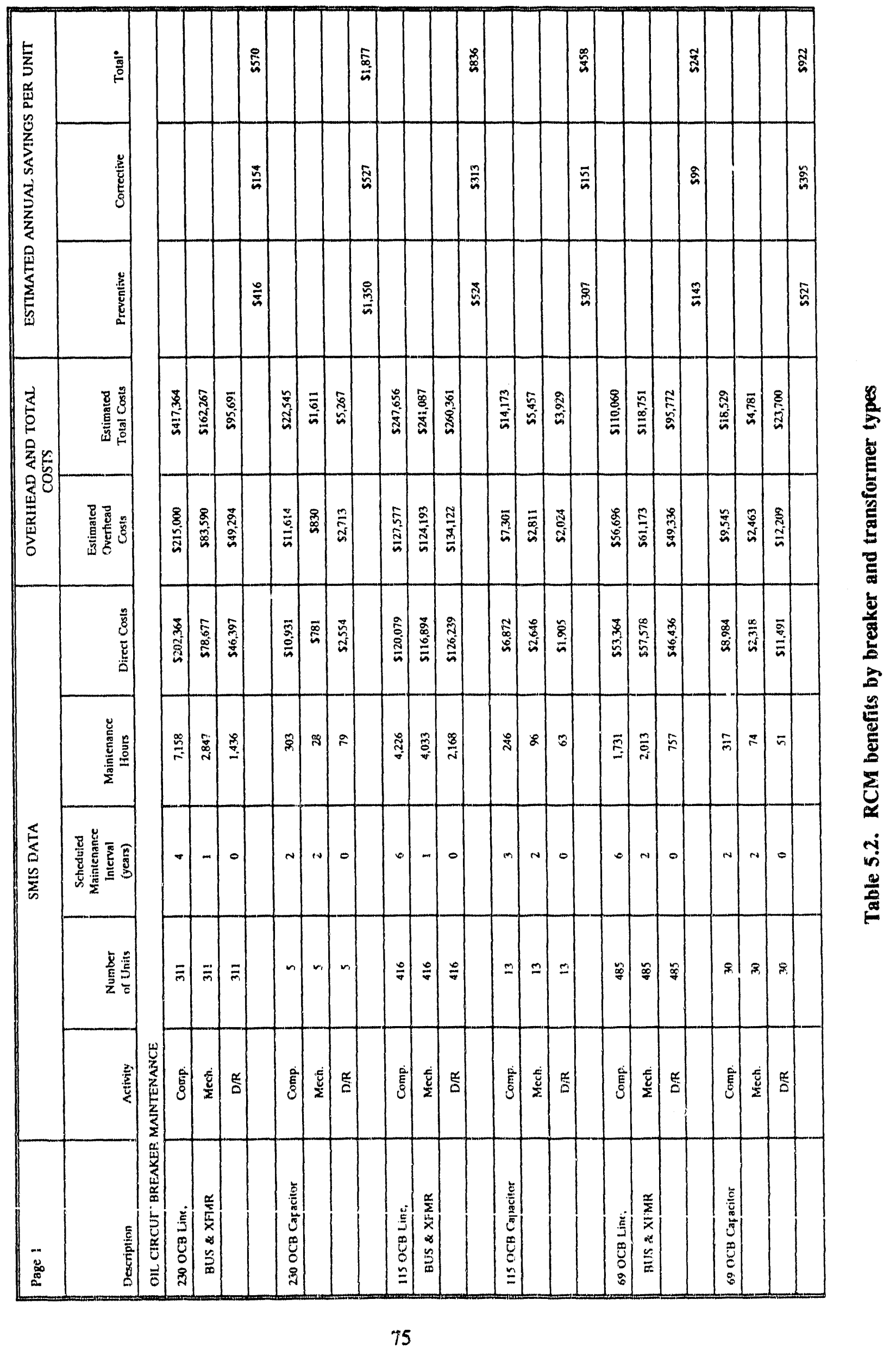




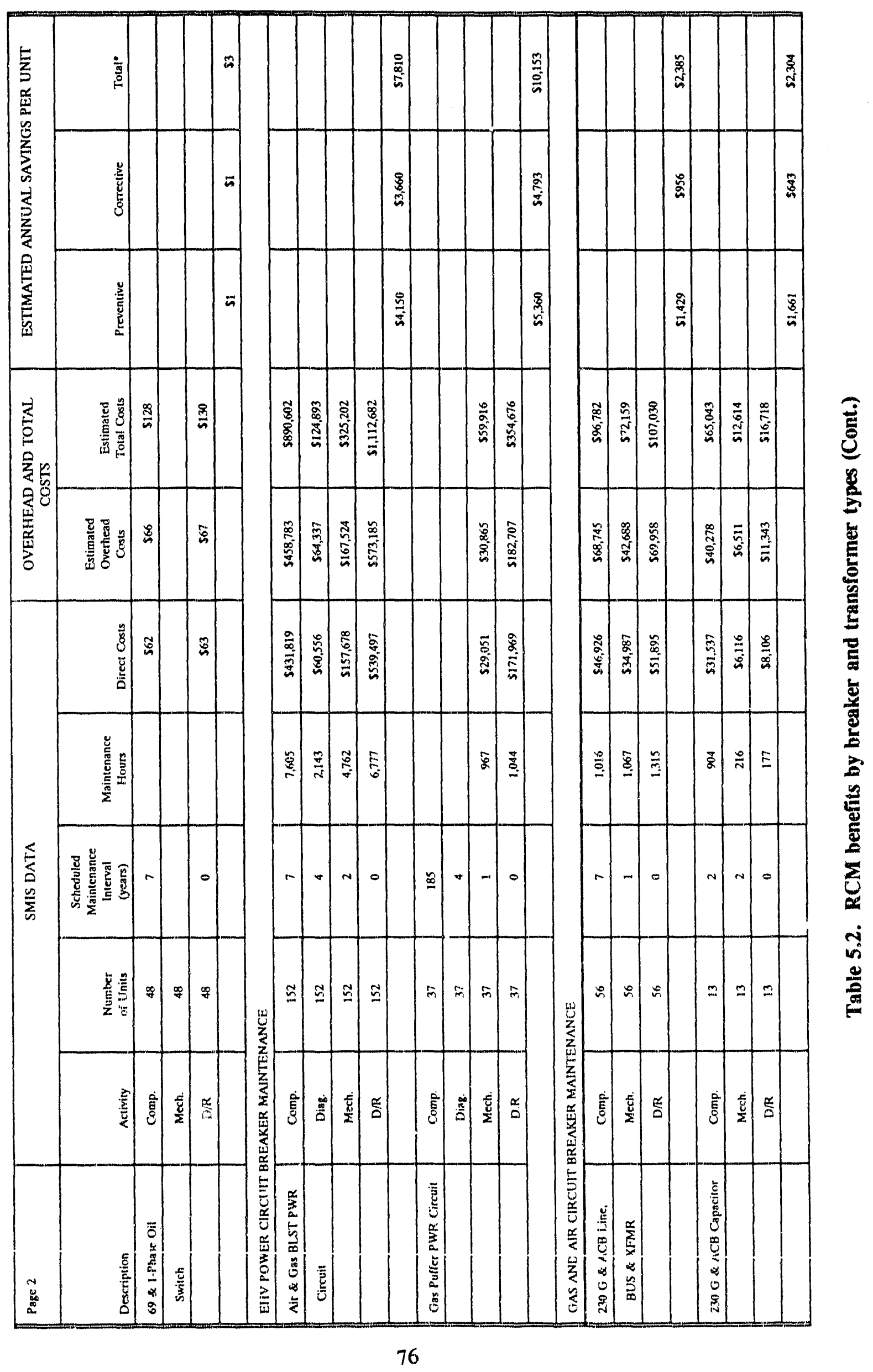




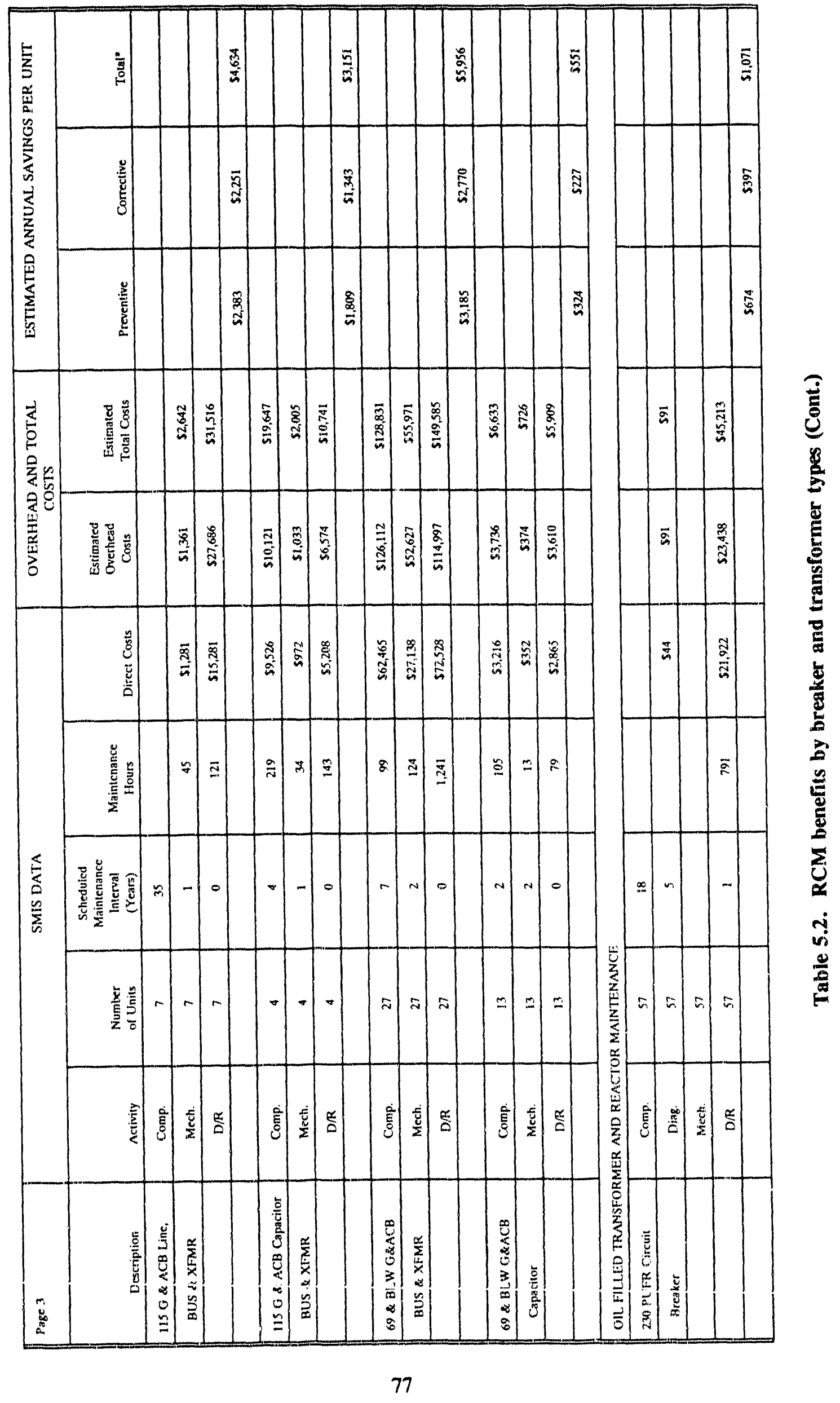




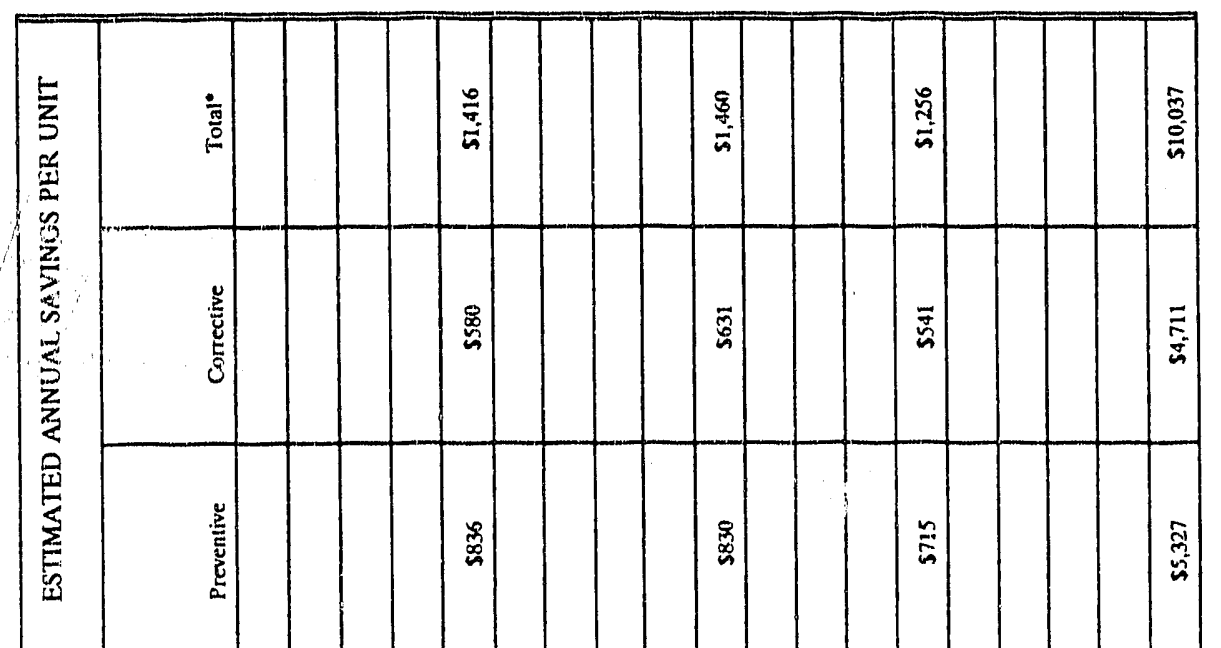

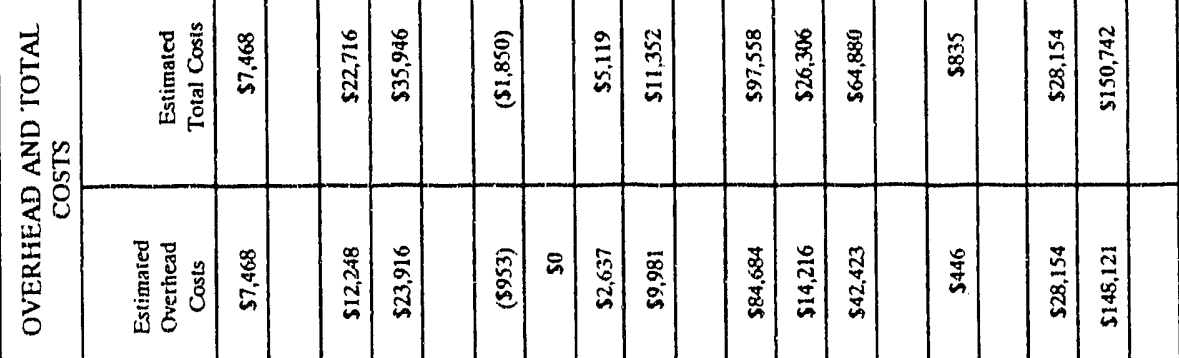

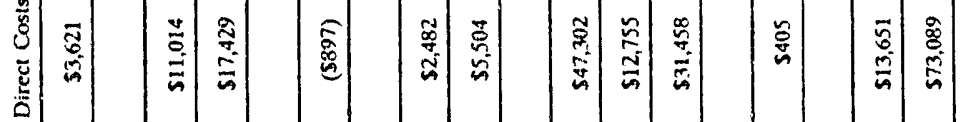

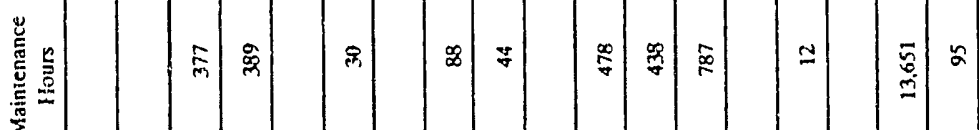

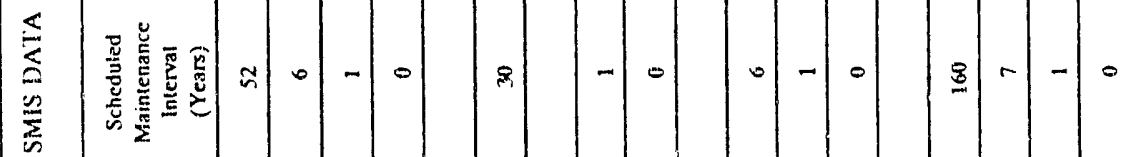

这突

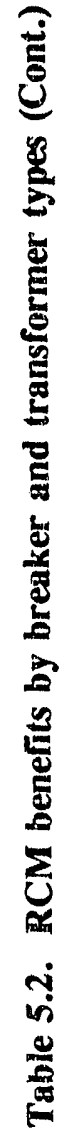

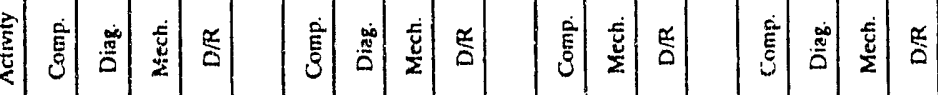

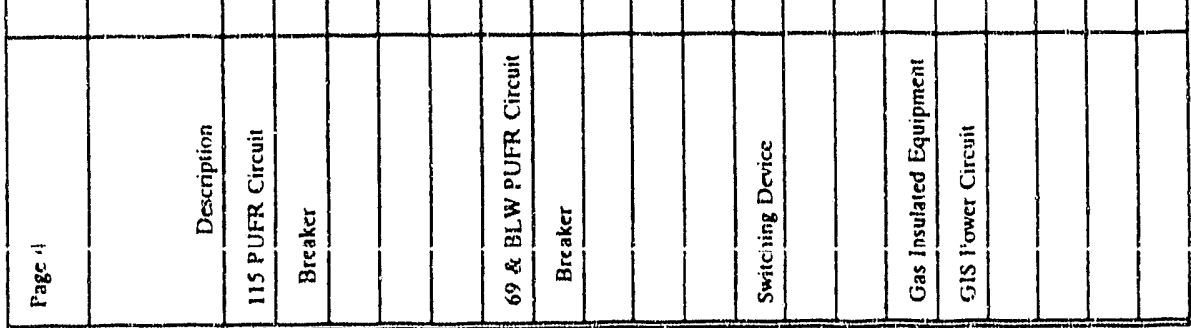




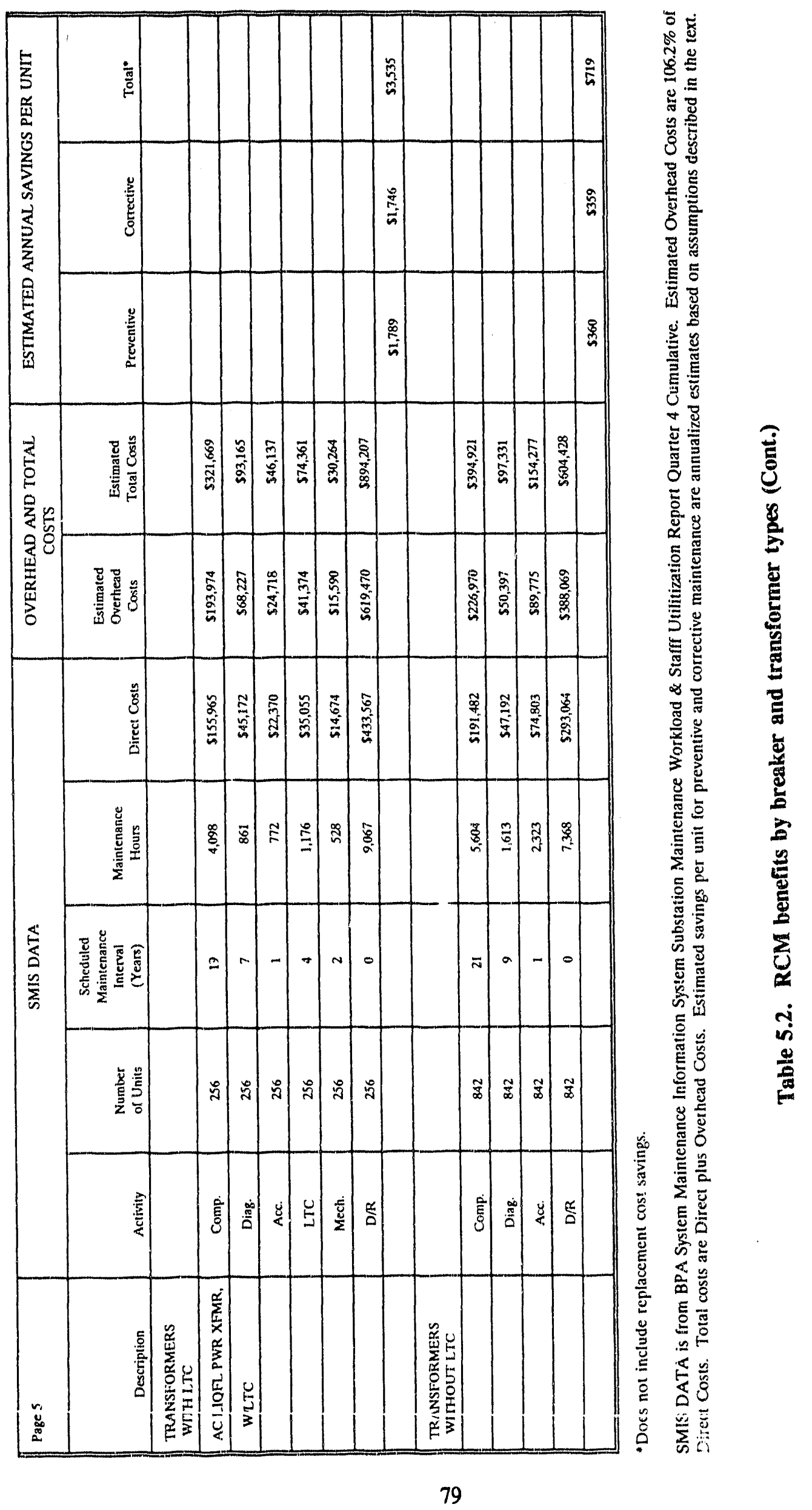




\subsection{BENEFITS FROM REDUCING CORRECTIVE MAINTENANCE}

RCM can also reduce costs by detecting problems that regularly scheduled maintenance might miss, thus avoiding increased costs for repair of damaged equipment. This tends to reduce the life-cycle cost of equipment. The constant monitoring of equipment by RCM provides a real-time diagnostic function, and therefore it is probable that existing diagnostic costs would be significantly reduced. Also, the continuous monitoring could significantly lower total maintenance costs by providing information that allows substitution of preventive maintenance for corrective maintenance. A study by the American Electric Power Service Corporation indicated that over six major categories involving circuit breaker problems, between $43 \%$ and $71 \%$, would be detectable with monitoring and between $23 \%$ and $38 \%$ of the problems would be predictable with monitoring. The combined totals for detectable and predictable problems ranged from $81 \%$ for oil circuit breakers to $94 \%$ for Airblast to $100 \%$ for Dual Pressure SF [P. Barkan 1988]. Based on this, it seems reasonable to reduce the diagnose and repair costs by $50 \%$. This assumption results in cost savings of about $\$ 749,000$ for transformers and $\$ 1.3$ million for circuit breakers.

\subsection{BENEFITS FROM EXTENDING EQUIPMENT LIFE BY REDUCING CATASTROPHIC FAILURES AND DELAYING SCHEDULED RETIREMENT}

The RCM monitoring could also reduce capital replacement costs. We have assumed that monitoring could reduce the capital replacement costs stemming from catastrophic failures by $50 \%$. The estimated rate of transformer failures is 0.46\% (BPA February 1990) which represents 6 transformers per year. The estimated capital cost for this rate of failure is $\$ 5,000,000$ per year or $\$ 833,000$ per transformer. Thus for transformers, annual savings would be $\$ 2.5$ million.

The annual savings for avoiding 50\% of circuit breaker capital replacement costs would be $\$ 269,000$. This is based on 38 violent in-service power circuit breaker (PCB) failures from 1968 to 1989. Slightly more than one 500kv PC.B failed per year. The replacement cost of a 500kv PCB was assumed to be $\$ 366,000$.

Another potential savings would be in delaying replacement of equipment normally scheduled for retirement based on "judgement" or rule-of-thumb criteria. The additional information provided by RCM data could result in a more economically efficient replacement strategy. We have assumed cost savings 
based on extending the life of the candidate equipment by two years. The total cost savings for delaying the replacement of transformers would be about $\$ 2.26$ million annually. The potential savings for circuit breakers would be about $\$ 570,000$ annually. These calculations were made by assuming that the average life of equipment is 40 years, which is equivalent to replacing $2.5 \%$ of all equipment every year. The savings are achieved by extending the average equipment life to 42 years. The calculation was made by taking an average of the summation of 2-year differences in present value factors at $5 \%$ for 40 years. This resulted in a present value factor of 0.042 which was applied to the total replacement value of all substation circuit breakers and transformers.

\subsection{IMPROVING RCM COST EFFECTIVENESS THROUGH TARGETING}

The potential savings that have been presented in Table 5.1 are gross cost reductions estimated on a system-wide basis. However, the rational economic objective should be to maximize net cost reductions after the costs of implementing RCM are considered. Since RCM is a decentralized concept, it can be targeted to specific types or classes of equipment. The approach should be to target RCM to all equipment for which the benefits of cost savings would be greater than the costs of implementing RCM for that piece of equipment. It is presently unknown what the actual benefits and costs of implementing RCM will be. However, given a set of assumptions such as have been made in this analysis, it is possible to identify the best candidates for implementing RCM and possible types of equipment that should initially be ruled out. The criterion for identifying the best candidates for RCM is the benefit-to-cost ratio.

Table 5.2, which presents the RCM data relevant to RCM benefits by equipment types, givas an indication of the categories of equipment that have high maintenance and repair costs per unit. These categories are more economically attractive targets than categories that have lower costs per unit. Also subcategories of equipme it with higher costs per unit might be identified by attributes such as age, vintage, previous maintenance experience, or vendor. This approach of targeting could increase the economic attractiveness of RCM, especially in the early stages when benefits and costs are uncertain. Obvious indicators of what types of equipment should be targeted are as follows:

- high maintenance costs per unit and 
- equipment that has high average replacement costs (i.e., the average replacement cost times the failure rate).

The average capital cost savings for circuit breakers were $\$ 318$ per unit and $\$ 2,057$ for transformers. Detailed information on specific types of equipment has not been assessed. However, even the gross breakdown indicates the advantage of targeting transformers as compared to circuit breakers.

\subsection{ADDITIONAL BENEFITS}

There are other potential benefits from RCM that we have not attempted to estimate. These benefits include higher system reliability and increased safety to personnel. Increased safety would be a by-product of any reduction in violent equipment failures that would be avoided by increased monitoring. From 1968 through 1989 there were 29 violent in-service equipment failures on the BPA system for $500 \mathrm{kV}$ power circuit breakers. Reducing these failures would reduce the associated risk of injuries and fatalities. So far there have been no injuries or fatalities from violent failures. However, this potential exists for electricians, station operators, and testers who work within range of porcelain that fragments with explosive force during violent failures. The destructive force of these failures has resulted in damage to nearby equipment, which bears testimony to the potential risk of serious personal injuries or fatalities.

The reliability would also be improved to the extent that equipment failures result in loss of load to any part of the system. According to a recent survey of utilities, the costs of unserved load were estimated at between $\$ 1$ to $\$ 16$ per $\mathrm{kWh}$ with a median value of over $\$ 4$ per $\mathrm{kWh}$ [Sanghvi 1991]. We have not estimated these benefits due to the inherent reliability and redundancy of the bulk power system, but in some cases they could be significant.

Another potential benefit that has not been estimated is improving equipment selection. The data that are generated through RCM monitoring can be used $t \mathfrak{c}$ analyze the characteristics of equipment that will lead to lower preventive and corrective maintenarice costs. This information should help in specifying criteria for new equipment that will reduce life cycle costs. This benefit should increase over time as more information is generated on equipment maintenance. 


\subsection{MEASURE RCM EFFECTIVENESS}

The effectiveness of maintenance programs are difficult to measure. If maintenance effectiveness can be measured it would help with the following:

- determine RCM's value,

- $\quad$ provide objective data to track progress and detect trends, and

- provide feedback to make positive changes to PM.

Ideally one would want to compare maintenance effectiveness before and after RCM was operable. However, only one substation is being instrumented so the post-RCM sample will be too small to reach statistically significant conclusions.

Four years of maintenance data are summarized in Section 3.2 on equipment reliability. Using four years of data instead of 15 or 20 years of data helps remove variations due to changing PM frequencies and maintenance practices. Equipment age and voltage are probably major determinants of reliability rates, and so reliability was calculated as a function of these variables. However, these data do not take into account several factors that contribute to maintenance effectiveness. These factors may be expressed in the form of questions.

(1) What would have happened to the reliability rates if the maintenance period were longer or shorter?

(2) What impact does prior loading or duty have on reliability?

(3) How much do individual designs and manufacturers contribute to differences in reliability and maintenance effectiveness?

(4) How accurate are manufacturer-suggested maintenance practices? Do they suggest excessive maintenance in order to insure higher reliability?

Despite our limitations to determine concretely maintenance effectiveness, maintenance factors can be calculated and accumulated over time. Several maintenarce factors are suggested in Table 5.3. Maintenance metrics include maintenance man-hours, costs, logistics, BPA equipment reliability rates, industry equipment reliability rates, substation reliability rates, and personnel safety. Each maintenance 
metric should include two values, estimated "target" values (predictions) and actual values (historical). The reason for developing and applying maintenance metrics as a tool is to aid in continually refining ways to optimize maintenance.

Table 5.3. Possible maintenance metrics

\section{INDICATORS}

ACTUAL

TARGET

Time (normalized by equipment or load)

PM Hours

CM Hours

PM Ratio

$$
\left(\frac{P M}{P M+C M}\right)
$$

Cost (normalized by equipment or load)

PM Costs

CM Costs

Logistics

Wrench Time

Ratio (Hours)

$$
\left[\frac{P M+C M}{P M+C M+\text { Admin }+ \text { Lost Time }+ \text { Supervision }}\right]
$$

PM Backlog

Ratio (Hours)

$$
\left[\frac{P M \text { Backlog }}{P M}\right]
$$

Equipment reliability

BPA Reliability Rates

Transformers

Breakers

Industry Reliability Rates

Transformers

Breakers

Substation reliability

MW-Hr Outage Due to Substation

Safety.

Injuries

Deaths 


\subsection{CONCLUSIONS}

This analysis shows that benefits associated with RCM are significant. The actual benefits would be determined by the ability of RCM to reduce maintenance intervals, corrective maintenance, and replacement costs. The data that have been examined indicate RCM benefits would vary significantly across various types of equipment. In general, the most attractive targets for RCM are equipment that have high average unit repair and/or replacement costs. With limited funds available for initial phases of RCM implementation, the most promising equipment should be targeted first. Some additional analysis is required to specify the most promising equipment for RCM.

\subsection{REFERENCES}

P. Barkan, J. Deni, A. McCabe, J. Reckleff, H. Scherer, Jr., and R. Woodward, "Methodolugy for Monitoring the Condition of High Voltage Circuit-breakers", International Conference on Large High Voltage Electric System, Paris, Aug. 28-Sept. 3, 1988.

BPA 1990. "Operations, Maintenance, and Replacement 10-Year Plan 1990-1999", Bonneville Power Administration, Final Report, February 1990.

EPRI 1989. "Demonstration of Reliability-Centered Maintenance", Volume 1, Project Description. EPRI NP-6152, Volume 1, January 1989.

Sanghvi, RCG/Hagler, Bailly, Inc., Washington, D.C., and N. Balu and M. Lauby, Electrical Systems Division, Electric Power Research Institute, Palo Alto, California, "Power System Reliability Planning Practices in North America", 91 WM 174-3 PWRS, 1991. 


\subsection{FUNCTIONAL REQUIREMENTS}

\subsection{INTRODUCTION}

One purpose of this chapter is to identify the general functions of an on-line monitoring and maintenance scheduling system for transformers and circuit breakers located at BPA's Alvey Substation, which we refer to as the Reliability-Centered Maintenance (RCM) System throughout the remainder of this chapter.

The proposed RCM System has two goals: to alert Bonneville substation operators about incipient problems associated with substation equipment and to provide input into the scheduling of preventive maintenance. The first problem area mentioned, that of incipient failure detection, usually can be detected from short-term data collection by determining when monitored equipment data are out of the normal range of operation and how the out-of-range data relate to various equipment failures. The second problem area mentioned, that of preventive maintenance, requires a longer-term collection of monitored data to detect equipment operating trends (i.e., those associated with aging) and to determine how the data trends relate to the probability of an evolving equipment failure. Much work has been done in the area of incipient failure detection. However, little has been done in the area of preventive maintenance for transformers and circuit breakers.

\subsection{OBJECTIVES}

The overall goals of the RCM project are to (1) determine the most effective number of data sensors as well as the most useful sensors required for adequate transformer and circuit breaker monitoring, (2) determine what software systems and data analysis models are needed for assessing the condition of transformers and circuit breakers, and (3) determine what maintenance needs to be performed at what time to assure adequate equipment reliability. The purpose of using an on-line monitoring system is to predict incipient equipment failures prior to their occurrence, to detect evolving equipment problems prior to causing an equipment failure, and to enable the adjustment of equipment maintenance on an as needed basis. The specific objectives of the project are as follows:

determine the most effective level of instrumentation required to implement RCM systems for transformers and circuit breakers; 
- develop analysis techniques and software needed to identify incipient equipment problems and evolving equipment operating problems for transformers and circuit breakers; and

- develop the knowledge base, decision logic, and software needed to determine preventive maintenance requirements for transformers and circuit breakers.

The project will be conducted in two phases: Phase 1 and Phase 2. During the first phase, the RCM system will monitor one transformer and one or more circuit breakers. Data collected during this phase will be displayed to BPA personnel, used to develop several decision rules for detection of incipient equipment problems (corrective maintenance), and used to begin development of decision rules needed for preventive maintenance decisions. The basic thrust of Phase 1 however, is to install the RCM equipment and be sure that it operates satisfactorily. During the second phase, the RCM system will be expanded to monitor multiple transformets and circuit breakers at the Alvey Substation. Decision rules will be expanded to include different types of circuit breakers and transformers found at the Alvey Substation. Decision software logic will be tested and improved, and instrumentation needs will be finalized.

Phase 2 will consider the compatibility of the substation level RCM system with a larger RCM system which may include as many substations as BPA considers appropriate. The ultimate RCM system should permit the RCM operator to compare transformers and breakers from across BPA's system and schedule maintenance based on need. Future instrumentation needs may be identified based on research and development conducted during Phases 1 and 2.

\subsection{HARDWARE REQUTREMENTS}

There are five levels of hardware required for the RCM system. They arc as follows:

- instrumentation and signal conditioning,

- equipment monitor,

- substation monitor,

- $\quad$ RCM System monitor, and 
- communications between equipment and substation monitors and existing Supervisory Control And Data Acquisition (SCADA).

A major requirement of the RCM system is that it must be able to interrogate the SCADA remote terminal unit (RTU) to collect substation equipment data from the SCADA database and write data (i.e., operation information concerning equipment status) directly to the SCADA RTU.

\subsubsection{Hariware Architecture}

The first phase of the RCM system is shown in Fig. 6.1. Ultimately, the system must have the capability to operate within the context of the existing SCADA and to communicate maintenance schedules to the SMIS. A dedicated SCADA RTU will be provided at the Alvey Substation to allow for the link between the RCM system and the BPA SCADA system. A substation monitor/computer will provide various substation-wide interface services. The R.CM system architecture will ultimately feanure inferencing which is distributed between the equipment monitors, substation monitor, and system monitor. Fig. 6.2 shows the ultimate RCM as currently envisioned.

\subsubsection{Instrumentation}

Since the field of on-line power system equipment monitoring is in an early stage of development, future discoveries may change the sensor array best suited for RCM monitoring. Therefore, an important requirement for the equipment monitors is the ability to incorporate additional sensors. The expectation at this time is that the equipment will be deliberately overinstrumented for the Phase 1 implementation. One of the objectives of the RCM project research is to determine what reductions can be made in the sensor array without reducing the quality of the inferences drawn by the RCM system. 


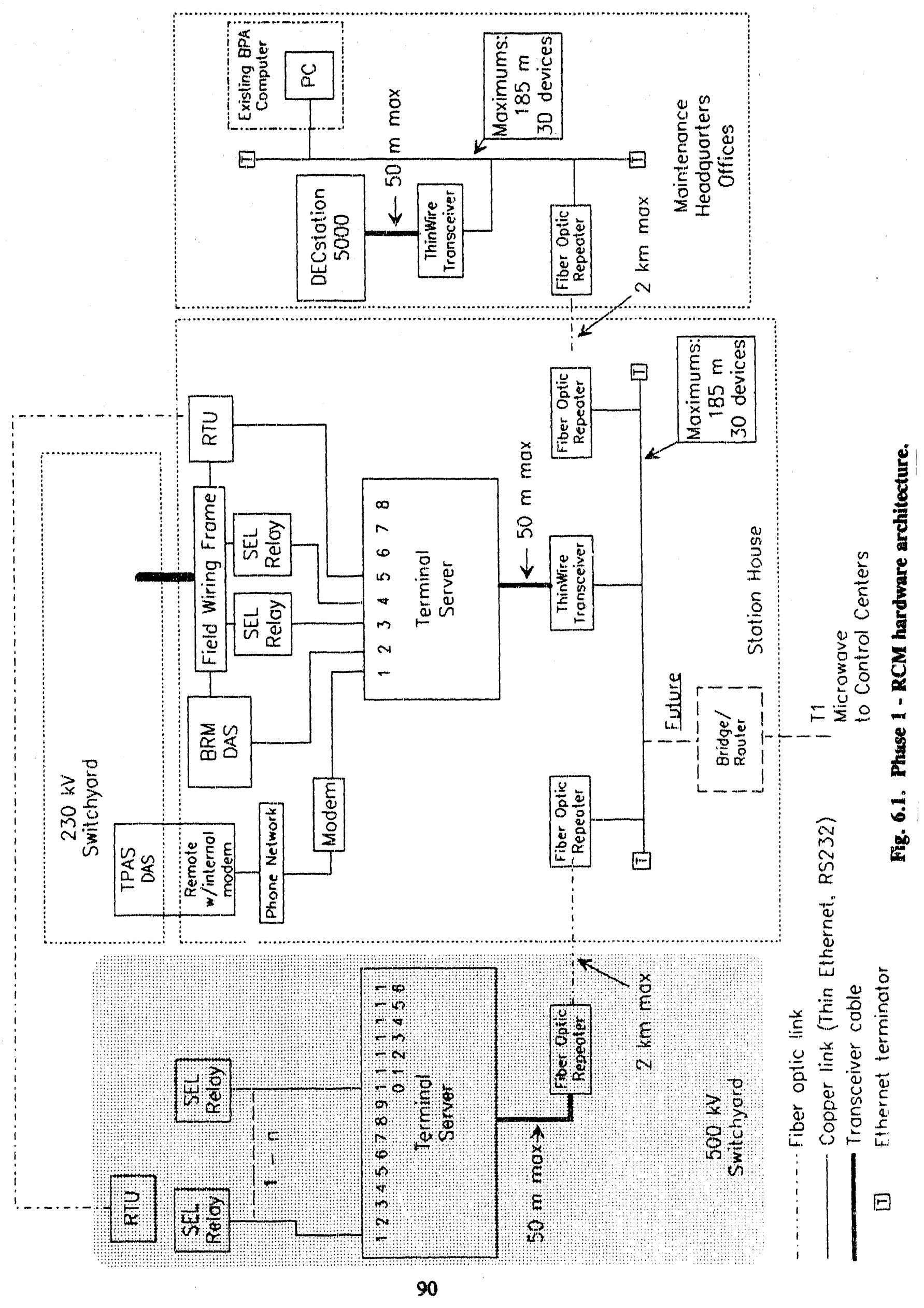



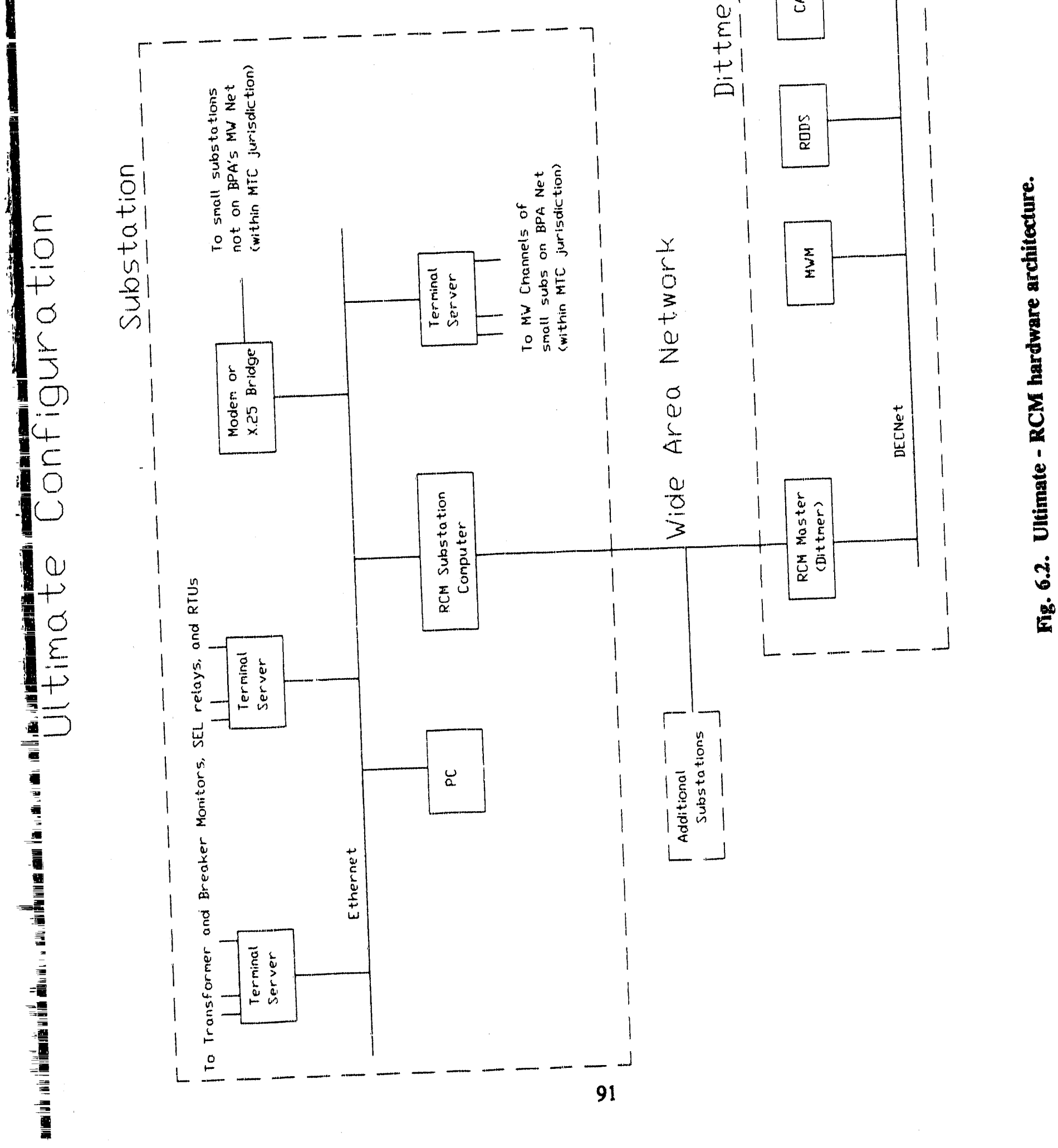


\subsubsection{Equipment Monitor}

The equipment monitor will have the computing ability to integrate the instrumented values and to perform analysis as appropriate (i.e., what is required to calculate model parameters model estimates, and data residuals). The Harley transformer monitoring system is an example of this type of equipment hardware. Equipment monitors will obtain on-line data from transformers and circuit breakers. The RCM system needs to be capable of (1) detecting equipment operation anomalies, (2) diagnosing the conditions of the transformer and circuit breaker, and (3) making maintenance recommendations (both corrective and preventive maintenance recommendations).

\subsubsection{Transformer Monitor}

The transformer monitor system will be designed to perform several tasks. These tasks include the following:

- monitor condition of the insulating oil,

- monitor condition of the solid insulation,

- detect presence of moisture and oxygen,

- detect harmful events such as short-circuits, switching surges, voltage surges,

- detect excessive temperatures, and

- detect partial discharges (noise signatures).

A transformer monitoring scheme similar to the one explored by Crowley at MTT is being commercially implemented by J. W. Harley Inc. This system uses a set of sensors in a proprietary scheme developed by Harley. Sensor data is fed into a data acquisition unit at the transformer and the data is transferred to a remote computer in the substation control room. Inferencing is done by the renote computer. The master computer in the Harley transformer scheme performs a role similar to the substation monitor in the BPA RCM scheme.

It is likely that elements of the Harley system can be adapted to the transformer monitoring part of the BPA RCM system. Specifically, the Harley data acquisition unit and remote computer might be used as the data acquisition unit and the inferencing processor needed for the transformer equipment monitor. 
The BPA RCM system operates in a larger context than that anticipated in the original Harley design. For that reason, it is not practical to simply purchase a Harley box and snap it into place in the RCM system as a free standing module. However, if Harley is willing to address the issues that would make their hardware fit into the BPA RCM context, then elements of their system could serve as the basis for the transformer monitor.

\subsubsection{Circuit Breaker Monitor}

The circuit breaker monitor will be designed to monitor and detect several things. These include the following:

- breaker operation characteristics;

- level of interrupting current;

- fault operations, magnitude, clearing time, arcing time and phases involved;

- detect internal contact wear and damage via I't calculations; and

- $\quad$ detect breakage and deformation problems (noise signatures).

The idea of monitoring a circuit breaker for incipient failures has been considered by Doble and others [i.e., the Electric Power Research Institute (EPRI)] and reported in CIGRE, T\&D Magazine, the IEEE Transactions, and in utility conference papers. The CIGRE paper is conceptual in nature and describes what quantities might be monitored and how the condition of the breaker might be inferred.

EPRI has been active in researching the area of noninvasive diagnostics of circuit breakers. The research has involved the development and application of circuit breaker diagnostics including acquisition of equipment vibration data, signal processing, and decision making. Also, the research has involved the development of a portable diagnostic unit for circuit breakers. The functional design of the Circuit Breaker Monitor might build on the work reported by EPRI as well as that reported by Doble in CIGRE.

BPA is working on an arrangement with Doble to monitor circuit breakers. This scheme uses sensors, a smart data acquisition system, and a system for recording data so that a copy can be shipped to Doble for analysis. There is no local inferencing. The scheme apparently uses a proprietary sensor layout and inferencing algorithm. It does not infer the condition of the breaker in real time. The Doble 
box might be used as the data acquisition unit in the circuit breaker monitor part of the RCM system if it can be connected easily, but an inferencing processor and I/O circuitry would need to be added.

\subsubsection{Substation Monitor}

The substation monitor will consolidate and integrate all the equipment values at the substation level. The substation monitor will also be used during Phase 1 of the RCM system implementation as the overall system monitor. The substation computer will perform the following functions:

- integrate equipment monitoring,

- communicate with the SCADA RTU and system computer,

- handle inquires from the system computer which monitors multiple substations,

- archive data from monitored equipment,

- provide the ability to integrate additional sensors,

- provide the ability to perform additional analysis,

- maintain status of substation equipment,

- maintain a schedule of equipment requiring maintenance, and

- display equipment information to substation personnel.

Ultimately, each substation monitored by the RCM system may require a separate workstation. However, the use of such a scheme will require evaluation of the cost and complexity of its implementation. If required, the computer at a minimum will perform the following functions. It will handle interrogations of the SCADA system (i.e., obtain SCADA data from the substation RTU) and provide equipment status data to the SCADA RTU. In addition, it will maintain substation-wide knowledge bases and/or databases produced or required by the inferencing processors, but too large to be stored locally within each inferencing processor. It will archive inferences and selected sensor data from the equipment monitors. Ultimately, perhaps in Phase 2, it will communicate maintenance data to the system-wide RCM computer.

In addition, the substation monitor might be used for other tasks. It will be used as a local point of interface where a maintenance manager could make direct queries to the RCM system on maintenance recommendations. Also, it might be used to make synergistic maintenance inferences based on selected data from several different pieces of equipment. 
It is necessary that the substation monitor be capable of two-way communications with each of the inferencing processors of the equipment monitors. The inferencing processors do not need to talk to each other. Therefore, a peer to peer network is not necessarily required. However, the substation monitor should be able to receive data from and transmit data to a variety of equipment monitors.

\subsubsection{Interface With Existing SCADA Environment}

The RCM system needs to interface with the SCADA system at BPA. The interface between the SCADA system and the outside world is handled by RTUs supplied by Systems Northwest. The RCM system should write information to the RTU and interrogate the RTU for information. The architecture of the RTU limits how this can be done.

The modules connected to the RTU multiprocessor bus are communications processors operating under various protocols. Communications between the RTU and the SCADA system are handled by a processor using GETAC protocol (a special GE protocol) communicating with the SCADA master station at 2400 bits per second. Interfaces to other computers, such as the substation monitor, can be handled by other communications processors using a variety of protocols. The only way that the outside world is allowed to write data to the SCADA system is through the analog or status I/O processors on the I/O bus of the RTU.

Database interrogations and responses between the RCM substation computer and the SCADA (via a dedicated RCM SCADA RTU to be placed at Alvey) will be handled serially via a standard communication protocol. A communications processor must be added to the dedicated Alvey RCM-RTU for this purpose. The RCM substation monitor will have a serial interface that supports the same protocol. 


\subsubsection{System Monitor (Maintenance Application Processor)}

The system monitor function will not reside in a separate computer during the early phases of the RCM project. Initially, system monitor functions will be implemented on the substation monitor. The overall system monitor/computer will archive and integrate the individual equipment data to provide statistics on equipment performance within voltage classes and to perform long-term performance assessment of the individual equipment. In addition, the past history data collected from the substation monitors may be utilized to improve equipment models utilized at the equipment monitors. The substation monitors and overall system monitor should have the capability of uploading software from the system monitor to substation monitors.

The most important function of the system monitor is identifying equipment requiring preventive maintenance. A Maintenance Decision Support Model will prepare a list of equipment requiring maintenance for verification by the maintenance manager and for dissemination to area maintenance personnel. The system monitor is also referred to as the Maintenance Application Processor (MAP). MAP will eventually be connected to the network at Dittmer.

\subsection{MAINTENANCE DECISION SUPPORT REQUIREMENTS}

The RCM system presents many challenging opportunities with respect to decision support. Realtime data from the system will support corrective maintenance decisions. Accumulations of real-time data will support preventive maintenance decisions. In addition, the RCM system will support both corrective and preventive maintenance decisions at various sites within the Bonneville Power Administration, specifically at the area offices and at Dittmer.

Fig. 6.3 illustrates the RCM system decision support components and criteria. As stated above, decision support components are conceptualized along two axes: types of decisions and sites of decisions. This results in four decision support components. As indicated, each component requires specially tailored decision methods and requires different types of data. This subsection examines each of these components in more detail. 


\begin{tabular}{|c|c|c|c|}
\hline & & $\begin{array}{c}\text { Corrective } \\
\text { Maintenance }\end{array}$ & $\begin{array}{l}\text { Preventive } \\
\text { Maintenance }\end{array}$ \\
\hline & $\begin{array}{l}\text { Area } \\
\text { Oftices }\end{array}$ & $\begin{array}{l}\text { (1) } \\
\text { - Determine when corrective } \\
\text { maintenance is required } \\
\text { - Threshold analysis } \\
\text { - Real time dats }\end{array}$ & $\begin{array}{l}\text { (2) } \\
\text { - Establish priority ranking of equipment } \\
\text { for preventive maintenance } \\
\text { - Dynamically fine tune maintenance plan } \\
\text { - Real time maintenance costs and } \\
\text { resounce availability data }\end{array}$ \\
\hline SITE & & & \\
\hline OF & & (3) & (4) \\
\hline DECISION & Dittmer & $\begin{array}{l}\text { - Support operator decision making } \\
\text { in corrective maintenance } \\
\text { situations } \\
\text { - Al-based system } \\
\text { - Rewl time data system } \\
\text { - Dynamic equipment ratings }\end{array}$ & $\begin{array}{l}\text { - Support substation maintenance } \\
\text { strategic planning } \\
\text { - Optimization } \\
\text { - Statistical data, rankings, capital } \\
\text { equipment and maintenance } \\
\text { budgets } \\
\text { - Maintenance criteria and trade- } \\
\text { offs }\end{array}$ \\
\hline
\end{tabular}

Fig. 6.3. RCM decision support components and criteria.

Before proceeding, it is important to lay a firm conceptual framework. In particular, it is important to distinguish between the concepts of diagnosis and decision making. Diagnosis is strictly concerned with ascertaining the state of the world, whether one is interested in the present, past or future. With respect to RCM, diagnosis involves using instrumentation and supporting systems to collect data about a problem and then using knowledge to turn the data into information. Expert systems are primarily concerned with diagnostic problems. The RCM system will support various diagnostic activities related to the present health of transformers and circuit breakers and their future health.

Decision making is concerned with determining proper courses of action. With respect to RCM, decision making is concerned with optimizing maintenance activities. To make these decisions, one needs to understand the maintenance criteria, have information on the relevani states of the equipment, have a set of goals, and know how to achieve those goals. Good decision making depends on good diagnoses but good diagnoses are only one element of a decision making process related to maintenance. Decision 
analyses involve ccncepts, such as ranking and optimization, which must be appropriately applied. The RCM system will provide data to make diagnoses about equipment health and these data will feed into the various decision making. components.

It is important to distinguish between diagnosis and decision making, especially where there is a tendency to synthesize the two. For example, when one observes that a piece of equipment enters a certain state, it may be standard practice to implement a specific action. In this case, there is a one-toone mapping between a diagnosis and a decision. However, this need not be the case. Various other factors, such as resource availability and weather, may also be important in making a decision. In other words, given an identical equipment diagnosis, maintenance decisions may differ from one time to the next due to differences in manpower availability or other factors. Thus, the possibility and even probability of one-to-many mappings between a diagnosis and a set of reasonable maintenance decisions must not be overlooked. The quality of a diagnosis is related to diagnostic knowledge, data quality, and availability. These will not be perfect in all cases and so, in these instances, there may be a many-tomany mapping between potential diagnoses and decisions. Decision heuristics play an important role in guiding actions in these uncertain situations. Multiple decision alternatives based on a diagnosis should be considered along with the uncertainties associated with diagnoses and decisions.

\subsubsection{Corrective Maintenance Decision Support at Area Offices}

One RCM decision support component will assist corrective maintenance decision making at the Area Offices. Initially, the RCM system will provide real-time data to allow Area Office staff to diagnose imminent equipment failures. However, this requires manpower to interrogate the RCM computer system. In time, the RCM system may assist maintenance personnel by automatically performing these diagnoses.

The type of decision support required depends upon the nature of the maintenance decision. For corrective maintenance decisions, it appears likely that most situations entail a one-to-one mapping between a diagnosis and a corrective maintenance action decision. In this case, decision support would involve providing information to Area Office staff on diagnostic knowledge and corrective maintenance considerations. 
Though corrective maintenance is basically a diagnostic problem there are distinct research considerations. Real-time data will flow continuously from some of the equipment sensors. For circuit breakers the data will consist essentially of a series of graphs or operation signatures over time. An important research task is to identify what analysis techniques are most useful to automate the diagnostic process. For example, a simple expert system could be employed if thresholds could be located on the graphs. Neural nets could be employed if entire signatures must be evaluated. If comparisons between graphs over time are required, time series analysis might be the preferred approach. As a first step towards this ultimate goal, attention will focus on acquiring the basic diagnostic logic.

\subsubsection{Preventive Maintenance Decision Support at Area Offices}

Preventive maintenance decisions are more complex than corrective maintenance decisions. In this case the goal is to establish some sort of priority ranking of equipment needing preventive maintenance. The ranking scheme must be able to distinguish between the relative needs for preventive maintenance among pieces of equipment under the jurisdiction of an Area Office. The ranking scheme must also be able to produce scores that indicate the absolute need for preventive maintenance for each piece of equipment. Given a rank ordering of pieces of equipment by need for preventive maintenance and local expertise, each Area Office could then develop its detailed weekly, monthly, or quarterly preventive maintenance schedules.

A ranking function requires numerous inputs. The RCM system will provide real-time data which, when appropriately aggregated, will be able to indicate the actual health of each piece of equipment. Statistical data on equipment failures as well as information on previous maintenance performed on each piece of equipment is also required. The estimated costs and manpower required for each type of preventive maintenance and the availability of funds and manpower are also necessary inputs.

A particularly interesting research problem is how to use this statistical data to make predictions about the probability of equipment failure over time or when a piece of equipment will eventually need maintenance, especially since a successful RCM program should continuously reduce the number of observed equipment failures. Another interesting research question is how to link corrective and preventive maintenance conducted by the area offices. For example, in many instances it may be cost 
efficient to accelerate preventive maintenance on pieces of equipment that have been identified for corrective maintenance.

\subsubsection{Preventive Maintenance Decision Support at Dittmer}

Preventive maintenance decisions at Dittmer are more strategic in nature than those made at the Area Offices. Staff at Dittmer are concerned with developing capital investment plans and formulating multiple year budgets for maintenance activities. This is a difficult process because goals of guarantced reliability and controlling costs often conflict. Thus, instead of a ranking problem, the Dittmer staff have a constrained optimization problem. That is, the task is to determine the best allocation of resources among items such as capital investment and preventive maintenance that meet predetermined reliability goals while minimizing overall costs and not exceeding manpower capabilities.

There are numerous inputs for automated decision support in this area. Reports will come from the RCM system on the overall current state of health of substation equipment and data on equipment failures. This data must be supplemented by other data on equipment age and past preventive maintenance activities which will be inputs into a predictive maintenance model. One particular challenge will be to take all this data and produce a budget plan that spans multiple time periods. A predictive maintenance model must consider reliability, resources, budgets, equipment replacement, maintenance criteria, equipment expertise, and other factors.

\subsubsection{Corrective Maintenance Decision Support at Dittmer}

Corrective maintenance decisions at Dittmer are distinctly different from the other three kinds of decisions. In this case operators at Dittmer may use information from the RCM system to make decisions that effect the transmission network. They may need to make decisions on whether to leave equipment on-line or take it off-line. Operators also make decisions on whether to overload equipment and for how long. Up-to-date data on equipment provided by RCM will greatly assist these types of decisions.

This decision environment can become exceedingly complex. If one were to focus on operator decision making, a decision support system could provide assistance by evaluating large numbers of 
potential equipment operation decisions. Artificial intelligence techniques could be used to optimize equipment loading decisions.

\subsection{SOFTWARE REQUIREMENTS}

Software requirements include the need for utilizing flexible software tools, a Maintenance Decision Support Model which predicts incipient problems (corrective maintenance) and determines equipment preventive maintenance requirements, and a suitable communication format for maintenance recommendations that is useable by maintenance personnel as well as other BPA personnel. These requirements may be stated simply as tools, models, and communication.

The preceding discussions on hardware (Sect. 6.3) and maintenance decision support functional requirements (Sect. 6.4) have identified the software needs that will be implemented in the Substation and System Monitors. This section briefly discusses the software requirements that will be part of the Substation Monitor in Phases 1 and 2, and will uitimately be part of the System Monitor (MAP) beyond Phase 2. It aiso discusses operational characteristics of the software requirements for zach phase and how they will be integrated.

Software development should proceed according to the functionality shown is Fig. 6.4. This diagram, which is conceptual, helps show the range of software that will be developed during Phases 1 , 2, and beyond. This diagram aiso helps identify the software structure.

In addition to identifying the software's structure, two additional elements must be identified in order to broadly define the RCM software. Namely, what is being developed and how it is being developed. What is being developed is generally identified in Section 6.4. RCM software will support four entities: corrective maintenance at Area Offices, preventive maintenance at Area Offices, preventive maintenance centralized at Dittmer, and corrective maintenance support for operators. The second software element refers to how the software is developed. Various software tools will be utilized to maximize the software development effort. To this end we have adopted the philosophy of buying software tools rather than developing them. 


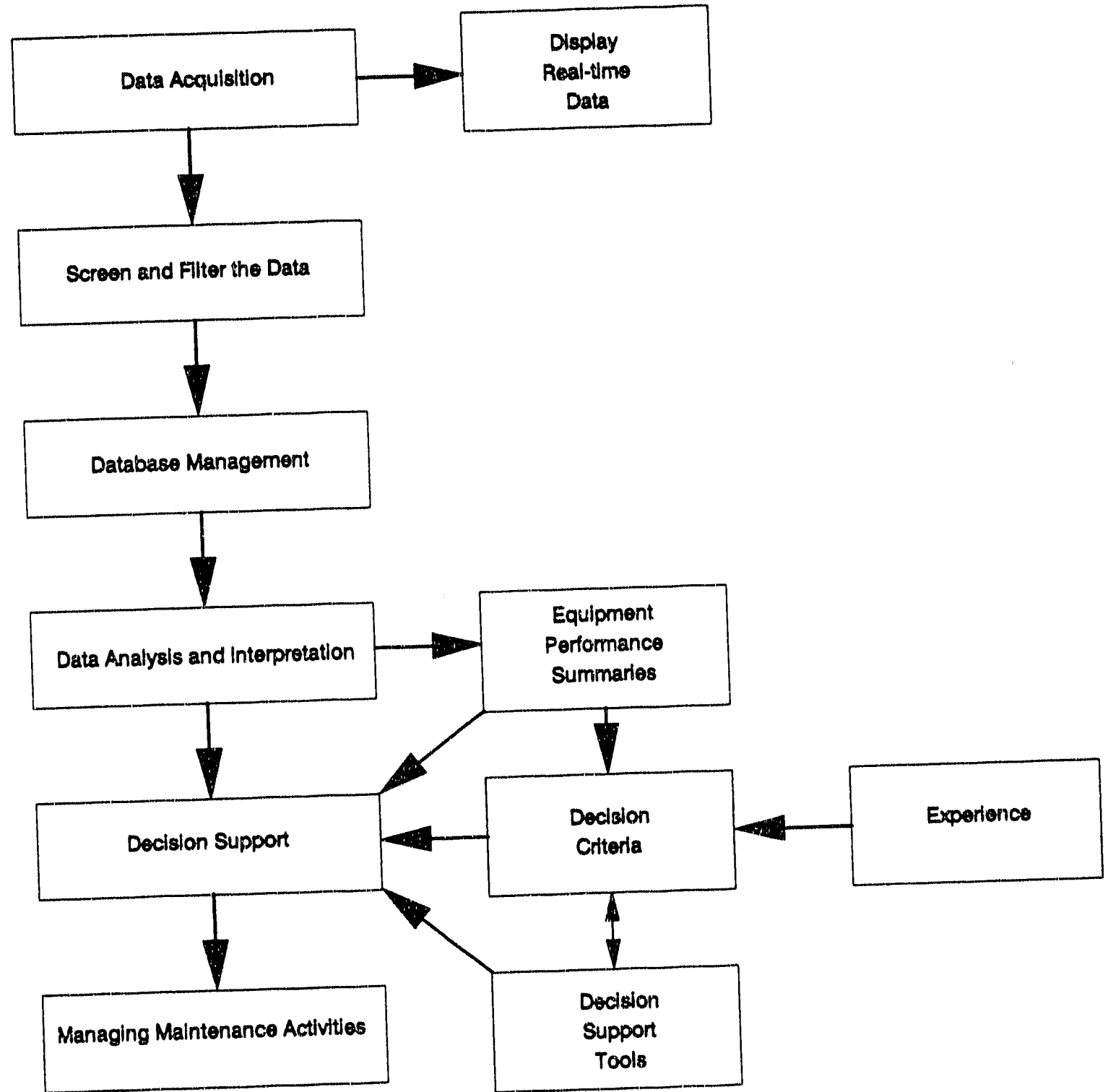

Fig. 6.4. RCM software development. 


\subsubsection{Software Tools}

Flexibility is extremely important for developing Phase 1 software. In particular, the suite of software tools must provide an environment conducive to exploration of the meaning of data and the value of various analysis techniques. Also, the software must manipulate a wide variety of data types ranging from a single monitored value to a statistic calculated for an entire class of equipment. The timing characteristics range from real-time data to long-term archives. There is a diverse set of data sources including Equipment Monitors, SCADA, SEL relays, and SMIS. Also, there is a diverse set of users including maintenance personnel, programmers, and other software systems. Therefore, an extensive database of equipment descriptions, maintenance, and performance must be built and maintained. Throughout Phases 1 and 2, the software tools and underlying databases must allow easy modification, integration, and use. All of the software components must provide effective methods for integration.

The software tools may be classified as follows: operating system, database management software, statistical analysis software, user interface development tools, algorithmic programming language, networking and communications software, and knowledge base tools.

\subsubsection{Maintenance Decision Support Modeling}

RCM involves decisions about when to maintain pieces of equipment and at what level (e.g., inspection, testing, routine maintenance, or detailed maintenance). To make these decisions a decision model requires several inputs about a piece of equipment such as the current state of a piece of equipment, as indicated by real-time sensors; recent operation of the piece of equipment; its maintenance history; the probability over time of various failure modes; the cost of maintenance by level of effort; and the cost to repair/replace. The decision model could also incorporate more global data such as overall system maintenance crew availability, overall system maintenance capital budgets, and overall equipment portfolio maintenance requirements.

Basically, an RCM decision model would determine the timing and level of the next planned maintenance for pieces of equipment to meet a set of rigorously defined objectives, such as the optimization of maintenance costs. The model itself could be based on operations research techniques 
such as linear programming; on artificial intelligence techniques (e.g., an intelligent search algorithm); or on a combination of these techniques.

The most important data in any information system is the output. The output of an RCM system is maintenance recommendations. Currently at BPA, the Substation Maintenance Information System (SMIS) handles maintenance information. Therefore, the RCM system should allow for easy interfacing (both software and hardware) with the SMIS system. It is not expected that RCM will interface with SMIS in the early phases. However, even in the first phase the system design must take the future addition of the interface into account.

\subsection{UNRESOLVED ISSUES}

There are several unresolved issues that must be settled as the RCM prototype proceeds.

1. Setting of maintenance schedules. Ultimately, will an RCM system set maintenance schedules?

2. Relationship between monitored values and maintenance. How do monitored values influence maintenance? Currently, relationships between monitored values and maintenance decisions are not known. There may be a tendency to include instrumentation because there is a technical interest; however, equipment instrumentation should be limited to that which will help determine maintenance needs.

3. Most effective number of sensors required. What is the most effective set of sensors required to predict incipient problems and the need for routine maintenance?

4. RCM equipment refundancy. How much RCM equipment redundancy should the RCM system provide?

5. Data backup. How often should the data on the computers be backed up?

6. Need for substation computer in final system. Is the substation computer needed for the ultimate RCM system? The substation computer can provide for communications coordination with the existing SCADA database. If enough of the monitoring and analysis can be performed by the equipment computers there may not be a need for the substation computer. In this event all the individual equipment computers may interface directly with the RCM system computer. 
7. Level at which maintenance decisions are made. Where is the maintenance decision made? The RCM system will produce a recommendation which the RCM maintenance manager will verify and include in the schedule. Alternatively, the RCM system may schedule the maintenance without verification by the RCM maintenance manager.

8. Equipment hardening. Is the equipment sufficiently hardened for the substation environment which is extremely harsh? Is equipment sufficiently protected from EMI, switching surges, lightning surges, and extreme temperatures?

9. Equipment compatibility and modularity. Should a vendor be identified for ultimately producing a modular black box that we can install in the vicinity of the transformer or breaker? The communication protocol and interaction between the "black box" and the substation computer should be transparent, so different vendors' units can operate together in a modular fashion. Equipment should be open, employing standards so other vendors may duplicate the interface and communicate easily with the substation computer and software. If a manufacturer has a closed proprietary system where source data is not easily available or communication is difficult, it will necessitate the development of our own equipment monitor. Different sensor techniques should be integrable into either the transformer or breaker equipment monitors.

10. Ability to install and maintain monitoring equipment. How should the equipment be made so that it will be easy to install and maintain?

11. Build knowledge database on long-term equipment operation. Should a high voltage transformer and circuit breaker similar to the equipment found in the Alvey Substation be instrumented in the laboratory? The purpose of a laboratory setup would be to allow accelerating the aging process of the equipment in order to start building a knowledge database on how sensor data varies as equipment ages. A great deal can be learned by subjecting the equipment to abnormal operating conditions and the laboratory data may also give us insight into how to schedule preventive maintenance. Another method of collecting this long-term data is to keep the monitoring system in place on several transformers and circuit breakers over a long period of time (i.e., the life of the equipment).

12. Integration of RCM transformer and circuit breaker systems. Ultimately, should the RCM equipment monitoring systems for the transformer and circuit breaker be standardized such that the instrumentation produces a standard output, allowing the use of only one equipment monitoring system for both the transformer and circuit breaker and only one inferencing computer system?

13. Estimate the impact of historical maintenance and usage. How should existing equipment be integrated into the RCM system. 
14. Distributed inferencing. Ultimately, identify which computer processes what type of data. The prototype indicates that data will be analyzed in the RCM computer. Ultimately, inferencing will be distributed between equipment monitors, substation monitors, and the system monitor.

\subsection{REFERENCES}

F. Flavin, "Fault Monitor Analyzes Circuit Breaker Exposure," Transmmission \& Distribution, pp. 64-65, March 1991.

M. Lai et. al., "Mechanical Failure Detection of Circuit Breakers," IEEE Transactions on Power Delivery, Vol. 3, No. 4, pp. 1724-1731, October 1988.

S. Wright, "Circuit Breaker Diagnostics," Paper presented at The Doble Conference, Boston, Massachusetts, 1989. 


\subsection{CONCLUSIONS AND RECOMMENDATIONS}

RCM is a tool which may be applied by BPA to substation maintenance to improve reliability while reducing maintenance costs. Currently, BPA's maintenance requirements exceed maintenance resources. There is a maintenance backlog and some breakers and transformers are not maintained according to BPA's PLG.

The RCM system must address two fundamental needs. The RCM system must be able to detect incipient equipment problems. It must also assist in identifying and scheduling preventive maintenance. This can be accomplished by focusing on the individual equipmeni level or the system level. Either the reliability of individual pieces of equipment or the reliability of the entire system will be maximized. Traditionally, RCM has been applied to the system level to maintain the function of the system (i.e., power supply reliability, nuclear power plant, aircraft). However, the design of substations is very reliable so the loss of critical components like expensive transformer banks may occur without loss of electrical service. Therefore, substation RCM should target the individual equipment, such as transformers and breakers, in order to minimize maintenance resources (i.e., time and costs).

The potential benefits associated with RCM are significant. The estimated present value of applying RCM to all BPA transformers and breakers is $\$ 133,281,000$ overall and $\$ 8,050,000$ when the figures are annualized. The actual benefits will be determined by the ability of RCM to optimize maintenance intervals, corrective maintenance, and replacement costs. The data examined indicate that $\mathrm{RCM}$ benefits will vary significantly according to equipment type. In general, the most attractive target for RCM is equipment that has high average repair or replacement costs. With limited funds available for the initial phases of RCM implementation, the most promising equipment should be targeted first.

Based on the conclusions discussed in this report, the report concludes with the following recommendations.

\footnotetext{
A prototype Reliability Centered Maintenance (RCM) system should be installed at Alvey substation. Monitoring equipment should be installed on a few pieces of equipment in Phase 1 (one transformer and several breakers) and later extended to the rest of the substation in Phase 2 (all transformers and breakers).
} 
The RCM system should be over-instrumented in the initial phases in order to optimize learning experiences.

RCM software should be modular to allow all software to be shifted between computers as required.

Software developed for RCM should be based, to a practical degree, on powerful yet flexible commercially available software tools.

The RCM should be designed so that its data will ultimately be accessible to many points within BPA.

The RCM hardware system should be based on an "open architecture" philosophy even if that requires custom designing some equipment monitors.

An RCM review board should be set up to review maintenance criteria, guide RCM implementation, interpret results, identify appropriate maintenance metrics, and suggest changes. BPA must have a comprehensive understanding of the impact of RCM as a maintenance management tool.

- Specific diagnostic data fusion techniques and RCM decision analytic techniques should be studied simultaneously during Phase 1 and Phase 2.

Changes to substation maintenance warrant a "go slow" approach. Changes to substation maintenance, whether positive or negative, will probably not show up in equipment reliability rates for years. This is because RCM experience will take time to acquire. The airline industry is still fine tuning its RCM system after more than 17 years experience. The benefits to the airline industry continue to improve as the RCM system is fine tuned. BPA's RCM substation maintenance program will also take time to fine tune. One should expect the effectiveness and efficiency of maintenance to improve over the years as experience is gained with RCM. Also, RCM will not have a significant impact until it is implemented system wide. It may take several 
years after system-wide implementation before RCM impacts BPA's inaintenance budget projections.

The basic issue in sensor development for RCM is not simply the incorporation of the latest technology into existing measurements, but rather the selection of a set of measurements which best indicate the health of equipment. Currently, the primary focus in the industry is detecting incipient problems. The RCM program must extend monitoring to find the best monitoring mix for longer term preventive maintenance while including the incipient failure detection necessary for corrective maintenance.

The RCM prototype should be viewed as a learning experience. An extra degree of freedom should be allowed so experiences can be gained from non-traditional utility views. These experiences can ultimately strengthen the effectiveness of the future RCM system.

Future sensor development should explore non-invasive techniques for diagnostics. These sensors should be cheaper than current systems. 
ORNL/TM-12051

\section{INTERNAL DISTRIBUTION}

1.

2.

3.

4.

5.

6.

7.

8.

9.

10.

11-15.

16.

17.

18.

19.

20.

21.
P. R. Barnes

H. R. Brashear

M. N. Burnett

T. L. Chiang

G. E. Courville

D. C. Bauer

B. G. Eads

S. R. Elliott

P. D. Fairchild

W. Fulkerson

R. T. Goeltz

E. A. Hirst

R. D. James

T. L. James

S. W. Kercel

J. O. Kolb

M. A. Kuliasha
22. B. W. McConnell

23. D. W. McDonald

24. D. E. McMillian

25. V. C. Mei

26-141. S. L. Purucker

142. D. T. Rizy

143. M. L. Simpson

144. S. F. Smith

145. J. P. Stovall

146-160. B. E. Tonn

161. J. W. Van Dyke

162. Central Research Library

163. Document Reference Section

164-165. Laboratory Records

166. Laboratory Records - RC

167. ORNL Patent Office

\section{EXTERNAL DISTRIBUTION}

168. Dr. Bruce G. Buchanan, Department of Computer Science, University of Pittsburgh, 206 Mineral Industries Building, Pittsburgh, Pennsylvania 15260.

169. Mr. W. Terry Boston, Tennessee Valley Authority, Manager Regional Operations, 6N 31B Signal Place, Chattanooga, Tennessee 37402-2801.

170. Dr. Steinar J. Dale, Transrhission Tectinology Institute, ABB Power T\&D Company, Inc., Centennial Campus, 1021 Main Campus Drive, Raleigh, North Carolina 27606.

171-185. Mr. Ken Hemmelman, Bonneville Power Administration, Power Systems Control, 905 Northeast 11th Avenue, Vancouver, Washington 98666.

186. Dr. Allan Hirsch, Vice President, Environmental Sciences and Director, Washington Operations, Midwest Research Institute, 5109 Leesburg Pike, Suite 414, Falls Church, Virginia 22041.

187. Dr. Narain Hingorani, Vice-President Electric Systems Division, Electric Power Research Institute, 3412 Hillview Avenue, P.O. Box 10412, Palo Alto, California 94303.

188. Dr. Helen M. Ingram, Director, Udall Center for Studies in Public Policy, The University of Arizona, 803/811 East First Street, Tucson, Arizona 85719.

189. Mr. Stanley R. Lindgren, Manager, Power Transformers, Electric Power Research Institute, 3412 Hillview Avenue, P.O. Box 10412, Palo Alto, California 94303.

190. Mr. Calvin D. MacCracken, President, Calmac Manufacturing Corporation, 101 West Sheffield Avenue, Englewood, New Jersey 07631.

191. Mr. Stig Nillson, Transmission Substation Program, Electric Power Research Institute, 3412 Hillview Avenue, P.O. Box 10412, Palo Alto, California 94303.

192. Mr. Frank M. Phillips, Project Manager, Electric Power Research Institute, 34.12 Hillview 


\section{EXTERNAL DISTRIBUTION (Continued)}

193. Dr. John H. Reed, HBRS, Inc., University Research Park, 585 Science Drive, Suite A, Madison, Wisconsin 53711-1060.

194. Mr. T. W. Reddoch, Electrotec Concepts, Suite 103, 10305 Dutchtown Road, Knoxville, Tennessee 37932.

195. Mr. Dietrich Roesler, Department of Energy, CE-141, 1000 Independence Avenue, SW, Washington, DC 20585

196. Ms. Jacqueline B. Shrago, Director, Office of Technology Transfer, 405 Kirkland Hall, Vanderbilt University, Nashville, Tennessee 37240.

197. Dr. Karl Stahlkopf, Director, Electric Systems Division, Electric Power Research Institute, 3412 Hillview Avenue, P.O. Box 10412, Palo Alto, California 94303.

198. Dr. Martin Williams, Professor, Department of Economics, Northern Illinois University, DeKalb, Illinois 60115.

199. Mr. Frank Young, Executive Engineer Electric Systems Division, Electric Power Research Institute, 3412 Hillview Avenue, P.O. Box 10412, Palo Alto, California 94303.

200-202. Mr. Shalom Zelingher, Director R \& D, New York Power Authority, 1633 Broadway, New York, New York 10019.

203. Office of Assist Manager for Energy Research and Development, DOE/ORO, P.O. Box 2001, Oak Ridge Tennessee 37831-8600.

204-205. Office of Scientific and Technical Information, U.S. Department of Energy, P.O. Box 62, Oak Ridge, Tennessee 37831. 
DATE FILMED $8117 / 92$ 
